\title{
POSITION SURVEILLANCE USING ONE ACTIVE RANGING SATELLITE AND TIME-OF-ARRIVAL OF A SIGNAL FROM AN INDEPENDENT SATELLITE
}

Roy E. Anderson

Richard L. Frey

James R. Lewis

General Electric Company

Corporate Research and Development

Schenectady, New York 12301

January 1980

Final Report for Period December 1978 - December 1979

Prepared for

NATIONAL AERONAUTICS AND SPACE ADMINISTRATION

Goddard Space Flight Center

Greenbelt, Maryland 20771

Technical Monitor - Dr. James P. Brown 
TECHNICAL REPORT STANDARD TITLE PAGE

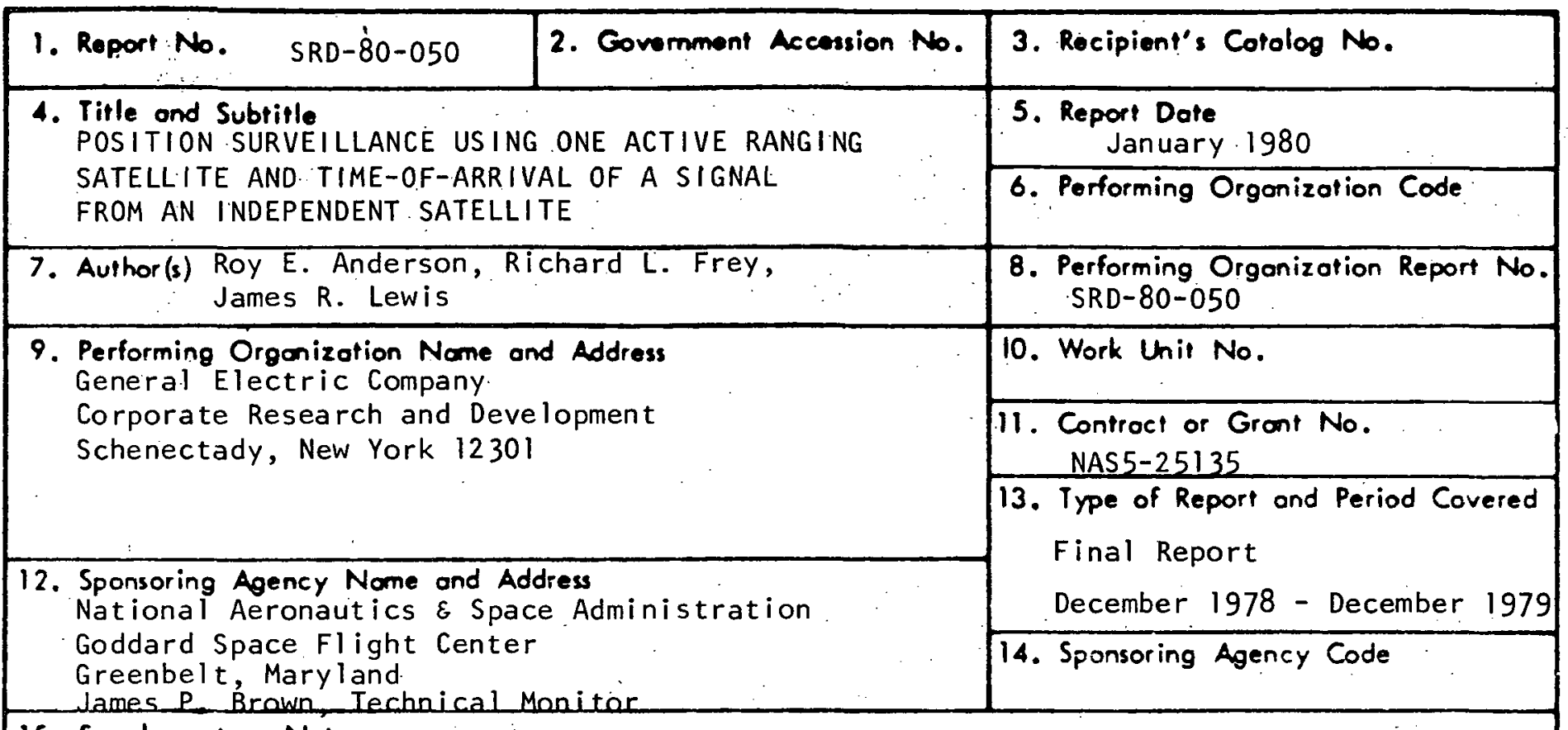

15. Supplementary Nates

16. Abstract

Position surveillance using. one active ranging/communication satellite and the time-of-arrival of signals from an independent satellite was shown to be feasible and practical. A towboat on the Mississippi River was equipped with a tone-code ranging transponder and a receiver tuned to the timing signals of the GOES satellite. A similar transponder was located at the office of the towing company. Tone-code ranging interrogations were transmitted from the General Electric Earth Station Laboratory through ATS -6 to the towboat and to the "ground truth" transponder office. Their automatic responses included digital transmissions of time-of-arrival measurements derived from the GOES signals. The Earth Station Laboratory determined ranges from the satellites to the towboat and computed position fixes. The ATS-6 lines-ofposition were more precise than $0.1 \mathrm{NMi}, 10$, and the GOES lines-of-position were more precise than $1.6 \mathrm{NMi}, 10$. High quality voice communications were accomplished with the transponders using a small non-directional antenna on the towboat.

The simple and effective surveillance technique merits further evaluation using operational maritime satellites.

17. Key Words (Selected by Author(s)) 13. Distribution Statement

Position Surveillance; Tone-code Ranging; Satellite Navigation; Satellite Mobile Communications.

19. Security Closif. (of this report) Unclassified
20. Security Clessif. (of this poge) Unclassified
21. No: of Poges

22. Price 
$1.0 \quad$ INTRODUCTION N I

2.0 POSITION FIXING TECHNIQUE : 4

2.1 Geometry 4

2.2 Location with One Active, One Passive Range Measurement 4

2.3 Tone-Code Ranging 6

3.0. EXPERIMENT PROCEDURE $\quad 11$

3.1 Equipment Deployment 11

3.2 Equipment Description and Performance 16

$\begin{array}{lll}3.2 .1 & \text { ATS }-6 & 16\end{array}$

$\begin{array}{ll}3.2 .2 \text { GOES } & 18\end{array}$

3.2.3 Earth Station Laboratory System 21

3.2.4 Towboat and Office Equipments 25

3.2.5 Equipment Requirements if Used in Operational
System

4.0 CONDUCT OF EXPERIMENT 29

5.0 RESULTS 35

5.1 Sample of Position Fixing Result $\quad 35$

5.2 Ranging and Data Link Performance 42

5.3. Detailed Comparison of Satellite and On-Board
Position Fixes

5.3.1 Geometry of Fix Determination 48

5.3.2 Precision and Accuracy of ATS-6 Lines-of-Position 51

5.3.3 Precision and Accuracy of GOES Lines-of-Position 63

5.4 Communication Performance

66

6.0 CONCLUSIONS 7 i

$\begin{array}{lll}7.0 & \text { RECOMMENDATIONS } & 73\end{array}$

$\begin{array}{ll}\text { 8.0 NEW TECHNOLOGY } & 74\end{array}$

$\begin{array}{lll}9.0 & \text { REFERENCES } & 75\end{array}$

Appendix A - Antenna Characteristics and Power Budgets A-1

Appendix B - Comments of Alter Company Representative B-1

Appendix C - Real-Time Computer Software C-1 


\section{LIST OF FIGURES}

FIGURE

NUMBER

1 Vehicle Position Fix Determination

2 Tone-Code Ranging Waveform. - 8

3 Tone-Code Ranging Transponder 9

4 ATS-6 Pencil Beam Footprint 17

5. Frequency Use Plan 19

6 Earth Station Laboratory - Arrangement for Position Location 22

7 Towboat and Office Transponders - Block Diagram 26

8 Arrangement for GOES Satellite Controlled Clock Evaluation 30

9 Position Fixes Relative to True Positión - Real Time 36

10 Computer Printout of Position Fixes 37

11 Position Fixes Relative to True Position - After Recalibration : 38

12 Time Variations of GOES Lines-of-Position 40

13 All Position Fixes on Renee G. 25 July $1979 \quad 44$

14 All Position Fixes on Renee G. 26 July 1979

15. Comparison of On-Board and Satellite Fixes, 25 July 1979 \%

16 Comparison of On-Board and Satellite Fixes, 26 July $1979 \quad 47$

17 Geometry of Fix Determination. 49

18. Range Measurement Error Effect on Line-of-Position 50

19 LOP Crossing Angle Effect on Position Fix 50

20 Satellite Fixes Vs On-Board Fixes 25 July 1979

2-1_Sate-l-1-i-te-Fi-xes-Vs-On-Board-Fi-xes-2.5-Jul-y-19-79 $05: 31: 13-05: 56: 13$

22 Satellite Fixes Vs On-Board Fixes 25 July 1979 $05: 55: 25-05: 56: 13$

23 Satellite Fixes Vs On-Board Fixes 25 July 1979 $06: 06: 37-06: 08: 57$

24 Satellite Fixes Vs On-Board Fixes 25. July 1979

25 Satellite Fixes Vs On-Board Fixes 25 July 1979
$06: 59: 38-07: 00: 40$

26 Satellite Fixes Vs On-Board Fixes 25 July 1979 27 Satellite Fixes Vs On-Board Fixes 25 July 1979
$07: 21: 33-07: 22: 15$ 
List of Flgures - page 2

FIGURE

NUMBER

PAGE

28 Satellite Fixes Vs On-Board Flxes 25 July 1979 $07: 29: 21$ - 07:30:45

60

29 Satellite Fixes Vs On-Board Fixes 25 July 1979 $08: 30: 06-08: 55: 48$

30. Variability of the GOES Receiver Time Ticks, Satellite Test 65

31 Variability of GOES Receiver Time Ticks, Test at Earth
Station Laboratory

Al GOES Receiver. Standard Devlation Vs Averaging Interval A-5 and Averaging Interval Vs Deviation Magnitude

A

Cl Computer Printout Sheet

$c-5$ 


\section{LIST OF TABLES}

PAGE

1 Signalling Performance, Ranging and Data

2 ATS-6 Lines-of-Position, Average Displacement and Scatter Limits

3 GOES Lines-of-Position, Average Displacement and Scatter Limits

4 : Time Tick Offsets of GOES Receivers $\quad 68$

5 Voice Communications Quality of Signals from Towboat 70

Al Davenport Office "Ground Truth" L-Band Antenna A-6

A2 Towboat L-band Antenna $\quad A-7$

A3 Davenport Office "Ground Truth" GOES Receive System A-8

A4 Towboat GOES Receive System A-8

A5 Two-Carrier ATS-6 Power Budget A-9

A6 Two-Carrier ATS -6 Power Budget $\quad$ A-10

A7 Two-Carrier ATS-6 Power Budget A-11

A8 Two-Carrier ATS-6 Power Budget A-12

A9 GOES Downlink Power Budget A-13

Al0 GOES Downlink Power Budget $\quad A-14$

C1 Mathematical Algorithms of Real-Time Computer Software C-2 
1. Báse Station Transponder and GOES Receiver, Davenport, lowa Office of Alter Company

2. GOES Receiving Antenna and ATS-6 Transmit-Receive Antenna, Davenport, lowa Office of Alter Company

3. Transponders in Use Aboard Towboat "Renee G."

4. Transmitter-Receiver Aboard Towboat "Renee G."

5. GOES Receiver and Experimental Tone-Code Ranging and Data Responder Aboard Towboat "Renee G."

6. GOES Receiving Antenna and Preamplifier and Filter Aboard Towboat "Renee G."

7. ATS-6 Receive-Transmit Antenna, Top of Mounting Post, Aboard Towboat "Renee G." 


\section{ACKNOWLEDGMENTS}

The authors wish to acknowledge the support and cooperation of the Alter Company Marine Division in making available their offices and the towboat Renee G. for the experiment described in this report. Individuals contributing to the experiment were as follows:

INDIVIDUAL

Roy E. Anderson

James $P$. Brown

Randy Elder

Richard L. Frey

Bob Gardner

Sam Gardner

James $R$. Lewis

Jack Libbey

James R. Murray

Glen Roe
General Electric Company

NASA Goddard Space

Flight Center

Alter Company.

General Electric Company

Alter Company

Alter Company

General Electric Company

Alter Company

General Electric Company

General Electric Company
Principal Investigator;

Concept Originator; Data

Analysis; Laboratory

Operations

Technical Monitor

Towboat Radio Operator

Vehicle and Laboratory Radio

Frequency Systems and Equipment; Laboratory Operations

Port Captain/Operations

Manager

Office Setup and Operation

Project Engineer; Vehicle

and Laboratory Digital

Systems; Data Management

Sof tware; Laboratory

Operations

Towboat Captain

Vehicle and Laboratory

Equipment Construction

Technical Software;

Mathematical Analysis 


\section{PREFACE}

Geostationary satellites can provide reliable, convenient and potertially low cost communications to ships, aircraft and land vehicles. A commercially operated system, MARISAT, now provides worldwide satellite communications to the Maritime industry, and INMARSAT is a planned internationally operated maritime system. It is probable that the advantages of satellite communications will some day be routinely available to aircraft and land vehicles also.

The experiment described in this report demonstrated that the surveillance function can be added to a satellite mobile communication system without change to the satellite or its communication function. Surveillance enables a central facility to determine the locations of distant participating craft immediately. The location information, together with the communications, can be used for many purposes including traffic control or advisories, management of a transportation enterprise, minimum time or minimum fuel routing, prompt alerting and accurate location in distress situations, and vehicle tracking in resource exploration. By transmitting the fix to craft, surveillance can fulfill the on-boardnavi-: gation function.

General Electric's Earth Station Laboratory near Schenectady; New York; tracked a towboat on the Mississippi River by interrogating the craft through NASA's ATS- 6 satellite and receiving automatic responses from the craft that included the time-of-arrival of signals received from a GOES satellite of the National Oceañic and Atimospheric Administration. An interrogation, response, and $\mathrm{fix}$ computation were accomplished in about one second. Precision of the lines-of-position derived from ATS -6 was about 0.1 nautical mile. Precision of the GOES lines-of-position was about 1.6 nautical miles, limited by the $100 \mathrm{~Hz}$ bandwidth of the GOES signals. Wider bandwidth signals from an independent satellite would enable fix determination with accuracy of approximately $0.1 \mathrm{NMi}$. except near the equator where only lines-of-position can be determined if geostationary satellites are used.

The communications equipment in the experiment was commercial land mobile radio gear with frequency conversion from UHF to $L$-band to match the frequencies relayed by ATS -6 . Voice communication and tone-code 
Preface (cont'd)

ranging used the narrowband frequency modulation standards of land mobile radio. The 25-watt transmitters and small, non-directional antennas on the towboat'provided high quality, reliable communications between the towboat and the Earth Station Laboratory.

The position fixing technique offers the advantages of surveillance, worldwide and continuously available, as an adjunct to satellite communications. The vehicle equipment that must be added for the surveillance function is likely to be lower in cost than equipment used with existing and planned radio and satellite navigation systems. The cost of position fixes in an operational system would be a trivial addition to the communication costs because the duration of the interrogation-response messages is short, as is the computer time for a fix determination. There are no space segment costs beyond those of the communication satellites, and the cost of ground station facilities are insignificant compared to those of any existing or planned radio or satellite navigation systems.

The potential advantages of the surveillance technique justify its further evaluation for operational implementation in comparison with other approaches that are under consideration in national plans for navigation. 


\section{$1.0 \quad$ INTRODUCTION}

The high density of air traffic over continental areas is made possible by position surveillance using ground-based radars. Air traffic controllers watch the positions of aircraft continuously, and with the use of radio voice communications they direct the pilots along their routes. Air traffic control insures safety of all the aircraft as they fly close to each other even under conditions of bad visibility.

By contrast, aircraft flying on transoceanic routes do not enjoy the benefits of position surveillance. They are assigned routes which are widely separated to insure their safety. As a result, some aircraft fly routes that require more time and fuel than would be required if closer separations could be safely assured, and all: of them could fly on minimum time and fuel routes.

Transoceanic aircraft are denied the advantages of surveillance because there are no available surveillance systems that have a range beyond their line-of-sight. Satellites offer the means to provide accurate position surveillance over oceanic and continental areas. Several satellite-aided techniques have been demonstrated successfully $[1,2,3]$. The experiment described in this report demonstrated that the tone-code ranging technique can be implemented with a single, unmodified communication satellite provided that the vehicles can measure the time of arrival of signals from an independent satellite. Means are now available for surveillance of cooperating vehicles on land, sea and in the air.

The-term ${ }^{-1}$ surveillance"l-refers-to-the-process-by-which-a-cent-ralfacility determines instantaneously the location of a distant craft. Position surveillance is one of three essential elements in traffic control or traffic advisory. A second essential element is a controller or advisor that observes the positions of craft that are within his or her cognizance, and the third element is undelayed communications between the controller or advisor and the individual craft.

Although the term navigation in its broader sense includes surveillance, navigation usually refers to the onboard determination of a vehicle's position. Radio navigation requires the reception on board the craft of signals 
from a navigation aid. Examples are GPS NAVSTAR, TRANSIT, OMEGA, LORAN and DECCA. Navigation is passive in the sense that the vehicle does not transmit or return a signal to the navigation system. Surveillance requires that the vehicle return a signal. In the case of passive radar, the signal is simply returned by reflection of the incident radar beam on the body of the craft. In active radar, or in satellite position surveillance systems, a transponder aboard the craft receives and automatically retransmits a signal to an interrogating source.

Navigation and surveillance thus have different functions. In navigation it is an onboard determination of present position for directing the craft to its destination. In surveillance it is the determination at a central facility of the location of a distant craft for whatever purpose the central facility may need that information. Such purposes include transoceanic air traffic control, maritime traffic advisories, monitoring the activities of fishing vessels, tracking and insuring the safety of hazardous cargos at sea and on land, law enforcement operations, and home office monitoring of the progress of ships at sea and shipments on land.

One way of accomplishing the surveillance function is the reception of navigation-aid signals aboard the craft and retransmission of those signals or the position fixes derived from them by radio to the central facility. One objection to that process is the concern that errors in the navigation aboard the craft may result in errors that cannot be detected as they.might be in a truly independent surveillance system where all the craft are monitored by a common means. Another consideration is that communications are nearly always essential in connection with the use of the surveillance information. Since the communications between the craft and the central facility are necessary, the choice is a matter of cost effectiveness. A surveillance transponder may be lower in cost as an addition to the communications equipment than the navigation equipment and its interfacing with the communications equipment.

Previous experiments sponsored by NASA-GSFC demonstrated that mobile equipment suitable for communications through satellites could be used for position surveillance by the addition of an automatic tone-code ranging responder. Surveillance could then be added to satellite-aided communications with an added circuit that is potentially modest in cost compared to 
the communications equipment itself. The time required for ranging over the satellite links is very short compared to the time required for usual communications, hence the addition of surveillance to a satellite-aided mobile communications systems was shown to be feasible and appears to be economically attractive.

Previous demonstrations of position surveillance using range measurements from. satellites have required one satellite for relaying the communications and the ranging interrogations, but two satellites to return the ranging response from the craft to the central station. The two satellites were needed in order to provide two lines-of-position on the earth whose intersection indicates the location of the craft. This experiment demonstrated that a single communication/ranging satellite is sufficient provided that there is another suitably located satellite independently transmitting signals whose time of arrival can be measured. Elimination of the need for a second active relay satellite opens the way to a practical operational system. It would, for example, be feasible to provide position surveillance over large areas of the world's ocean basins by the use of the MARISAT or the planned INMARSAT satellites together with the operational and planned GOES meteorological satellites. 


\subsection{POSITION FIXING TECHNIQUE}

\subsection{Geometry}

A vehicle can be located by measuring the distances, or ranges, between the vehicle and two earth satellites if the vehicle altitude above the earth is known. The vehicle is at an intersection of three spheres. Two spheres are centered at the locations of the satellites with radii equal to the measured ranges; the third sphere is centered at the earth's center with a radius equal to the earth's radius plus the altitude of the vehicle above the earth's surface.

There are two intersections of the spheres. If the satellites are in geostationary orbit, one intersection is in the northern hemisphere, the other is in the southern hemisphere. A priori information will usually resolve the ambiguity.

\subsection{Location with One Active, One Passive Range Measurement}

The range from a communication satellite to a vehicle can be measured by transmitting an interrogation to the vehicle through the satellite and receiving an automatic response via the satellite from the vehicle. The range from a second, independent satellite to the vehicle can be determined by measuring the time-of-arrival of a signal from the independent satellite relative to the time it received the interrogation from the communication satellite.

The method of determining the vehicle location is illustrated in Figure 1. When $R_{3}$ and $R_{4}$ are measured, the location of the vehicle on the earth's surface can be computed from the known locations of the two satellites in. space. $R_{3}$ is determined by active ranging, $R_{4}$ by measuring the time-of-arrival of a signal from $S$ relative to the active ranging interrogation from $S_{R^{*}}$ In Figure 1 :

$$
\begin{aligned}
0 & =\text { fixed earth station } \\
V & =\text { vehicle } \\
S_{R} & =\text { active ranging satellite } \\
S & =\text { time distribution satel lite } \\
C & =\text { velocity of light }
\end{aligned}
$$

Certain time delays that are known constants are omitted to simplify this explanation of the process. Start time, $T_{S}$, represents the instant when 


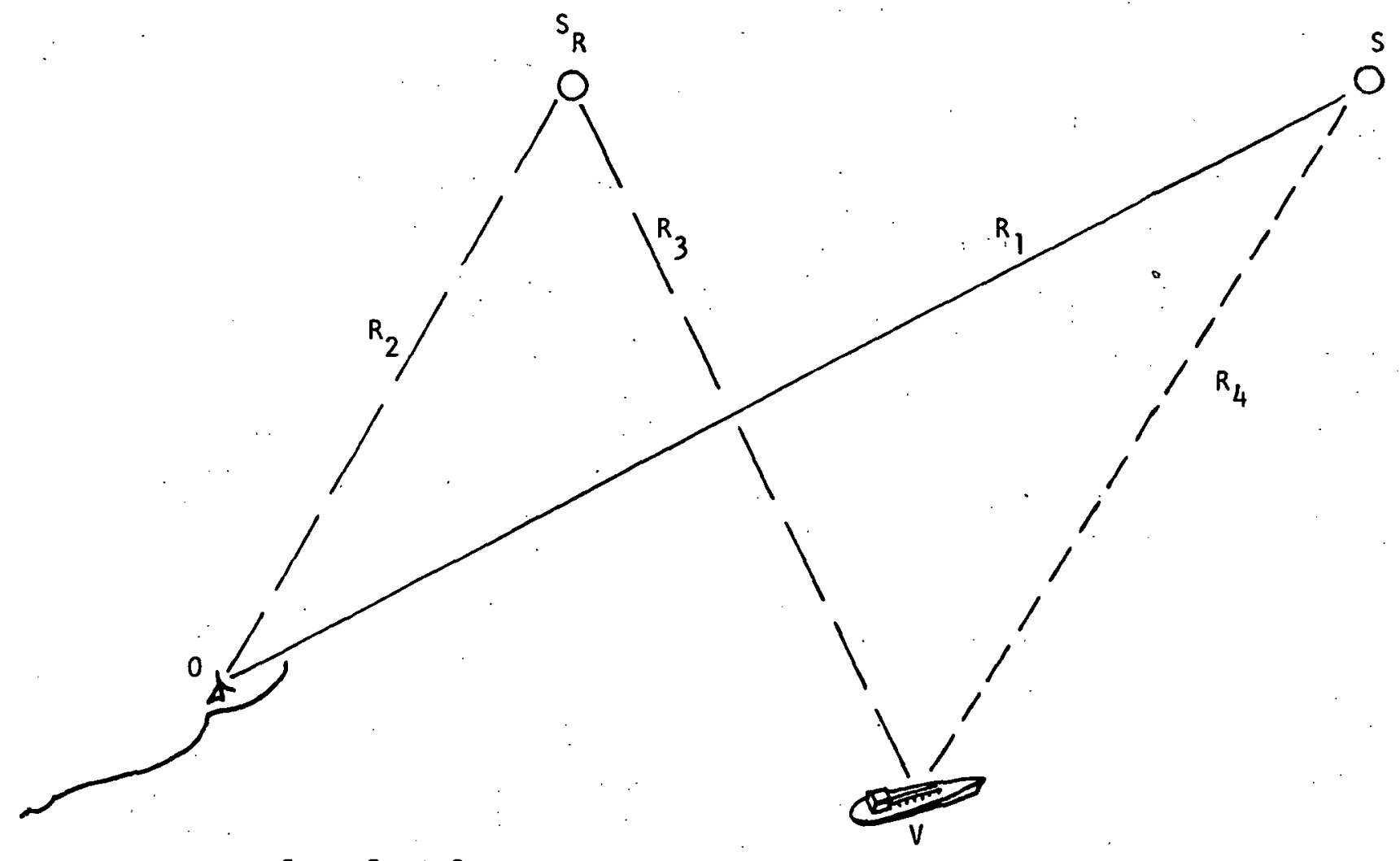

$$
T_{\text {VO }}=T_{S}+\frac{R_{1}+R_{2}+R_{3}}{C}
$$

Where: $R_{1}$ is known from tracking $S$. Time intervals $\frac{R_{2}}{C}$ and $\frac{R_{3}}{C}$ are known from : active ranging on vehicle.

$T_{S}=T_{v 0}-\frac{R_{1}+R_{2}+R_{3}}{C}$

also

$T_{V S}=T_{S}+\frac{R_{4}}{C} ; \frac{R_{4}}{C}=T_{V S}-T_{S}$

Then

$$
\frac{R_{4}}{C}=T_{V S}-\left(T_{V 0}-\frac{R_{1}+R_{2}+R_{3}}{C}\right)=\frac{R_{1}+R_{2}+R_{3}}{C}-\left(T_{V 0}-T_{V S}\right)
$$

but $T_{V O}-T_{V S}=X$ is interval measured on vehicle and returned as data during ranging interrogation

$$
R_{4}=R_{1}+R_{2}+R_{3}-C x
$$

Ranges $R_{3}$ and: $R_{4}$ from known positions of satellites determine vehicle fix.

FIGURE 1

VEHICLE POSITION FIX DETERHINATIOH 
a time tick is transmitted from $S$. When the time tick is received at 0 , it immediately transmits a tone-code ranging interrogation containing the address of the vehicle, $V$. The tone-code signal is repeated by $S_{R}$ and received at 0 and $V$. The vehicle regenerates the tone-code signal, and it is relayed back to 0 by $S_{R}$. The two-way travel time is measured at 0 to determine $R_{2}$ plus $R_{3}$. Since $R_{2}$ is known, $R_{3}$ is determined.

The vehicle receives time ticks at regular intervals, such as once per second, from $S$. Its onboard time-tick generator is maintained in synchronism with the received ticks. A time interval count starts at each tick from the generator. If no interrogation is received from $S_{R}$, the counter returns to zero and starts over at each tick. If an interrogation is received, the counter stops, and the interval from tick to interrogation is sent as a digital message along with the tone-code response to the vehicle. That interval is $\left(T_{V 0}-T_{V S}\right)$ in the expression for $\frac{R_{4}}{C}$ in Figure 1 . The ranges $R_{3}$ and $R_{4}$ from the known positions of the satellite are then used to determine two lines of position on the earth that intersect at the vehicle location.

\subsection{Tone-Code Ranging}

Ranges from a commications satellite to a vehicle are measured by the tone-code ranging technique. Tone-code ranging was employed in several previous experiments with good success. $[1,3,4)$

Range measurements from a.satellite to a vehicle are made by measuring the radio propagation time of a signal from a master ground station via the satellite to the vehicle and back. Following corrections for ionospheric and tropospheric propagation time delays and equipment internal time delays, the ranging time can be converted to a slant range by multiplying the time by the speed of light. In this experiment, propagation time was measured by placing a time marker in the form of a tone-code interrogation, Figure 2, on the transmitted signal and observing its two-way transmit time. The interrogation signal consists of a short audio frequency tone followed by a digital synchronization and address code in which an audio cycle is inhibited for a digital zero and transmitted for a digital one. 
Vehicle-satellite communications equipment supplemented with a digital logic responder unit, Figure 3 , becomes a ranging transponder. For vehicle-satellite slant ranges, the master ground station transmits a tone burst followed by the unique digital address code of the transponder. The satellite repeats the tone-code interrogation and all transponders within the satelitite antenna beamwidth receive the retransmission. Only that transponder that recognizes its address code will retransmit the tone-code sequence after a precise delay. The satellite repeats the transponder's response. The master ground station recognizes the address code as the one sent and records the two-way master ground station-satellite range time and the two-way master ground station-transponder ranging time. Any number of remote transponders may be interrogated in sequence. Ranging measurements to two or more fixed transponders at known locations allows the determination of satellite position.

The basic tone-code ranging transponder depicted in Figure 2 is configured to operate in narrow bandwidth communications channels. Audio tone cycles received from the satellite are applied to the phase matching circuit of the responder unit even though they may be part of an interrogation for another transponder. The phase of a locally generated continuous audio tone is matched to the phase of the received tone burst so that their zero crossings agree within \pm 0.05 . $\mu \mathrm{s}$. Phase matching occurs over 256 tone cycles. When the sequence of pulses representing the transponder address code agrees with a prewired code, the correlator circuit produces a single unambiguous output pulse that simultaneously keys the transmitter and initiates the output of a precise number of locally generated tone cycles. The transponder address code and a data stream follow the audio tone cycles.

Narrow bandwidth communications channels are susceptible to equipment internal time delay variations. Typical daily temperature variations can cause internal time delay variations of the order of $20 \mu \mathrm{s}$, which if uncorrected would generate slant range measurement errors of two miles. The vehicle ranging transponder was equipped with a self-calibration circuit to measure the internal time delay on every range measurement. The taps and local oscillator of the self-calibration loop shown in Figure 3 tap a small fraction of the transponder's output transmission. The selfcalibration loop translates the response signal through the same frequency 

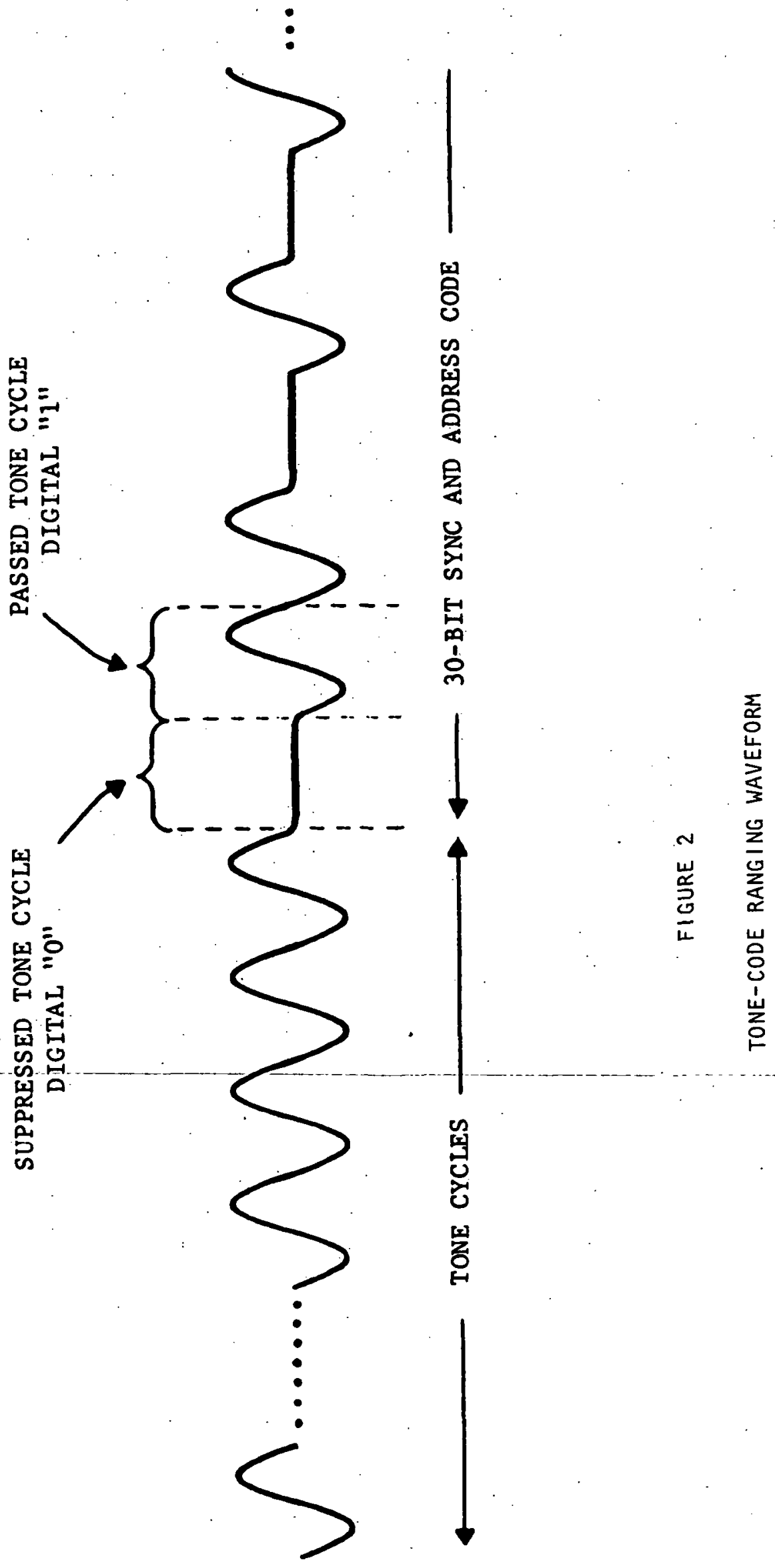
TO ANTENNA

FROM ANTENNA

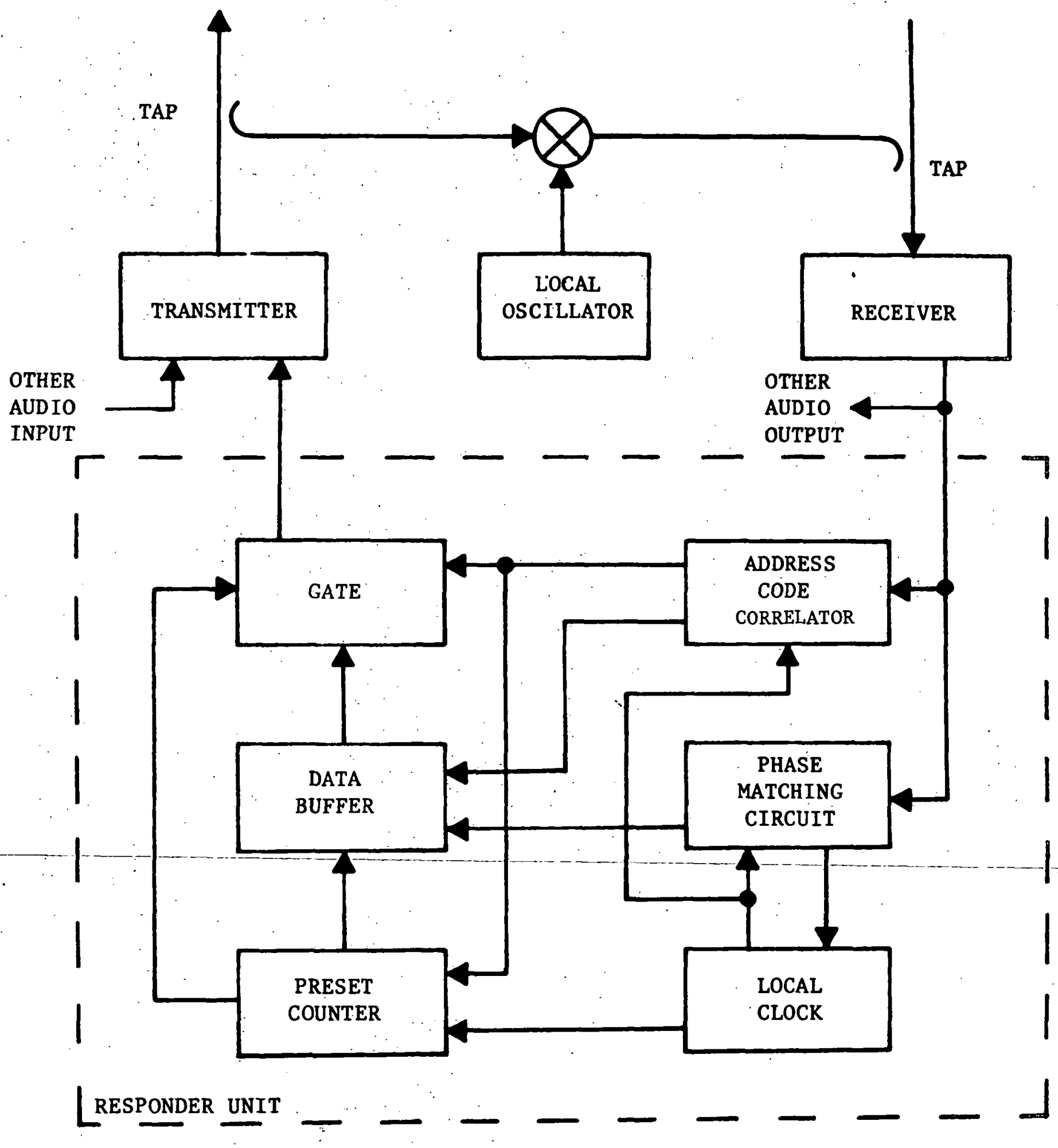

FIGURE 3

TONE-CODE RANG ING TRANSPONDER 
as does the satellite and injects it into the transponder receiver. The responder compares the phase of self-calibration tone cycles with the tone phase being passed to the transmitter. A digital representation of the phase difference completes the tone-code response in the data stream immediately following the transmission of the transponder address code. 


\subsection{EXPERIMENT PROCEDURE}

$3.1 \quad$ Equipment Deployment

The ATS- 6 satellite was in geostationary orbit, 19,300 nautical miles above the equator at 137 west longitude. GOES was in geostationary orbit at 102 west longitude.

General Electric's Earth Station Laboratory near Schenectady, New York, at $42^{\circ} 50^{\prime} 53^{\prime \prime} \mathrm{N}$. latitude, $74^{\circ} 04^{\prime} 15^{\prime \prime}$ west longitude, 1325 feet above mean sea level, served as the principal earth station. Tone-code ranging signals originated there, data were recorded, fix computations were made, the Laboratory served as the experiment direction and coordination center and provided interconnection with the telephone system when required.

A base station transponder and GOES receiver with directive antennas were installed at the Davenport, lowa office of the Alter Company, Marine Division, $41^{\circ} 30^{\prime} 53^{\prime \prime}$ north latitude, $90^{\circ} 36^{\prime} 40^{\prime \prime}$ west longitude, 590 feet above mean sea level. When the transponder received a tone-code interrogation with its own address, it transmitted the signal back to ATS-6 followed immediately by a digital message stating its internal time delay variation and the time interval between the last GOES time "tick" and its reception of the tone-code signal. In addition, the transponder was used for voice communication via ATS -6 with the GE laboratory, and with the towboat.

The transponder and GOES receiver installed on the towboat "Renee G" were-l-ike-those-insta-l-led-at-Davenpor-t-except-that the antennas-were-omnidirectional in azimuth. The Renee $G$ is a typical inland waterways vessel, 141 feet long, 35 feet wide, with 3800 horsepower diesel engines. It pushes up to 15 barges, each with a total tonnage of 22,500 tons. During the experiment the vessel was underway in normal operations on the Mississippi River where it borders the states of 111 inois and lowa. The vessel was under the command of Jack Libbey. A steersman, Randy Elder, was assigned to take frequent position fixes relative to buoys and landmarks during the position fix experiment periods and to participate in the communication demonstrations. No special crew member assignment would be necessary for an operational system as the position fixing is fully automatic and the communications are as convenient as a telephone. 


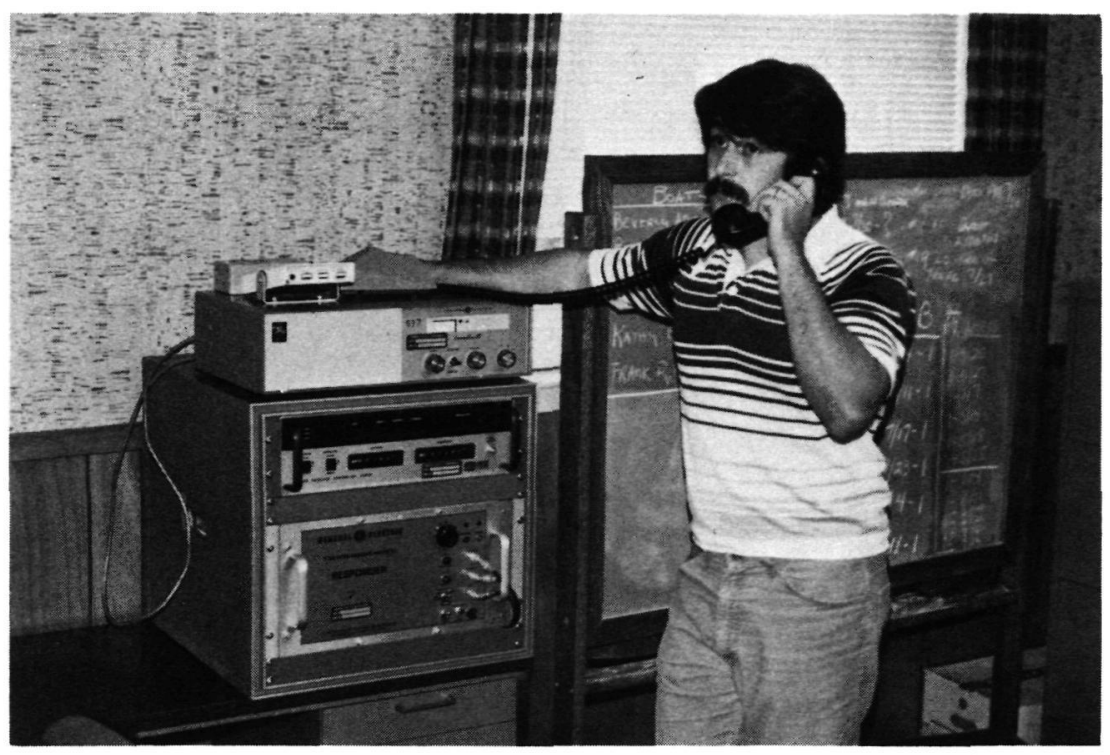

РHOTO 1

BASE STATION TRANSPONDER AND GOES RECEIVER, DAVENPORT, IOWA OFFICE OF ALTER COMPANY

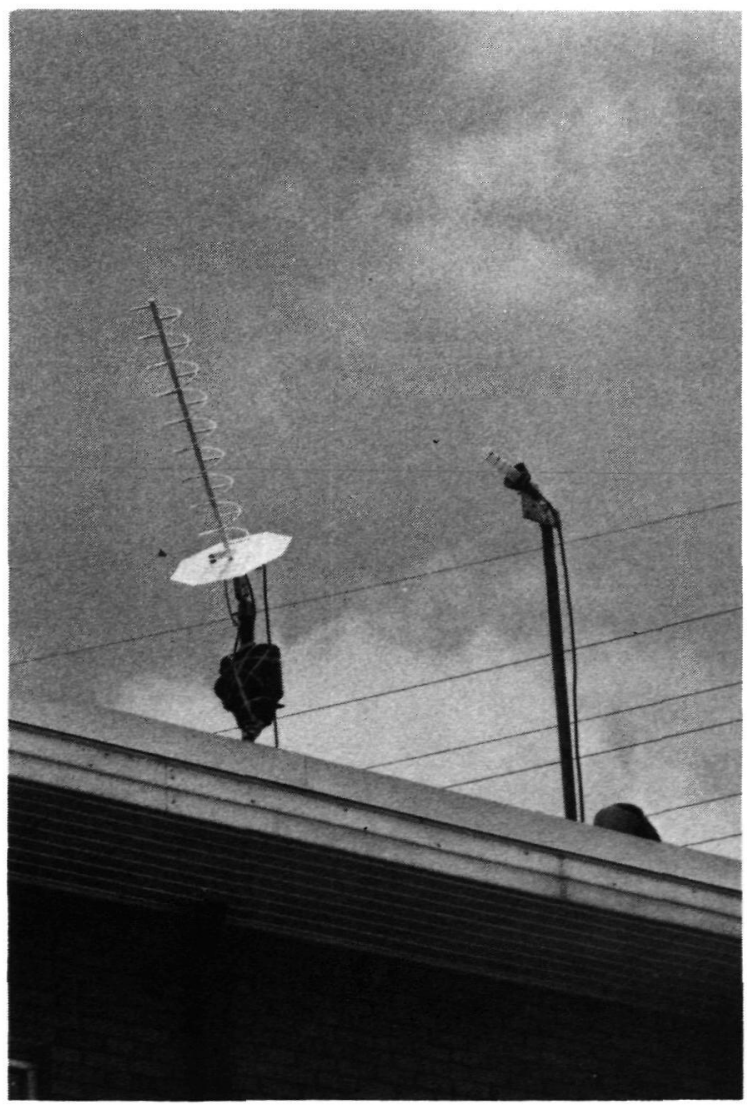

PHOTO 2

GOES RECEIVING ANTENNA, LEFT

ATS-6 TRANSMIT-RECEIVE ANTENNA, RIGHT

DAVENPORT, IOWA OFFICE OF ALTER COMPANY 


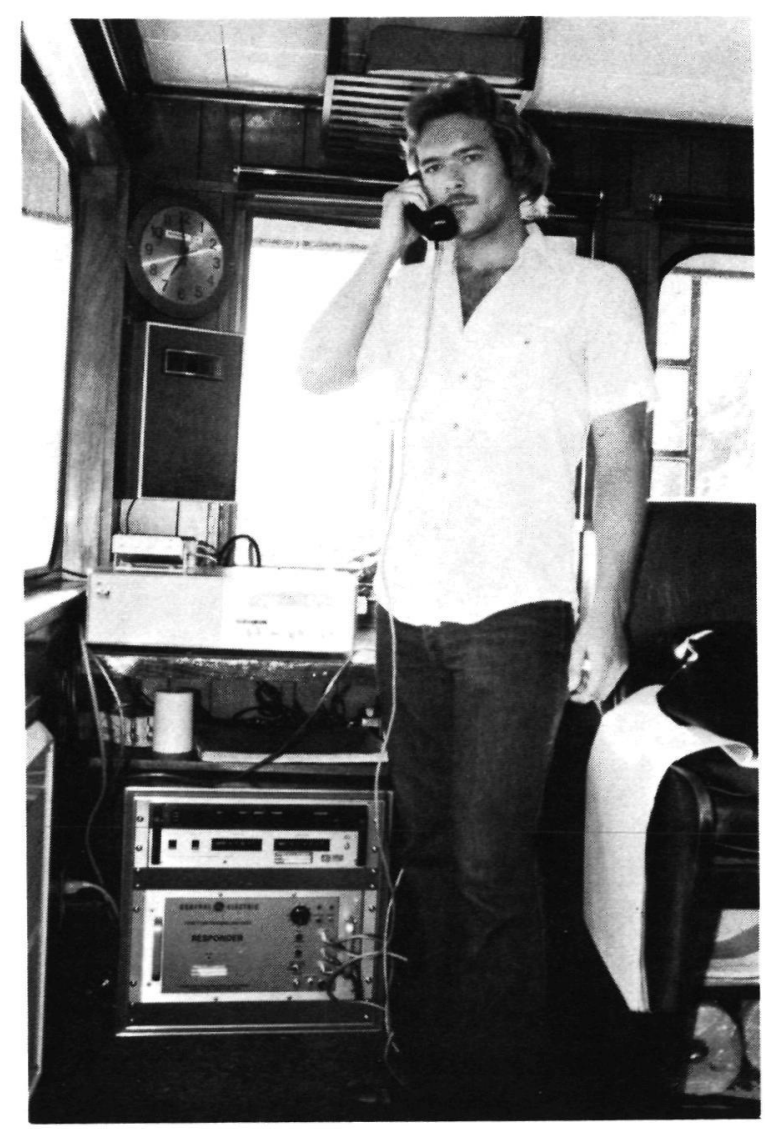

PHOTO 3

TRANSPONDERS IN USE ABOARD TOWBOAT "RENEE G" 


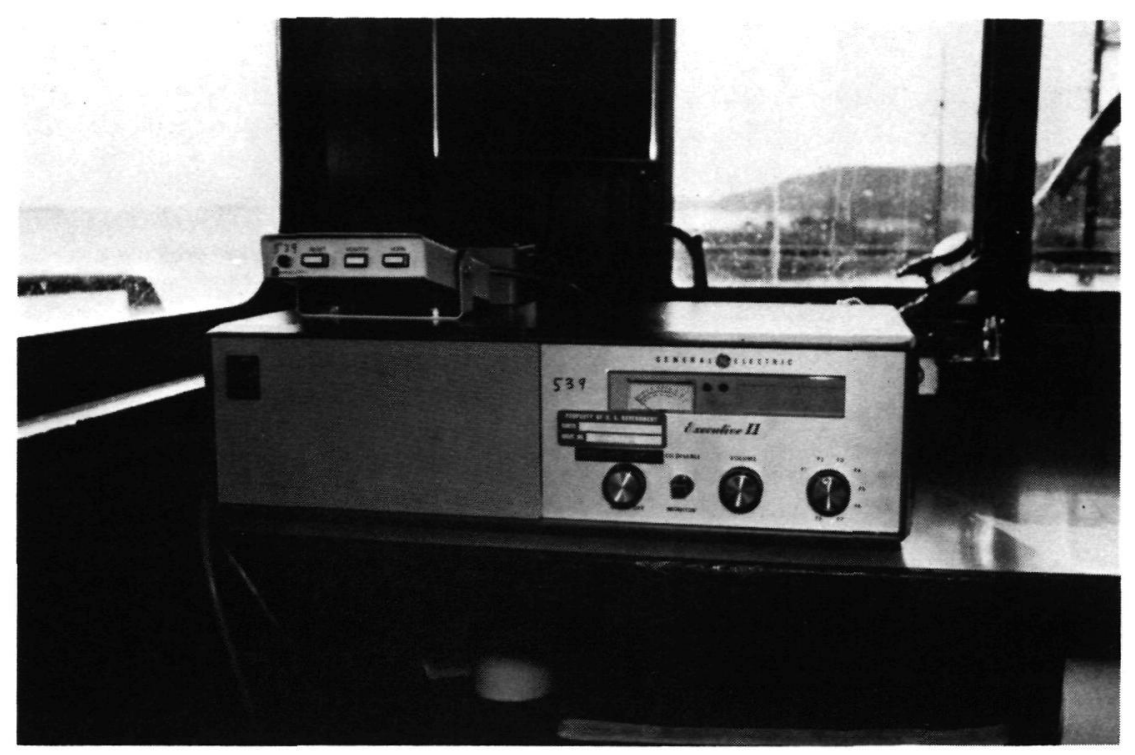

PHOTO 4

TRANSMITTER-RECEIVER ABOARD TOWBOAT "RENEE G"

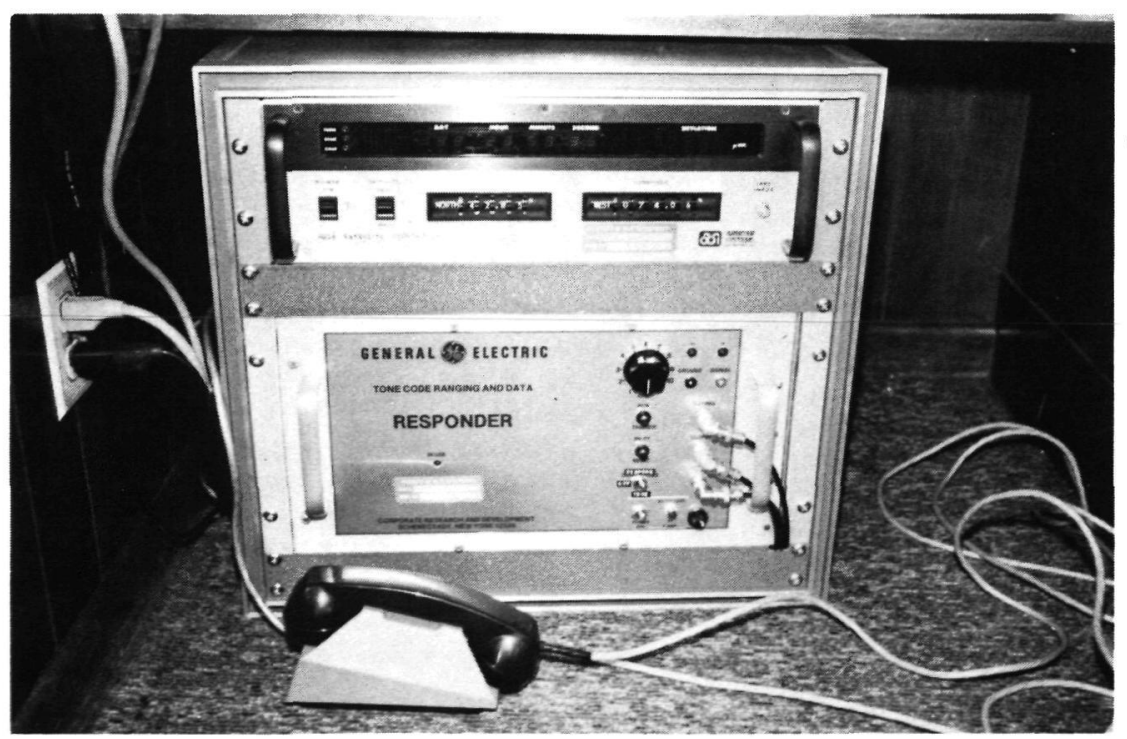

PHOTO 5

GOES RECEIVER (TOP)

EXPER IMENTAL TONE-CODE RANGING AND DATA RESPONDER (BOTTOM) ABOARD TOWBOAT "RENEE G" 

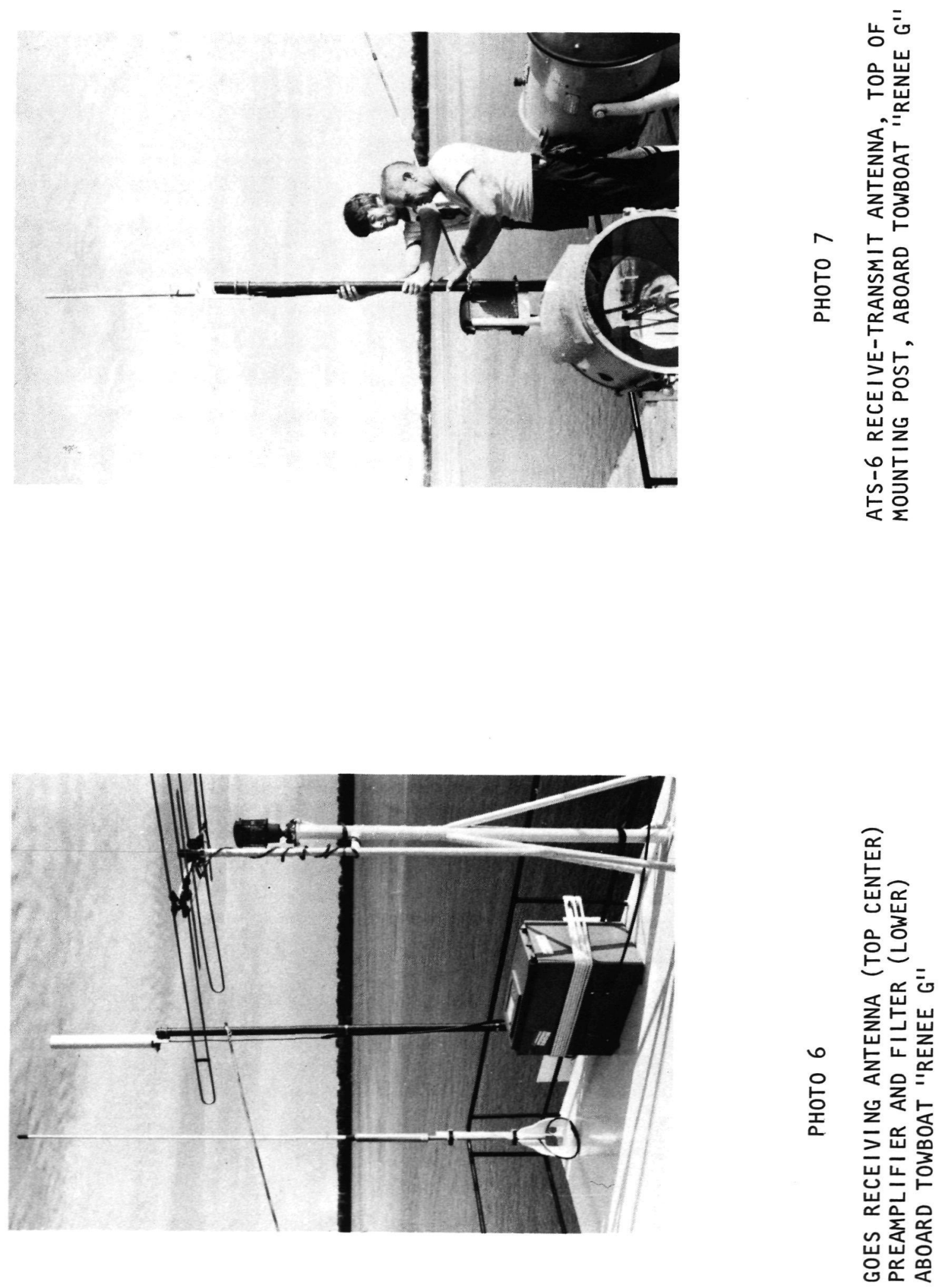


\subsection{Equipment Description and Performance}

\section{$3: 2.1 \quad$ ATS -6}

The National Aeronautics and Space Administration, Goddard Space

Flight Center launched ATS-6, the sixth and last in its series of Application Technology Satellites, on May 30, 1974. The satellite was used for a wide variety of experiments and demonstrations at several radio frequency bands. The experiment described in this report was the last one conducted with the satellite before it was thrust from geostationary orbit and deactivated on 3 August 1979.

ATS-6 featured a 9.14 meter $(30-f o o t)$ diameter parabolic antenna with a variety of feeds. The experiment employed the "pencil" beam at L-band in the narrowband frequency translation mode. The pencil beamwidth was $1.5^{\circ}$; sufficient to illuminate the northeastern contiguous states. With the satellite oriented in space to center the beam at $85^{\circ}$ west longitude, $38^{\circ}$ north latitude, the beam "footprint" on the earth illuminated the area shown in. Figure 4. The narrowband frequency translation mode at L-band configured the satellite to receive signals in a $12 \mathrm{MHz}$ bandwidth centered at $1656 \mathrm{MHz}$ and to retransmit the signals in a $12 \mathrm{MHz}$ bandwidth centered at $1556 \mathrm{MHz}$.

During the experiment, the Earth Station Laboratory transmitted a carrier to the satellite at $1652.1 \mathrm{MHz}$ when no ranging or communication signals were being transmitted. The "idle" carrier transmission avoided a possible desensitization of the satellite receiver that was reported to occur when no signal was présent. "Sidebands of the satellite-'s transmitter couldenter its receiver when it relayed the wide bandwidth of its own receiver white noise. Ranging and communication signals were transmitted from the Earth Station Laboratory on $1652 \mathrm{MHz}$ with a power of 25 watts from a 6 ' diameter antenna. The 9.6 kilowatt EIRP signals were linearly polarized. The satel-. lite antenná was circularly polarized. The satellite relayed the signals from the laboratory on $1552 \mathrm{MHz}$ with a power of 34 watts, or an EIRP of 17 kilowatts. The fixed transponder at Davenport employed a six-turn helical antenna with $13 \mathrm{dBi}$ gain. The $2.6 \mathrm{~dB}$ noise figure receiver achieved a signalto-noise ratio of $30.3 \mathrm{~dB}$ in its $15 \mathrm{kHz}$ bandwidth. The transponder on the towboat employed a vertical linearly polarized antenna with $7.3 \mathrm{~dB}$ gain, 4.3 $d B$ net gain for receiving the circularly polarized signals from the satellite. Received signal-to-noise ratio was $18.9 \mathrm{~dB}$ in its $15 \mathrm{kHz}$ bandwidth. 


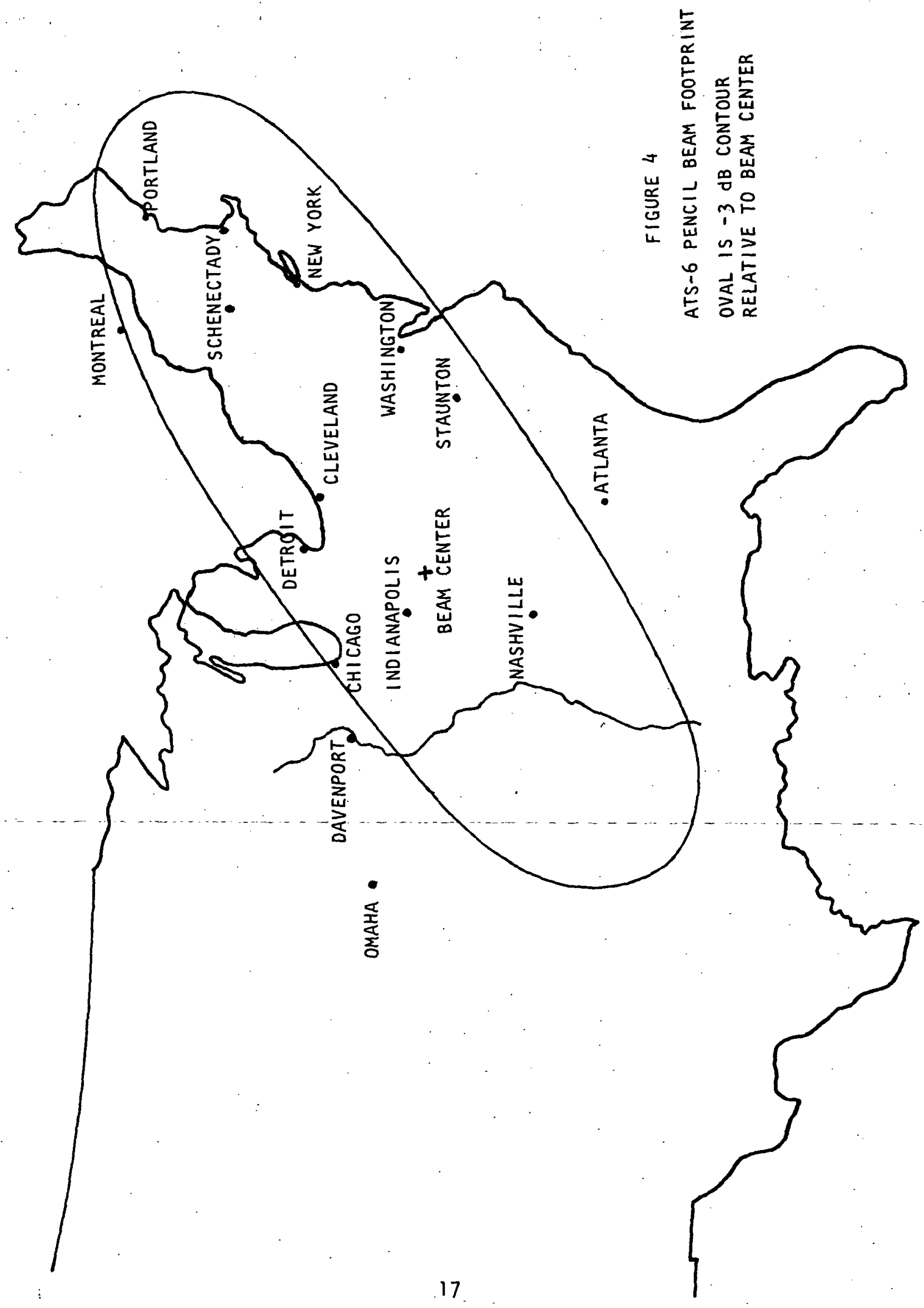


Signals were transmitted from Davenport and the towboat with a power of 12 to 15 watts on $1655.05 \mathrm{MHz}$. The satellite relayed their signals while it was also relaying the more powerful "idle" carrier from the Laboratory. Signals from the fixed transponder were relayed by the satellite with an EIRP of 1000 watts; signals from the towboat were relayed with an EIRP of 2.50 watts. The Earth Station Laboratory received the signals on a 9.14 meter (30 feet) diameter antenna. Signal-to-noise ratios at the Laboratory from each of the transponders was limited by the noise floor of the satellite transponder. For the fixed transponder, the received signalto-noise ratio at the Laboratory was $21.7 \mathrm{~dB}$, and for the towboat $15.5 \mathrm{~dB}$.

The technique for avoiding receive desensitization was developed by NASA-GSFC and first used with their briefcase size portable-mobile transceiver. The frequency use plan for the technique is shown in Figure 5 .

\subsubsection{GOES}

The Geostationary Orbiting Environmental Satellites (GOES) of the National Oceanic and Atmospheric Administration are part of an operational system to collect meteorological and environmental data. One function of the satellites is to relay data from large numbers of small platforms that measure factors such as water level in streams. Many of the platforms transmit short digital messages at random times. Others of the small platforms are individually interrogated through the satellite and then respond with their data.

Interrogations to the platforms are transmitted on a frequency near $468 \mathrm{MHz}$. The interrogations are included in a continuously transmitted data stream modulated on the carrier by phase shift keying at a rate of 100 bits per second:- The data-are transmitted with-a-one-second-frame rate.

Under a memorandum of agreement with the National Bureau of Standards, two of the five US GOES satellites transmit time signals as part of the data stream. Specially designed clocks receive the GOES signals, phase lock to the bit stream for precision of measurement, and correlate on the frame synch to identify each one-second time "tick". Included in the data stream are day of the year, hour, minute and second. In addition, the latitude, longitude and earth center distance of the satellite is transmitted so that a clock equipped with a microcomputer can correct its time "tick" for the propagation time from the satellite to the clock.

The correction feature of the clocks is not needed for the experiment, as the ranging system establishes its own reference at the central earth 


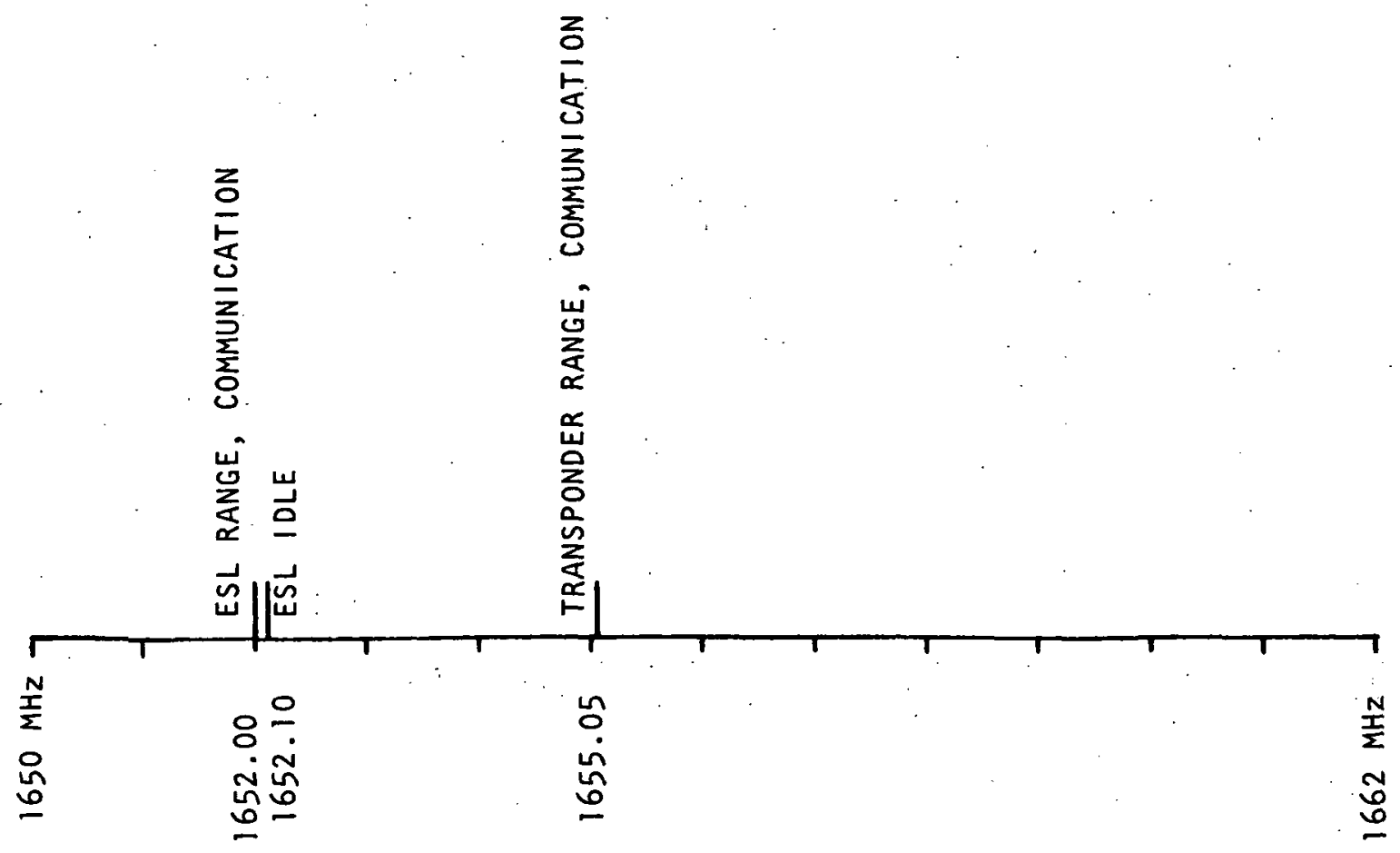

UPLINK TO SATELLITE
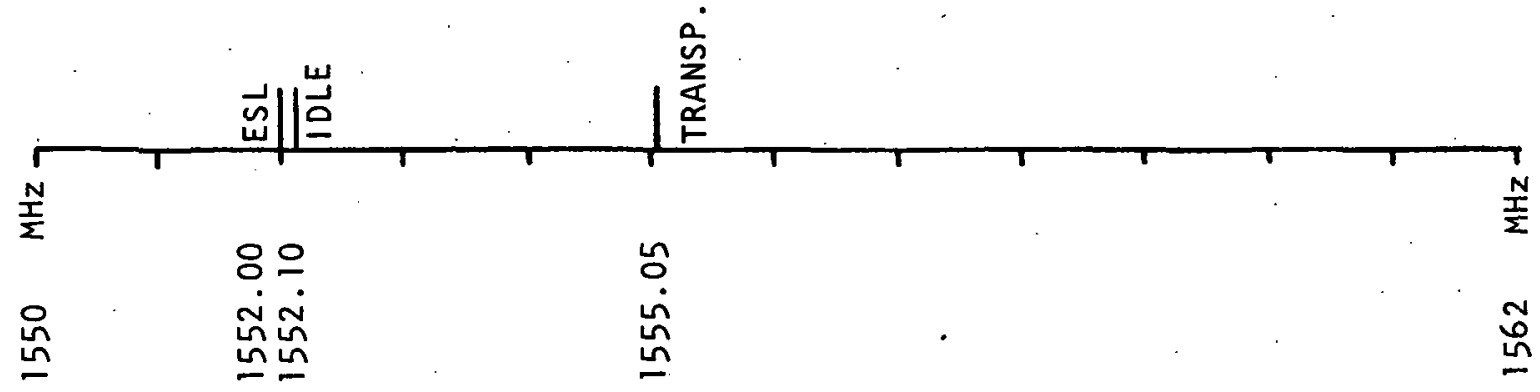

DOWNLINK FROM SATELLITE

EARTH STATION LABORATORY TRANSMITS CONTINUOUSLY TO SATELLITE, ON IDLE FREQUENCY (1652.10 MHz) WHEN RECEIVING AND WHEN NOT RANGING OR COMMUNICATION, SHIFTING TO 1652.00 WHEN TRANSMITTING RANGING OR COMMUNICATION SIGNALS.

TRANSPONDERS TRANSMIT ONLY FOR RANGING AND COMMUNICATIONS.

FIGURE 5

FREQUENCY USE PLAN 
station. The timing signals themselves are not required as long as there is an identifiable synchronizing sequence of bits transmitted at regular intervals, such as once per second.

Five United States GOES satellites are in orbit. Satellites with meteorological functions similar to GOES are in operation by Europe (METEOSAT) and Japan (Geostationary Meteorological Satellite). Signalling format and operating frequency band are the same for all the satellites, by international agreement.

By the end of 1979 a GOES satellite at $75^{\circ}$ west longitude, and another at 135 west longitude will transmit the timing signals coordinated by the National Bureau of Standards. The experiment employed timing signals transmitted from a GOES satellite at 102 west longitude. The transmissions are on $468.8375 \mathrm{MHz}$. The spacecraft transmits a circularly polarized signal with an EIRP of 70 watts. The 100 bits per second data stream is transmitted. by phase shift keying with a phase shift of \pm 60 degrees.

GOES signals were received at the Laboratory and at Davenport on 8-turn helical antennas with a gain of $13.5 \mathrm{dBi}$. They were received on the towboat with a full wave quadrifiler helical antenna, omnidirectional in azimuth with a gain of $3.5 \mathrm{dBi}$.

The Laboratory, Davenport, and the Renee G. each received the GOES signals on an Arbiter Systems, Inc., Satellite Controlled Clock, Model 1026. The clocks comprise phase lock receivers, a correlator that generates a time tick each second when it recognizes the frame synchronizing sequence of bits, a mi.crocomputer that reads the satellite location and the day of year, hour, minute and second. It also reads the location of the clock that is inserted manually by front panel controls. The microcomputer computes the propagation time from the location of the satellite to the location of the clock and initiates the generation of a time tick that is corrected for propagation time. The corrected time is available at an output terminal on the clock.

The microcomputer formats the day of year-time information for presentation on a digital display, 
The ranging experiment required the use of the uncorrected tick derived by the microcomputer when frame synch occurred. Precision of the time tick is achieved by phase locking a $100 \mathrm{~Hz}$ reference in the clock to the zero crossings of the received data, and generating the time tick from the reference. Access to the uncorrected time ticks required a minor modi: fication to the clocks.

Factors limiting the accuracy of the GOES range measurements are discussed in Appendix A.

\subsubsection{Earth Station Laboratory System}

The experimental arrangement at the Earth Station Laboratory is shown as a block diagram in Figure 6 . The ranging and position fixing sequence is controlled by the Master Control Unit (MCU) and is timed with reference to the reception of a time tick from the GOES satellite.

The MCU has twelve transponder address controls, each having twelve positions, enabling the selection of up to twelve transponders in any desired sequence. Prior to an experiment period the operator selects the transponders, the order in which they will be interrogated and the rate at which interrogations will be transmitted; for example, one interrogation each three seconds. The MCU performs three functions: supplies the fifteen-bit address code to the tone-code generator and the correlator; starts the tone-code generator; starts the time interval counters at the end of the transmission of the code from the tone-code generator.

The tone-code generator turns on the L-band transmitter and formats the 1024 cycles of tone at $2.4414 \mathrm{kHz}$ followed by fifteen synchronizing bits and fifteen address bits.

The L-band transmitter sends the Frequency Modulated (FM) tone-code signal at 1652 megahertz via the diplexer and the six-foot diameter antenna to the ATS-6 satellite.

The Timing and Control Unit (TCU) receives a start command from the MCU at the end of transmission. of the tone code signal. It then switches the L-band receiver to 1552 megahertz so that it will receive the interrogation signal when it returns from the ATS- 6 satellite, about $1 / 4$ second.after its transmission from the Laboratory. The L-band receiver receives the 


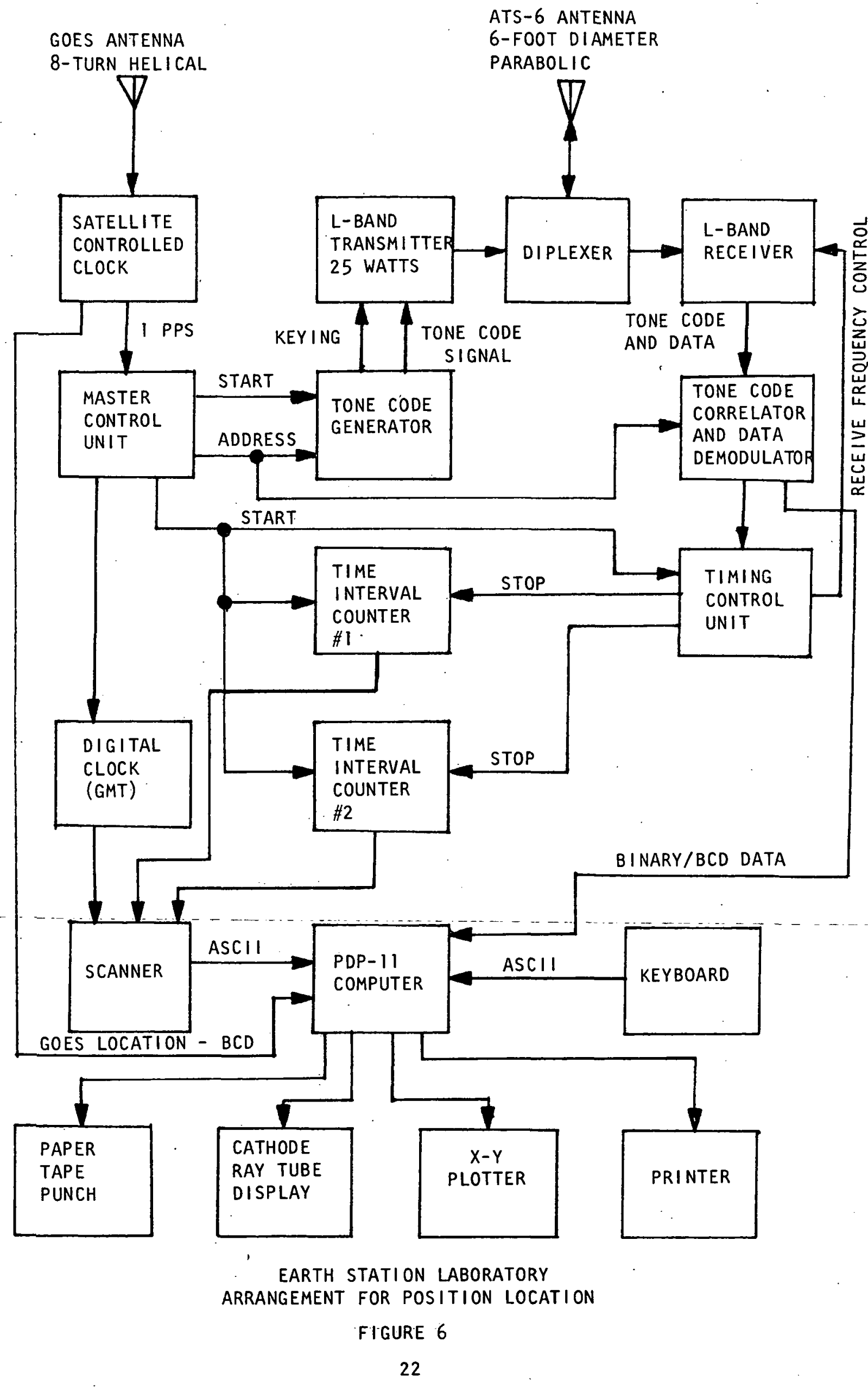


interrogation signal from ATS- 6 via the six-foot diameter antenna and presents its demodulated output tone to the tone-code data correlator. The tone-code data correlator matches the phase of its local tone generator to the received tone phase then correlates on the user synchronizing and address bit sequence. The correlation pulse is routed through the TCU to the stop input of the first time interval counter. The interval stored in the counter represents the time for the radio signal to travel from the laboratory to the satellite and return plus the known internal time delays of the laboratory and satellite equipments.

The TCU switches the L-band receiver to 1555.05 megahertz which is the downlink frequency for the signals from the distant transponders. The detected signal is passed to the tone-code data correlator, where correlation occurs when the synchronizing and address code match the code set in the correlator. The correlation output pulse is applied to the TCU and thence to the stop input of the second time interval counter. The interval stored in the counter then represents the two-way radio signal travel time from the observatory through the satellite to the distant transponder plus the known internal equipment time delays of the laboratory, the satellite and the distant transponder.

A data message is received from the transponder immediately following the tone-code synchronizing and address signal. While the tone-code synchronizing and address signal are transmitted using one suppressed audio cycle for a zero and a transmitted audio cycle for a one, thus using a -2.4414 kilobi-t-rate, the following digital message is transmitted with three audio cycles suppressed for a żero and three audio cycles transmitted for a digital one; hence the data rate is at 814 bits per second. The lower bit rate is used to 'reduce the bit error rate.

The digital message following the tone-code signal includes two numbers essential to the position fix determination calculation. The first number is the internal time delay measurement of the transponder equipment (Section 2.3). The second number is the time interval between the most recent GOES time tick received by the distant transponder and its reception of the tone-code ranging interrogation. As explained in Section 2.2, that time interval is used to determine the range from GOES to the transponder. 
When the first time interval counter is stopped, the scanner reads the counter in parallel and presents the data to the PDP-11/20 computer in serial, using the ASCII code. The scanner reads the time in Greenwich mean time along with the identification number of the distant transponder. When the second time interval counter has completed its count, the scanner presents its output to the PDP-11/20.

The data that follows the tone-code ranging response from the distant transponder passes to the PDP-11/20 computer via the tone-code data correlator. The computer extracts the transponder's internal time delay and also the measurement of the time interval between the user's reception of a GOES clock "tick" and the reception of its tone-code ranging interrogation. These data are added to the 1 ine of data supplied by the scanner and all of the data are fed from the output ports of the computer to a paper tape punch, a CRT display and to an alphanumeric printer.

Additional data needed for the position fix determination includes the position of the GOES and ATS- 6 satellites. The GOES positions are received directly from the satellite and decoded in the GOES receiver. Its output is connected directly to the PDP-11/20. The position of the ATS 6 satellite was derived from data supplied by NASA and manually entered into the computer before each scheduled use of the satellite.

Before the data could be processed by the fortran subroutine, it was first tested to ensure that it was of the correct format; if not, a "FORMAT ERROR" was generated and no further processing was done. Data of the correct format was further tested by matching its transponder identifi= cation number with a programmable table to determine if the transponder was the ground truth reference or the unit aboard the towboat. If the data were for the ground truth reference, the computer used the result to update the variables needed to correct the towboat position. A choice was then made on the basis of the data items that were available whether a position fix should be determined, whether only a line-of-position should be determined or if the data should be rejected. When the vehicle position fix was determined, its latitude and longitude were presented by the computer to the cathode ray tube and the printer.

Appendix $C$ is a summary description of the software. 
When the system operator has completed the insertion of manually entered data at the beginning. of the experiment period and placed the master control unit in the "GO" state, the entire process continues automatically. The system at the Earth Station Laboratory can sequence through the entire process of interrogation; correlation, time interval measurements and computation and printout of a transponder's latitude and longitude each two seconds. Slower interrogation rates are possible and during the period of the experiment independent fixed determinations were made at three or four-second intervals, alternating between the ground truth transponder and the moving towboat. The result was a position fix for the towboat every six or eight seconds during the ranging interrogation periods. A higher interrogation rate would merely add more data without adding useful information to the result.

\subsubsection{Towboat and Office Equipments}

Equipments aboard the Renee $G$. and at the Davenport Office of Alter Company were alike except for their antennas. The transponder equipments were modest in size, each consisting of two units: one 19-1/2"' $\times 21^{\prime \prime} \times 22-1 / 2^{\prime \prime}$, the other $19^{\prime \prime} \times 8^{\prime \prime} \times 15^{\prime \prime}$. The ATS-6 L-band antenna on the towboat was $30^{\prime \prime}$ high, " "in diameter. It was omnidirectional in azimuth, but with directivity in the vertical plane to include the range of elevation angles to the ATS-6 satellite as viewed from locations throughout the contiguous United States. The towboat GOES antenna was $30^{\prime \prime}$ high, $3^{\prime \prime}$ in diameter. No pointing of the towboat antennas was necessary. The office antennas were fixed, pointed helices, 2-1/4"' in diameter, 8"' long for ATS-6 at L-band, and 8"' in diameter, $55^{\prime \prime}$ long for reception of the $468 \mathrm{MHz}$ GOES signals.

The arrangement of the equipments is depicted in the block diagram, Figure 7. The signal from the GOES satellite was received, detected and decoded in the arbiter model 1026 GOES clock. An output of the clock was a 


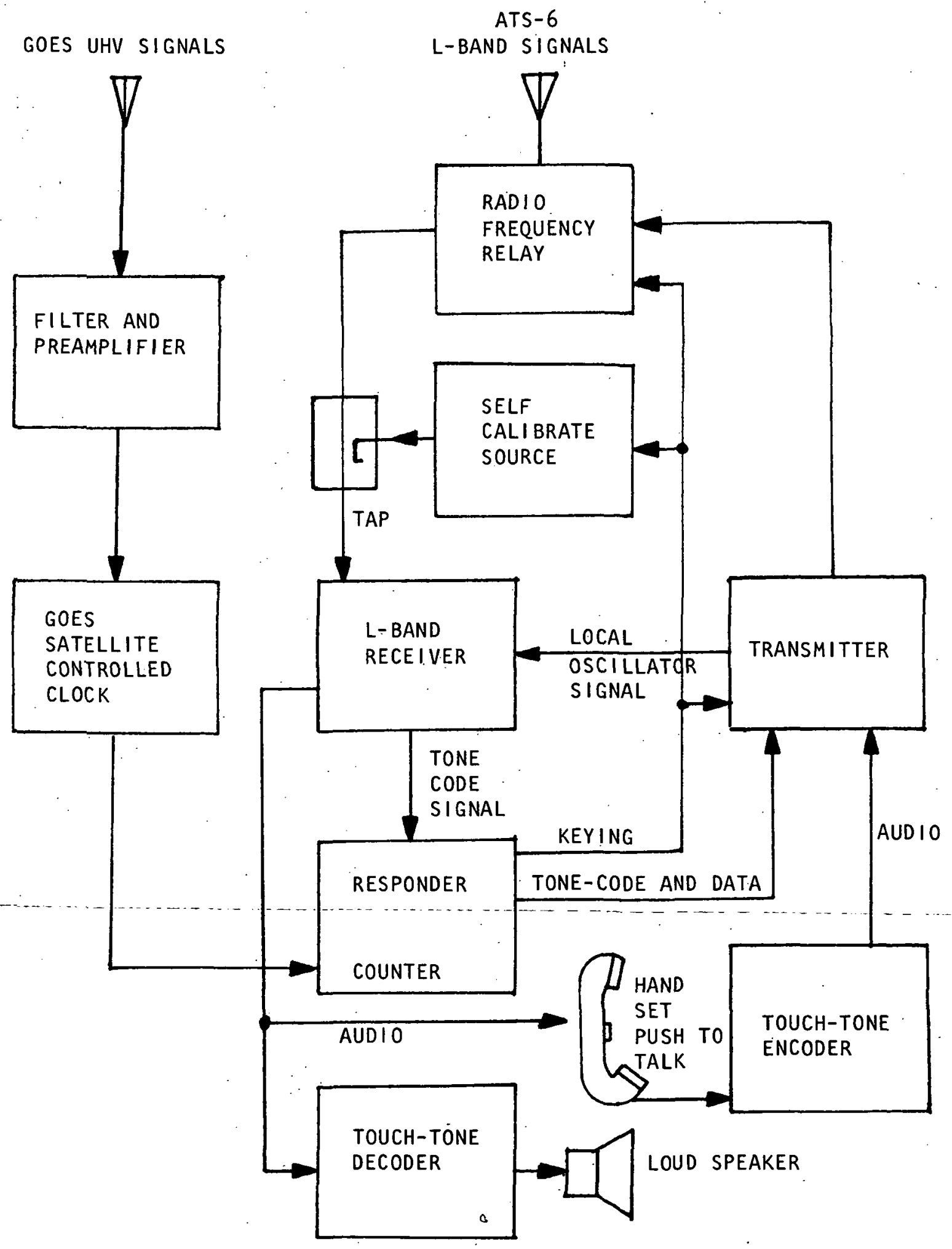

TOWBOARD AND OFFICE TRANSPONDERS BLOCK DIAGRAM

FIGURE $?$ 
time. "tick" once each second. The tick started a counter circuit in the responder, which counted at a rate of $10 \mathrm{MHz}$. The counter, was reset to zero on every tick from the GOES clock unless a tone-code ranging interrogation was received during the second.

When a tone-code ranging interrogation was received from ATS-6, the detected audio frequency signal was applied to the responder. The phase of the audio tone portion was compared with the phase of the locally generated audio tone, and the local tone matched in phase to the received tone. The code portion of the signal was applied to the correlator in the transponder. If the received address code matched the prewired address in the responder's correlator, the correlator produced an output that stopped the counter that had been started by the previous GOES time tick. The correlation signal also switched the antenna to the transmitter output, and keyed on the transmitter and initiated the transmission of a tone-code response identical to the one that it received except that it was followed by a digital message containing the count that was accumulated in the responder's counter between the GOES time tick and the correlator output. It also included the measurement of the transponder's internal time delay as determined by the operation of the self-calibrate circuit. The interrogation response sequence took less than one second.

Voice communications employed narrowband frequency modulation with the 16 F3 signalling parameters that are standard for mobile communications. The audio frequency baseband is limited to $2.5 \mathrm{kHz}$, and the RF bandwidth to $15 \mathrm{kHz}$. Telephone style handsets were ușed for the convenience of the operators. When an operator spoke into the microphone, the self-calibrate circuit coupled his voice signal back through the transponder and was audible in the earpiece of the telephone handset. He was thus able to confirm that his voice was being transmitted.

As an aid to keeping a record of all transmissions, a touch-tone encoder was incorporated on each transponder. It transmitted its own identification message every time the microphone pushed-to-talk button on the handset was depressed. All of the communications with their identification codes were recorded on magnetic tape at the General Electric Earth Station Laboratory. 
Each transponder had a loud speaker in addition to the handset. The loud speaker was activated only when the individual touch-tone address code of the transponder was received. The speaker was muted during tone-code ranging experiments or when the satellite was relaying the signals to other destinations. If desired, the operator could switch on the loud speaker to hear whatever signals were being relayed through the satellite. When the transponder's individual touch-tone identification code was received, an indicator light was lighted. A buzzer sounded for about one second and the loud speaker was activated. The earpiece of the handset was activated whenever the handset was lifted from its cradle.

\subsubsection{Equipment Requirements if Used in Operational System}

The experimental equipment was more complex and expensive than the equipment that would be required for an operational system using the techniques. It was selected for its availability and convenience in assembling the mobile and fixed terminal transponders. The tone-code ranging responder is an engineering model designed several years ago for a series of ranging and position fixing experiments with the ATS satellites. A production model would be built on a single circuit board and probably sell for less than $\$ 1000$. An operational receiver for the GOES signals would not require the time display or much of the logic associated with it that is contained in the Model 1026 satellite clock. A UHF receiver with a data frame synchronization circuit and pulse output circuit.would be sufficient. 
4.0

CONDUCT OF EXPERIMENT

Each portion of the system was tested and evaluated at the earth station laboratory prior to its incorporation in the system and its deployment for the experiment.

The characteristics of the GOES receiver and the GOES signalling system were important to the accuracy of the 1 ine of position derived from GOES and hence to the position fix accuracy. The Arbiter Model 1026 GOES receivers detect the $468 \mathrm{MHz}$ phase shift-keyed digital transmissions from the GOES satellites. The digital data from the satellites are at one hundred bits per second. Correlation of a frame synchronizing sequence of bits causes the GOES receiver to generate a time tick once per second. Data received from the satellite includes the day of the year, the hour, the minute and the second. In addition, it includes the latitude, longitude and earth center distance of the satellite. The total amount of data cannot be transmitted within a one-second frame. Transmission of the complete message requires 30 seconds.

The GOES receiver enters the satellite position data into a microprocessors within the clock. In addition, the latitude and longitude of the clock are manually inserted by setting front panel controls. The microprocessor computes the delay appropriate to the distance from the satellite to the location of the clock and corrects the timing of an internallygenerated time tick so that it occurs on the real time second referenced to the National Bureau of Standards. A digital display on the clock presents the day of the year, hour, minute, and second, either in local time or Greenwich mean time.

The purpose of the ranging and position fixing experiment was not to determine time aboard the craft but rather to determine its location; hence it was not appropriate to use the internally generated correction for the time of arrival referenced to a fixed location on the earth. It was therefore necessary to present at the output of the receiver a time tick that represents the correlation of the synchronizing pulse.

The three GOES clocks for the earth station laboratory, the Davenport office and the towboat were modified by an internal connection that made the uncorrected time tick available at an output terminal. Figure 8 is a block diagram of a test setup used to evaluate the GOES receivers before the 


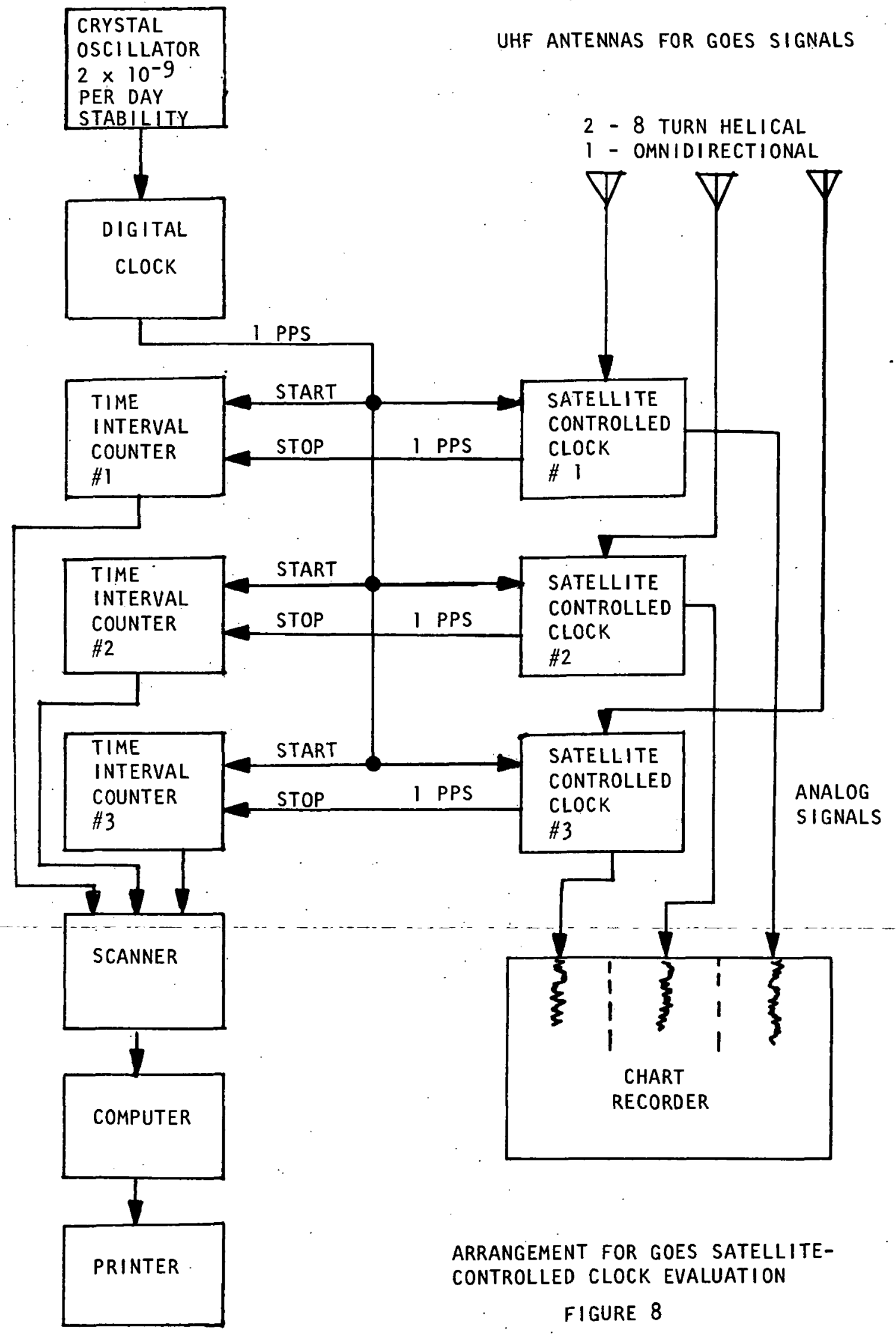


ranging experiments and again after the ranging experiments were completed. The system was used initially to test the receivers before any modifications were made to them.

The Manson Model RD180 oscillator is crystal-controlled with a proportional oven to provide a stability of $2 \times 10^{-9}$ : per day which supplied a stable source of $100 \mathrm{kHz}$ to the Hewlett-Packard Model 113BR frequency divider. This provided a clock with one pulse per second to start time interval counters, and the counters were then stopped by the one pulse per second outputs of the GOES clocks. The Model $113 \mathrm{BR}$ also provided the reference pulse to the time interval counter in the satellite controlled clock, which has an analog output. The time intervals between the reference pulses and the GOES clock output pulses were recorded in analog form on a Hewlett-Packard Model 7700 chart recorder and also in digital form through the scanner, the PDP-11/20 computer and an alphanumeric printer.

The first tests were made before the modification to the clocks. The corrected output ticks of the clock representing the real time seconds exhibited two characteristics unsuitable for the position fix process. These were a short-term jitter and a step every four minutes. The four-minute steps were due to the clock's computer reading a new GOES satellite location calculating a new fixed delay and applying it to the clock's output tick.

When the clocks were modified, the step every four minutes was eliminated leaving the jitter of the received time tick compared with the stable time tick derived from the Manson oscillator and Hewlett Packard clock.

The internal oscillator of the GOES clocks was a $1 \mathrm{MHz}$ oscillator that $t^{-1}$ imits the corrections of the clock to - microsecond per second. If the clock is in error by several microseconds, it changes in the correct direction at a rate of 1 microsecond per second until the error is less than one microsecond. No change in the timing of the output pulse occurs if the error is less than one microsecond, thus limiting the ranging precision to approximately 300 meters.

The analog chart recording was useful for quick evaluation of the clock performance, but unsatisfactory for detailed statistical analysis. The digital outputs to the computer were passed to a computer file and a Fortran program was prepared and run to derive the standard deviation along with minimum and maximum deviations of the GOES clock outputs reference to the stable Manson oscillator.: The results are presented in Section 5.3.3. 
When the modifications to the GOES receivers were completed, the units for the towboat and the Davenport office were incorporated into the cabinets that contained the L-band tone-code ranging transponders and the GOES receivers outputs were interfaced with the responder units.

Complete system tests were conducted at the Earth Station Laboratory using a frequency translator. when the satellite was not available because it was assigned to other uses: Tests at the Earth Station Laboratory were also conducted with the ATS -6 satellite when it was available. The test period prior to the experiment deployment was limited because of the imminent termination of the ATS- 6 satellite.

The sequence of tests with the towboat were as follows:

12 July 1979 Final equipment tests at Earth Station Laboratory 13-16 July 1979 Shipment to lowa

17-18 July 1979. Equipment installation. Tests showed broken wire (corrected), faulty circuit board card on the towboat responder, intermittent reception on towboat

23 July 1979. Circuit board replaced, antenna connection repaired

25 July $1979 \quad$ 0500-0900 Position fixing and communications tests 26 July $1979 \quad$ 0500-0900 Position Fixing and communications tests 26 July- End of life tests for ATS- 6 conducted by NASA-GSFC. 3 August Satellite not available to GE.

3 August 1979

ATS- 6 thrust from geostationary orbit and deact ivated.

The equipments on the towboat and at the Davenport office worked flawlessly during the tests on July 25 and 26. The Alter Company assigned an additional crew member. With the advice of the Captain he determined the position of the towboat at suitable intervals as it passed buoys and landmarks that were accurately plotted on charts. A copy of the charts was available on the towboat and also at the Earth Station Laboratory.

Ranging interrogations were transmitted each three seconds alternately to the ground truth reference at the Davenport office and to the towboat. The data were inputted to the computer and the position fixes were printed out within about one second after each interrogation of the towboat, together 
with all of the essential data that were used in the position fix computation. The ranging procedure was interrupted at intervals of 10-30 minutes for voice exchange for the purpose of recording the position of the towboat as determined by the on-board crew member. In addition, communications were demonstrated between the Davenport Office and the towboat. The voice communications from the Davenport Office were transmitted on $1655.05 \mathrm{MHz}$ to ATS-6, received at the Earth Station Laboratory on a downlink frequency of $1555.05 \mathrm{MHz}$; retransmitted to the satellite from the Earth Station Laboratory on $1652.00 \mathrm{MHz}$, and received aboard the towboat on $1552.00 \mathrm{MHz}$. The signalling characteristics and power budgets for these communications are detailed in Appendix A.

The 26 July experiment period was conducted like the 25 July experiments except that three phone-patch interfaces were made at the Earth Station Laboratory to demonstrate interconnection of the towboat mobile communication with the public switched telephone network. One call was placed by the Captain of the towboat to the home of the Alter Company Port Captain. The other two were personal calls. In each case the calls were in a half-duplex mode. The towboat could operate only in a simplex mode, that is, it could not transmit and receive simultaneously. As a consequence, the speaker on the towboat could interrupt the person speaking on the telephone, but the person speaking on the telephone could not interrupt the person speaking on the towboat. All of the ranging and communications data were recorded on magnetic tape, chart recordings or punched paper tape as appropriate for the data.

The real-time position fixing results were offset from the true positions of the towboat because the equipment internal time delays were not correctly determined before the equipment was deployed for the experiment. The imminent deactivation of the ATS 6 satellite did not allow sufficient time for calibration before it was necessary to ship the equipment from the Earth Station Laboratory to the field. New estimates of the internal time delays were made after the real time tests. The post experiment recalibration using the recorded data is believed to be technically sound, but the termination of the satellite prevented a later positive verification that the recalibration was correct.

Equipment time delays were determined after the experiment by adjusting the assumed delays to correct the computed lines of position for a 
specific set of data taken when the towboat was stopped at a known location, Lock 19 at Keokuck, lowa. The new equipment time delays were then entered as constiants in the computer program and all of the data were rerun.

The procedure is essentially the one that would have been used to calibrate the equipment at the Earth Station Laboratory. It was corivenient and believed to be as accurate as any other means of measuring the equipment delays. The result could not be verified by fix determinations made at widely separated locations over a long period of time in this experimental program. The technique was used and verified in a previous experiment "Application of Satellite Communications and Position Fixing Techniques to Land Mobile Systems," Contract DEA-76-20, sponsored by the Drug Enforcement Administration and the Immigration and Naturalization Service. In that experiment, an automobile was located by tone-code ranging through ATS- 3 and ATS- 1 as it travelled across the contiguous states over a period of several weeks. 
5.0. RESULTS

$5.1:$ Sample of Position Fixing Result

A sample of the data obtained during the 26 July experiment is presented as an overview of the results, the causes of position fix error, and an evaluation of the results. The following subsections present detailed results of all the tests, including communications.

The towboat and office were interrogated alternately at threesecond intervals. Data received at the General Electric Schenectady Earth Station Laboratory were immediately entered into the on-site computer and within one second after interrogating the towboat, its latitude and longitude were printed out.

Figures 9, 10 and 11 illustrate the results. Every small cross in Figure 9 is an independent fix made in real time while the Renee $G$. was in Mississippi River Lock 19, Keokuck, lowa. The intersection of the reference lines represents the true position of the vessel. The fixes are displaced from the true position because it was not possible to complete the calibration of the internal time delays of the equipments before they were installed.

All of the raw data were recorded on punched tape during the experiment. The equipment was recalibrated and the raw data were reprocessed using the equipment time delay constants that were determined from the recalibration. A portion of the alphanumeric printout of the fixes is shown in Figure 10. The result of the recalibrated and reprocessed data is plotted in Figure 11. The azimuth angles to the satellites are shown. Lines-ofposition lie at right angles to the satellite azimuths. All of the fixes lie within 0.1 nautical mile of the true 1 ine-of-position derived from ATS-6. It is clearly demonstrated that narrow bandwidth signals, 2.4414 kHz tone frequency, and a relatively short integration time, 0.1 seconds, can result in accuracy that is useful for most surveillance-navigation applications. It is significant because it once again verifies the tone-code ranging technique is compatible with commonly used maritime and mobile voice communications equipment. 
26 JULY 1979

08:07:22 - 08:15:22 GMT

FIGURE 9

M/V RENEE G., MISSISSIPPI RIVER

LOCK 19, KEOKUCK, IOWA

POSITION FIXES

RELATIVE TO TRUE POSITION

- REAL TIME

TOWBOAT AT CENTER OF

DIAGRAM.

SCALE DIVISIONS - 1 MINUTE

PLOTTED FROM REAL TIME PRINTOUT OF POSITION FIXES

(EQUIPMENT CALIBRATION NOT COMPLETED BEFORE EXPERIMENT)

1 N. MI.
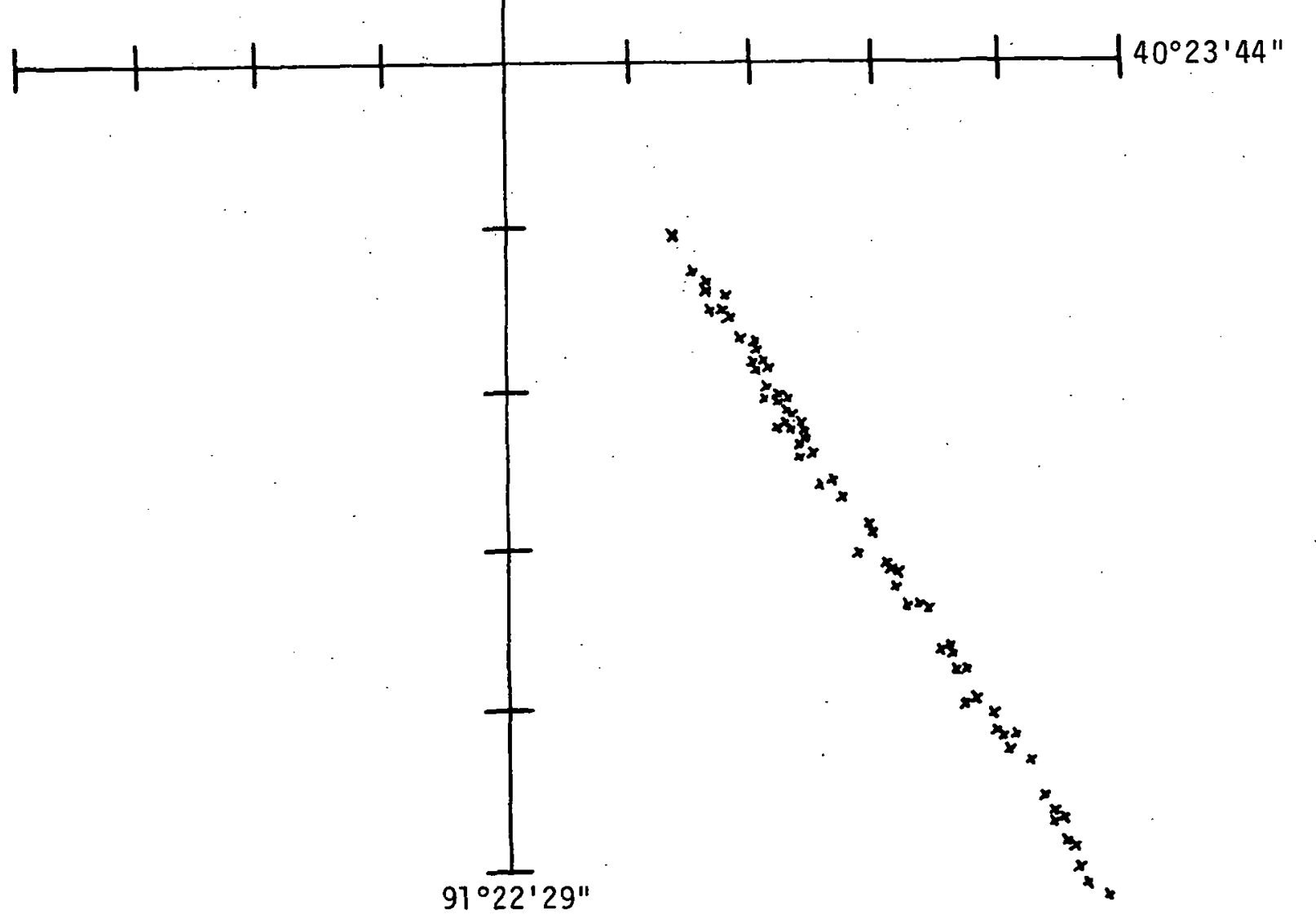

ONE FIX

$08: 12: 34$

$40^{\circ} 16^{\prime} 24^{\prime \prime}$

$91^{\circ} 16^{\prime} 21^{\prime \prime}$

(DATA TRANSMISSION ERROR)

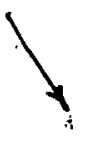




\begin{tabular}{|c|c|c|c|c|}
\hline TIME (GMT) & LATITUDE & LONGITUDE & & \\
\hline $8: 18: 4$ & $40,23,58$ & $91,22,38$ & 221 & \\
\hline MEAN $P$ & $40,24,56$ & 91.2528 & 10 & NUMBER OF FIXES: IN COMPUTING MEAN \\
\hline$P \cdot 8: 10: 10$ & $40,25,47$ & $91,22,31$ & 221 & 22-NASA PREDICTIONS USED AS SATELLITE \\
\hline MEFIN $P$ & $40,24,51$ & 91.2324 & 10 & POSITIONS, I-GROUND TRUTH CORRECTION \\
\hline $\begin{array}{l}P: 10: 16 \\
\text { PE }\end{array}$ & $40,24,25$ & $91,23,07$ & 221 & USED IN COMPUTING FIX \\
\hline $\begin{array}{l}\text { HEFH } F \\
P \quad 8: 10: 22\end{array}$ & $40,24,46$ & $91,23,20$ & 10 & \\
\hline $\begin{array}{l}P \text { 8:10:22 } \\
\text { MEAN } \mathrm{P}\end{array}$ & 40.25 .209 & $91 ; 23,39$ & 221 & \\
\hline MEAN $P$ & $40,24,47$ & 91.23120 & 10 & \\
\hline$P \quad 8: 10: 28$ & $46,25,14$ & $91,23,38$ & 221 & \\
\hline NEAN $P$ & $40,24,44$ & $91,231.18$ & 10 & \\
\hline $8: 10: 34$ & $40,24: \geq 0$ & 91,2305 & 221 & P IDENTIFIES A FIX MADE ON A SINGLE \\
\hline NEFH P & $40,24,42$ & $91 / 2315$ & 10 & MEASUREMENT \\
\hline$P \quad 8: 10: 40$ & $40,24,25$ & 9122313 & 221 & \\
\hline MEAN $P$ & $40.24: 59$ & $91-2315$ & 10 & MEAN P IDENTIFIES THE MEAN OF PREVIOUS \\
\hline$P \quad 8: 10: 46$ & $40,24,49$ & 91.2318 & 221 & FIXES (UP TO 10) \\
\hline MEAH $P$ & $40.24 \cdot 41$ & 91,2316 & 10 & \\
\hline $\mathrm{P} \quad 8: 10: 52$ & $40,25,10$ & 91.2239 & 221 & \\
\hline MEAH $P$ & $40,24,41$ & 91,2316 & 10 & \\
\hline$P \quad 8: 10: 58$ & $40,24,49$ & $91.23: 24$ & 221 & \\
\hline WEAH $F$ & $40,24: 58$ & $91: 23,13$ & 16 & \\
\hline P 8:11: 4 & 40.24942 & 91,2318 & 221 & \\
\hline MEAN $F$ & $46,24,42$ & 91,2217 & 10 & \\
\hline$P \quad 3: 11: 10$ & $40,24: 28$ & $91 \cdot 23066$ & 221 & \\
\hline MEAN F & $40,24: 40$ & 91,2321 & 10 & \\
\hline$P \quad \varepsilon: 11: 16$ & $46,24,37$ & $91 \cdot 22 ; 17$ & 221 & \\
\hline HEFH $P$ & $40.24,47$ & 91.23122 & 10 & \\
\hline P $\quad 8: 11: 22$ & $40,24: 28$ & $91,22,11$ & 221 & \\
\hline MEFH P & $46,24,42$ & 91.2219 & 10 & \\
\hline$P \quad 8: 11: 28$ & $40,24 / 3 \%$ & $91: 2313$ & 221 & \\
\hline MEFIH $P$ & $49,24,40$ & 91,2316 & 10 & \\
\hline$P \quad 8: 11: 34$ & $40,28,46$ & $91 / 21.40$ & 221 & \\
\hline MEAH $P$ & $40.24: 29$ & $91.23,68$ & 10 & \\
\hline$p \cdot 8: 11: 40$ & $49,23,05$ & $91 ; 21,50$ & 221 & \\
\hline MERH $P$ & $40,24,21$ & $91 \cdot 23100$ & 10 & \\
\hline$P \quad 8: 11: 46$ & $40,2 \geq 136$ & $91,22: 21$ & 221 & \\
\hline MEAM $P$ & $40: 24: 14$ & $91+22,54$ & 10 & \\
\hline $0: 11: 52$ & $40,24,22$ & $91.22 \cdot 58$ & 221 & \\
\hline MEAH P & $40,24,09$ & $91 \cdot 22,50$ & .10 & \\
\hline$P \quad 8: 11: 58$ & $40,24,15$ & $91: 22: 55$ & 221 & \\
\hline MEHH $P$ & $40,24,06$ & 91 12264? & 10 & \\
\hline$p \quad 8: 12: 4$ & $40.24,29$ & 91,2366 & 221 & \\
\hline MEAN $P$ & 40.24 .94 & $91+22846$ & 16 & \\
\hline F $\quad 8: 1:: 19$ & $40,24,50$ & $91,23.24$ & 221 & \\
\hline MEPIN $P$ & 40.24 .207 & 91.27 .49 & ta & \\
\hline
\end{tabular}

FIGURE 10

COMPUTER PRINTOUT OF POQSITION FIXES 


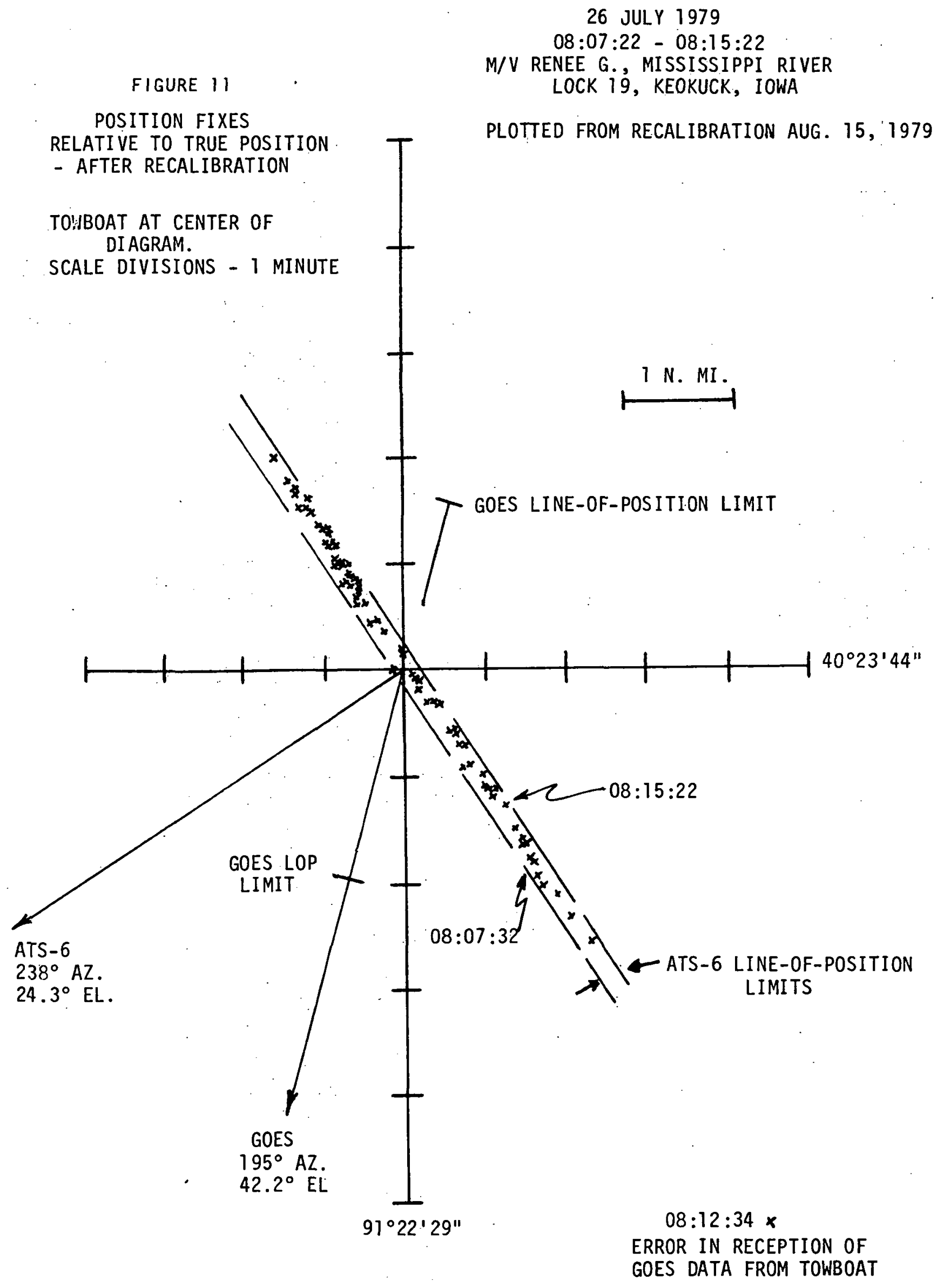


The GOES lines-of-position lie within $+1.5,-2.2$ nautical miles except for one large error resulting from faulty reception of GOES data that is clearly evident in the raw data printout. The poor accuracy of the GOES lines-of-position in comparison with those of ATS-6 are the result of the narrow bandwidth, $100 \mathrm{~Hz}$, of the GOES data transmissions.

The unfavorable crossing angle of the ATS-6 and GOES 1 ines-ofposition at the location of the towboat result in fix errors more than three miles due to geometrical dilution of precision.

Figure 12 shows that the variations in the GOES lines-of-position are not entirely random. The largest component of the variation has a time varying characteristic. The exact cause was not determined. It may be due to differences in error correction time constants in the three GOES receivers involved in the fix determination process - the one at the Schenectady Earth Station, and the others on the towboat and at Davenport.

Independent tests of time "ticks" from the GOES receivers relative to a stable oscillator have shown the standard deviations of sets of ten sequential time ticks to be of the order of 1 microsecond; much smaller than the systematic variations evident in Figure 12. As noted above, the systematic variations are believed to be characteristics of the equipment. The effects may be substantially reduced by insuring that all GOES receivers used in the system have the same characteristics. A further improvement may be possible by the frequent, automatic measurement of receiver internal time delay and correction of the output time tick based on the measurement. A similar technique is used with the tone-code transponder and is one of the design features contributing to the high accuracy of the ATS-6 lines-ofposition.

The results for the Keokuck Lock are typical of the thousands of position fixes made during the two test periods. Independent position fixes were determined on board the vessel as it proceeded past buoys and other landmarks. Satellite derived position fixes compared with the independent fixes while the vessel was underway exhibited precision and accuracy like that experienced with the vessel in the lock. 


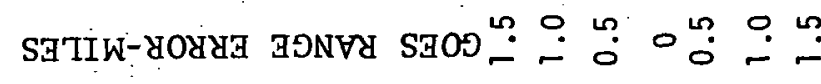

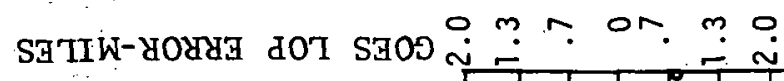

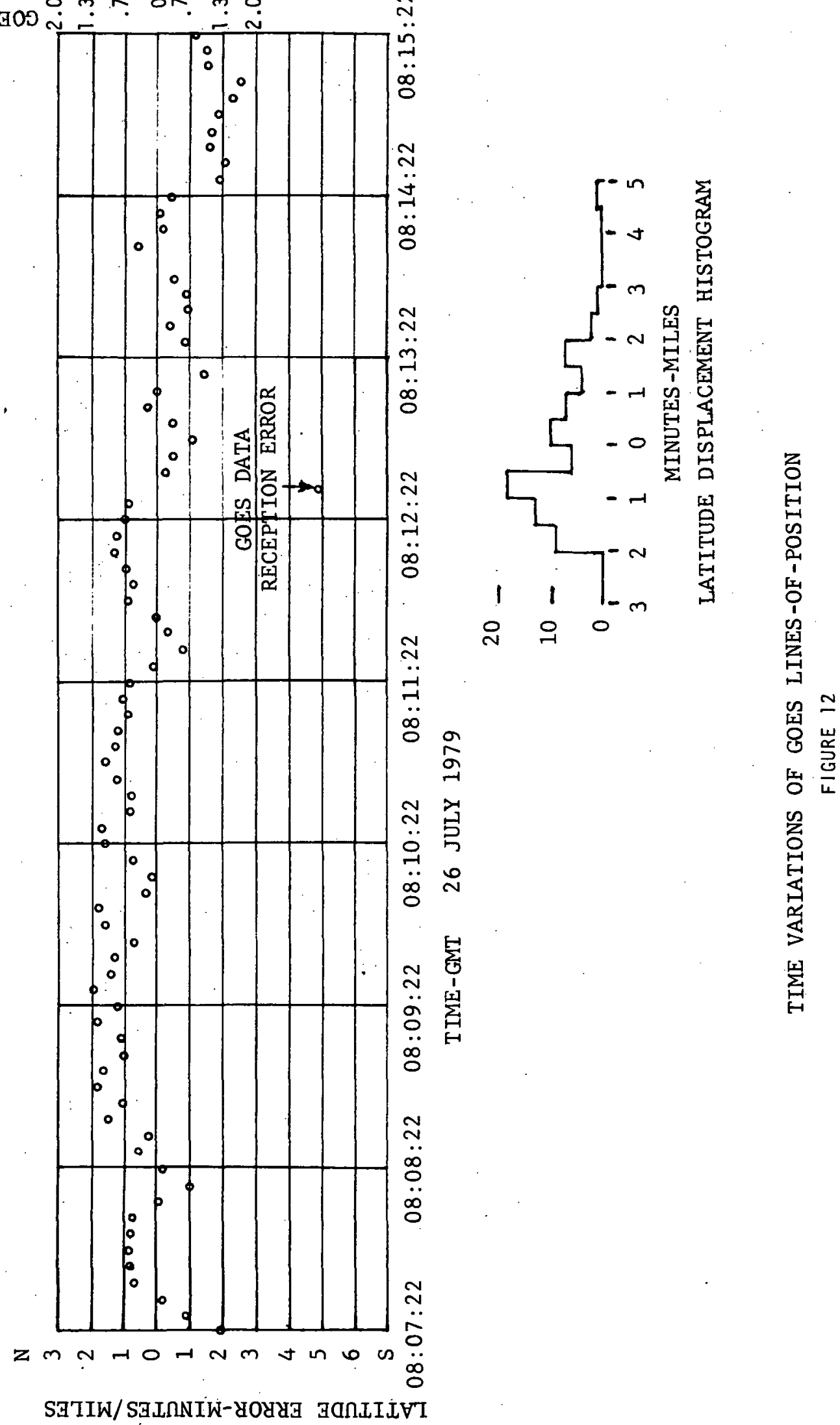




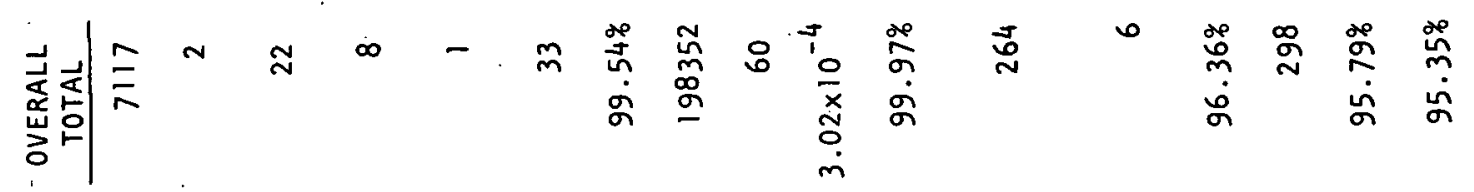

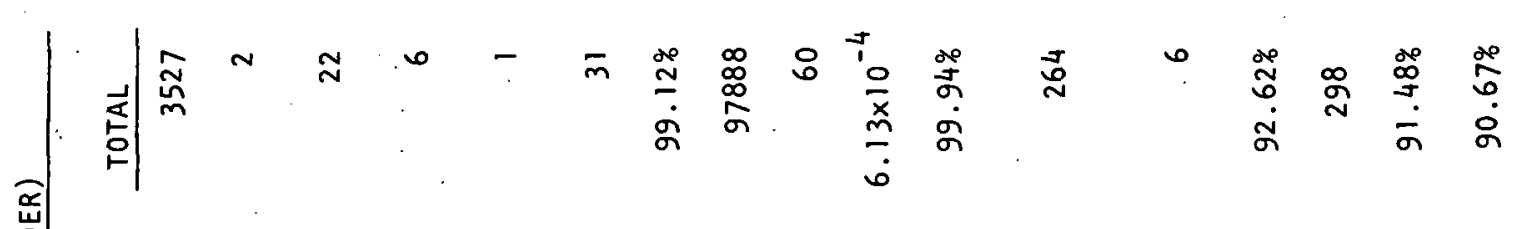

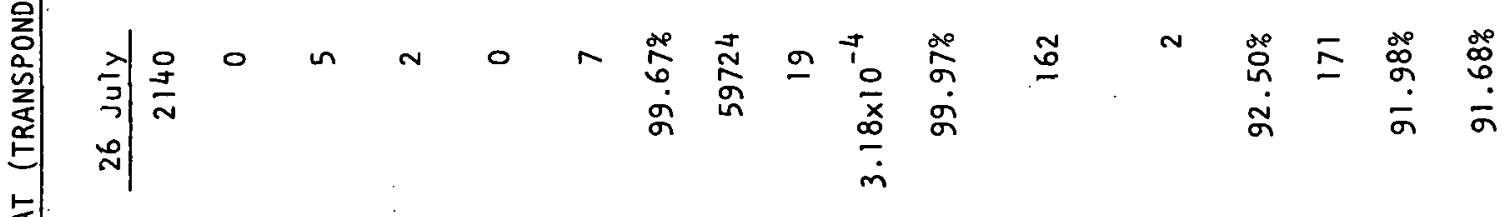

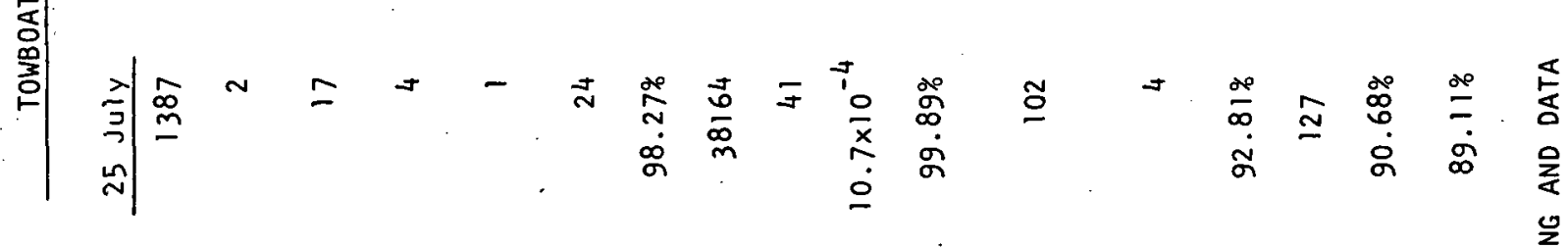

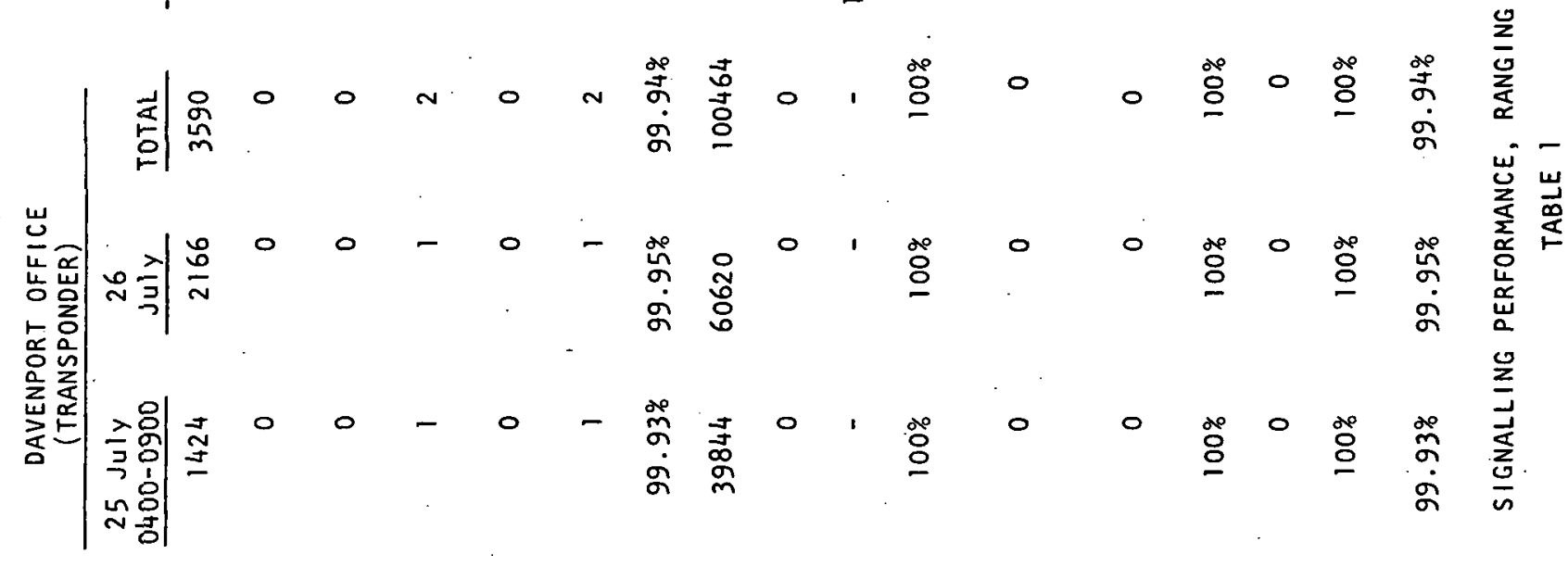

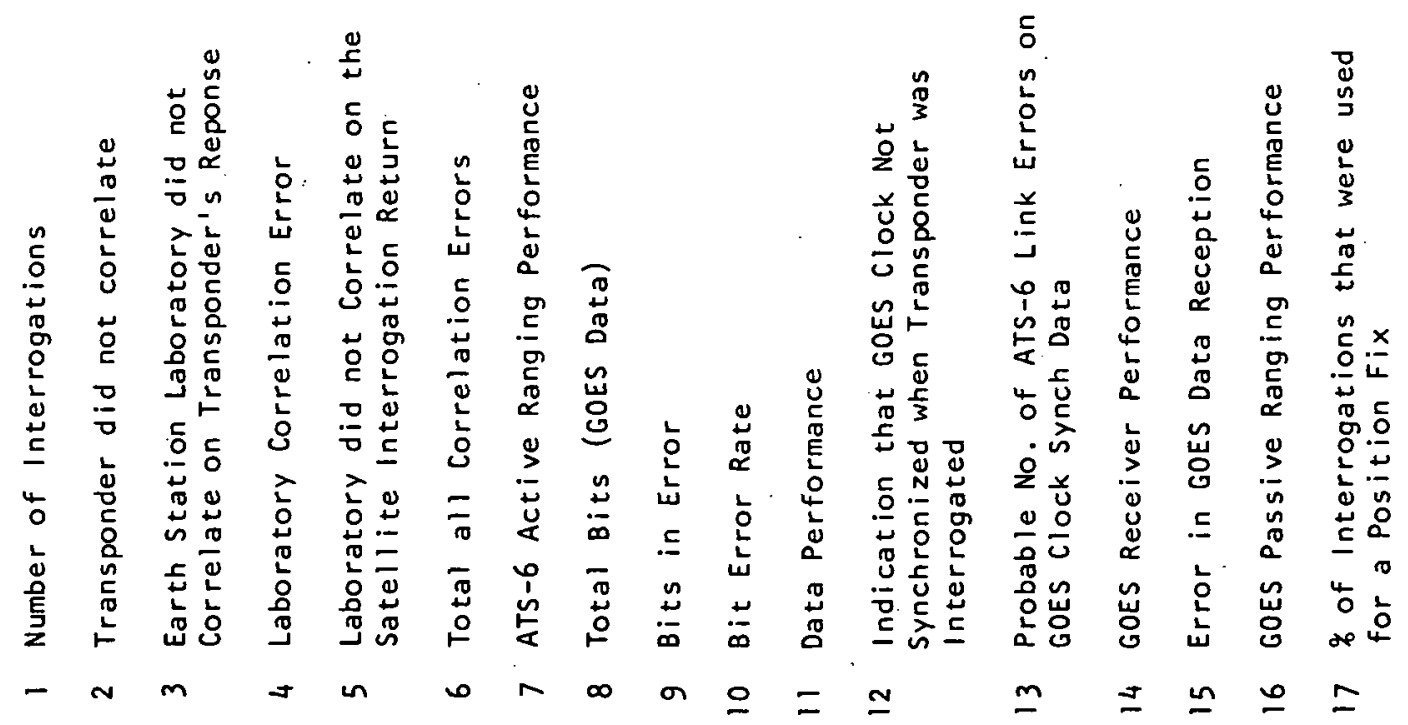




\subsection{Ranging and Data Link Performance}

Table 1 presents the signalling performance for the ATS-6 active ranging link, the reliability of the GOES data transmissions through ATS 6 and the performance of the GOES receiver. The data are presented for the fixed transponder at the Davenport office and for the transponder on the towboat. It is immediately apparent that the higher gain of the fixed antennas at the Davenport office provided better signalling performance over the link than the lower gain antennas on the towboat.

While most of the headings of the table are self-evident, some comments with respect to specific headings are in order.

1. The bit rates for tone-code interrogations and responses were at 2.441 kilobits per second. A digital one was transmitted as an audio cycle; a digital zero was transmitted as a suppressed audio cycle.

2. The GOES data transmissions were at 814 bits per second. Three audio cycles were transmitted for digital one and three audio cycles were suppressed for digital zero.

3. It will be noted that the Earth Station Laboratory did not correlate on the transponder's response on 17 interrogations on $25 \mathrm{July}$, and there were five failures on 26 July. Part way through the 26 July test it was discovered that a faulty antenna relay at the observatory was degrading the received signal-to-noise ratio below the value for the normal link. When the relay problem was corrected, the performance was improved.

4. A correlation on the return code, which is an integral. number of bits too early or too late, results in a substantial but correctable error in the ranging measurement. The cause is a weak or noisy signal.

11. Each user response consisted of 28 bits comprised of seven characters with four bits per character.

12. The indication that the GOES clock was not synchronized when the transponder was interrogated is derived from a three-bit message transmitted with the response to every interrogation. The PDP-11/20 computer was programmed to print a minus sign in front of the GOES time tick data measurement if any of three error bits was a one. The three conditions detected at the transponder are no power, phase of data not synchronized, and data not framesynchronized. No distinction was made in the computer printout between the 
three possible causes of error. It is not possible to determine why a minus sign was printed; whether it was due to a GOES receiver out of synchronization or a bit error in the data transmission.

The performance of an operational system could be better than the experimental performance if the signal-to-noise ratio from the vehicle were improved, and if a data error recovery code were used. A data error checking system is needed, such as parity or check sums, but neither of these coding improvement techniques was used in the experiment.

\subsection{Detailed Comparison of Satellite and On-Board Position Fixes}

Every position fix determination during the 25 July test is plotted in Figure 13 and every fix determination during the 26 July test is plotted in Figure 14. The crosses are position fixes made by satellite, the circles are position fixes made by Randy Elder aboard the towboat with reference to buoys and landmarks. All of the plots in this section were computergenerated. All ranging data were recorded on punched paper tape as the signals were received. Real time computations of the position fixes were printed out alphanumerically. The paper tapes were run through the computer later, and the computer output applied to an $x-y$ plotter to generate the plots for the report. The satellite derived position fixes of Figures 13 and 14 were plotted after recalibration of the equipment time delay constants as explained in Section 4.0 .

It is difficult to compare the satellite and on-board fixes in Figures 13 and 14 because of the large number of fixes in the plots. A time comparison was made by plotting only those satellite fixes made within one minute before and one minute after each of the on-board fixes. Figure 15 shows the results for 25 July, and Figure 16 for 26 July.

The cause of the disagreements between the GOES LOPS and the true positions is primarily due to a time varying difference in the characteristics of the GOES clocks as discussed in section 5.1. The exact cause was not identified. The receivers performed within the manufacturers' design specifications for their intended applications. It is possible that the more recent design by the same manufacturer (which was not available for this experiment) or that a receiver specially designed for the ranging application would provide better precision and accüracy. 


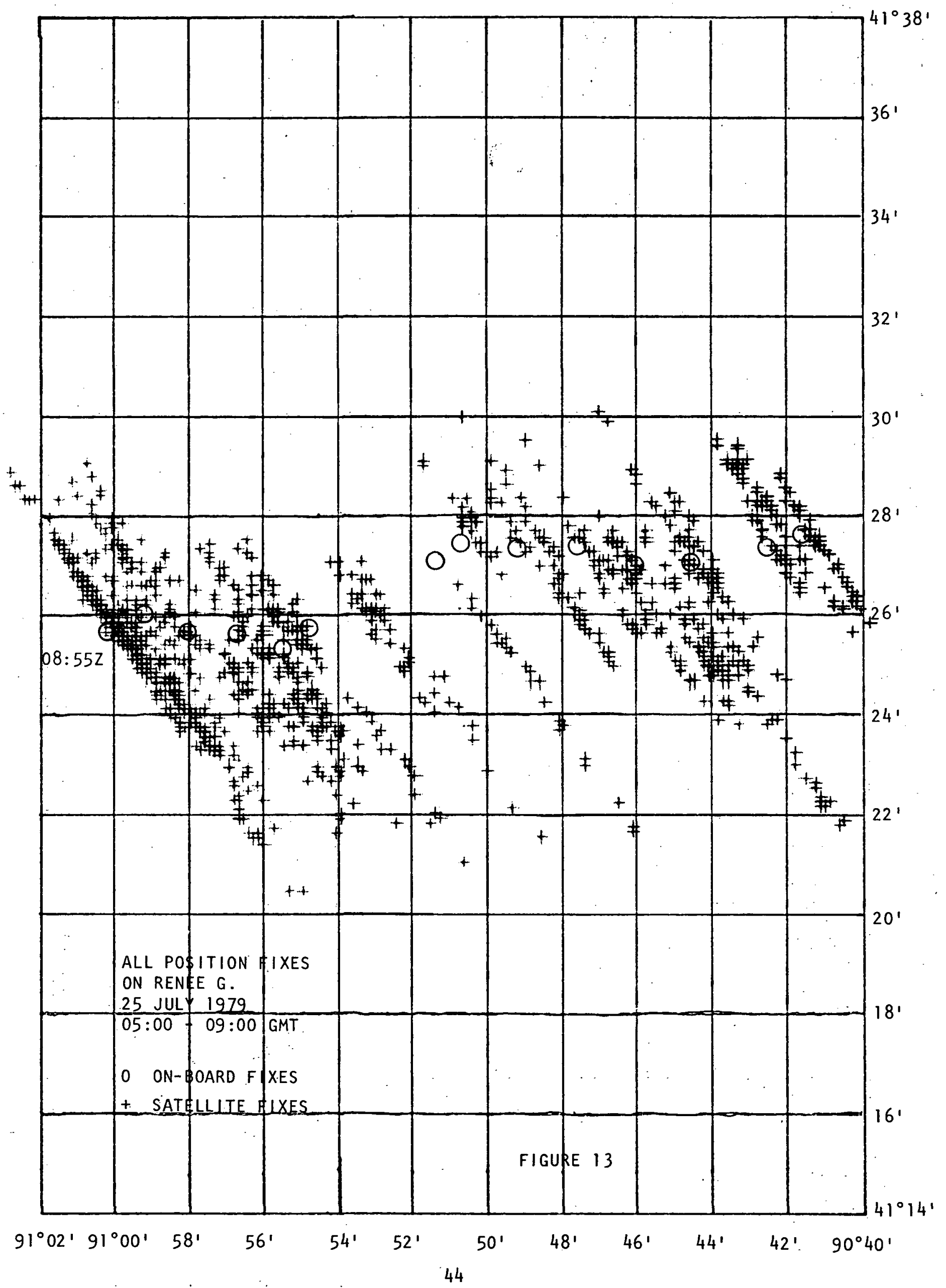




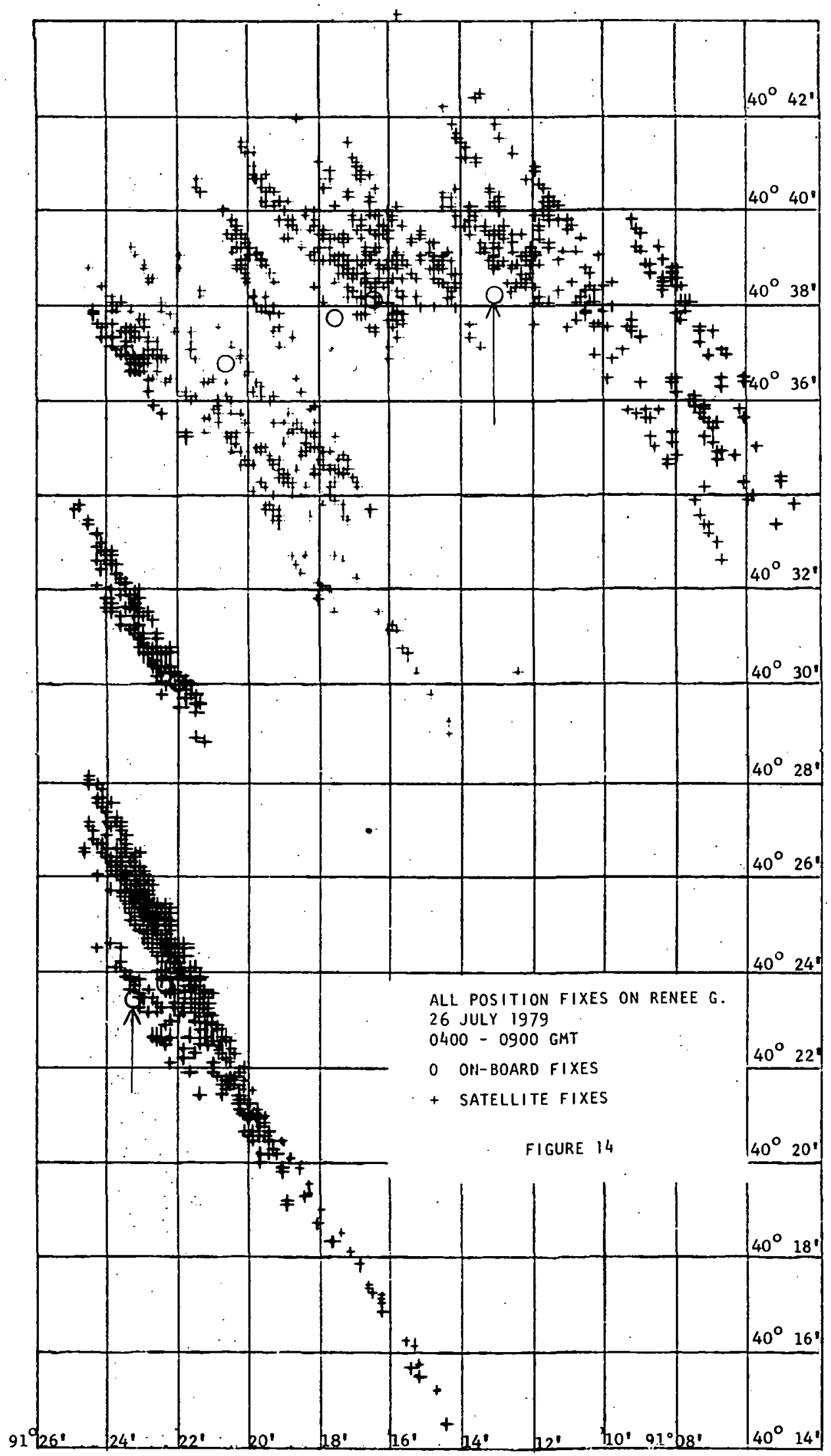




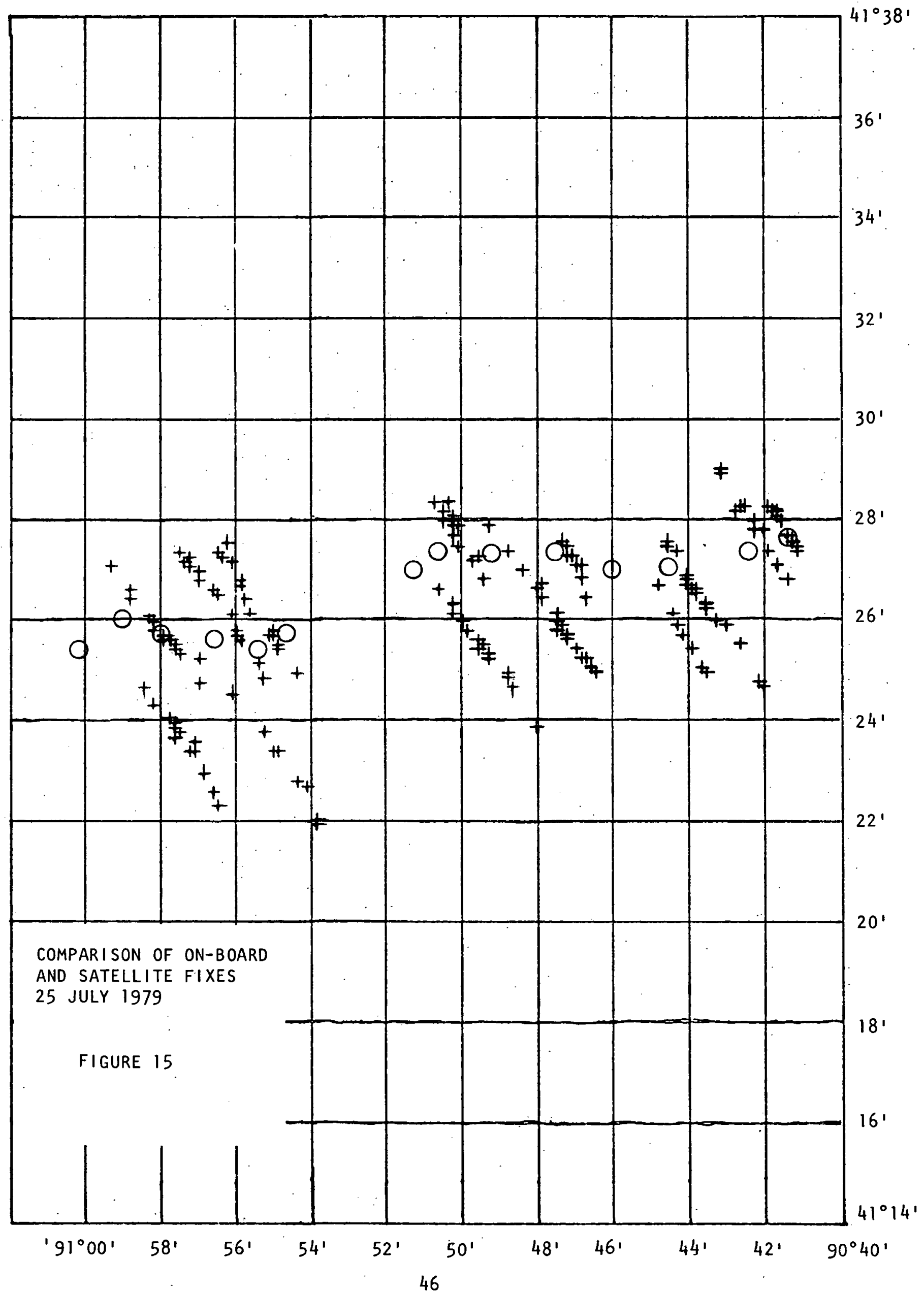




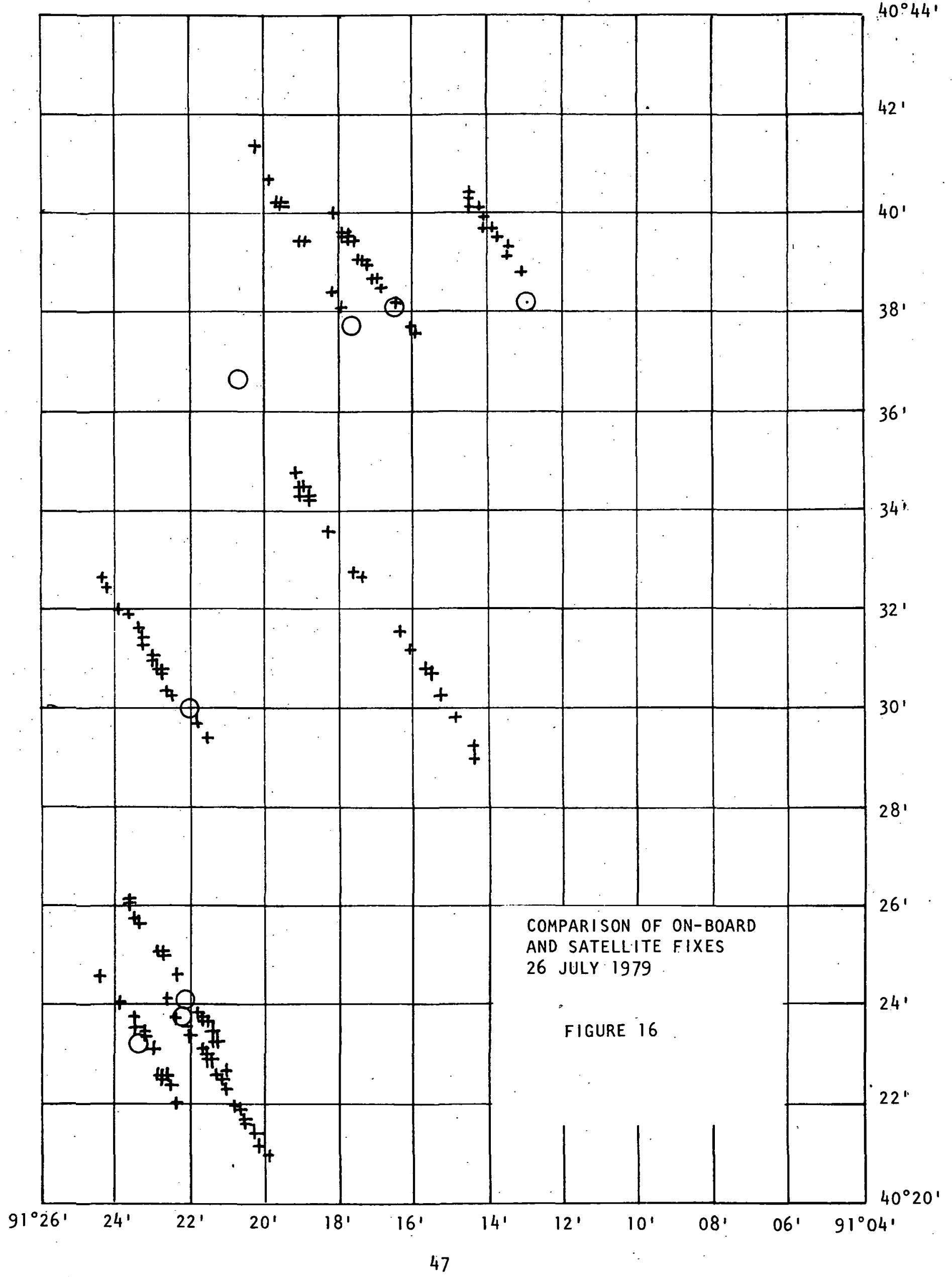




\subsubsection{Geometry of Fix Determination}

The geometry for determining the LOPS of ATS 6 and GOES is depicted in Figure 17, a two times expansion of the plot of Figure 11. It was advantageous to use the Lock 19 set of data because the towboat was not moving when the data were taken, and because there are a sufficient number of fixes to have statistical significance. Data taken while the towboat was moving could not be used conveniently for estimating the ATS- 6 LOP precision because the towboat, moving about 10 nautical miles per hour, moved a distance comparable to the precision of the ATS -6 LOPs during the one minute before and one minute after each on-board $f i x$ determination.

The fixes in Figure 17 are clustered within $\pm 0.1 \mathrm{NMi}$ of the true ATS- 6 LOP, but are scattered +1.5 and $-2.2 \mathrm{NMi}$ with respect to the true GOES LOP. The difference in precisions is due to the difference in bandwidths and signal-to-noise ratios of the ATS- 6 and GOES ranging signals. If the GOES signals had the same bandwidth and signal strength as the ATS- 6 signals, the GOES precision would approximate that of ATS- 6 and the fixes would be in a small cluster.

The parallelogram encloses all the fixes. It is often the practice to specify precision, the variability of the LOPs or fixes, and accuracy, their displacement from true position, in terms of their statistical probability. The Greek letter, $\sigma$, denotes the probability. If the fixes have a Gaussian distribution, a one $\sigma$ limit would enclose $67 \%$ of the fixes, a 2 o limit would enclose $95 \%$ and $3 \sigma, 99 \%$. A contour of error probability would approximate an ellipse enclosing a portion of the fixes, and yielding stated dimensions of precision and accuracy smaller than the dimensions of the parallelogram in. Figure 17.

Uncertainty in the range measurement from the satellite to a vehicle projects onto the earth an uncertainty in the LOP that is greater than the uncertainty of the measurement. The magnitude of the "broadening" of the LOP is a function of the elevation angle to the satellite as shown in Figure 18. For elevation angles less than $90^{\circ}$, the LOP uncertainty is proportional to the secant of the elevation angle:

$$
\delta_{m r}=\Delta_{m r} \sec e
$$

At the subsatellite point, where the elevation angle is $90^{\circ}$, the projection for range uncertainty may be approximated by: 


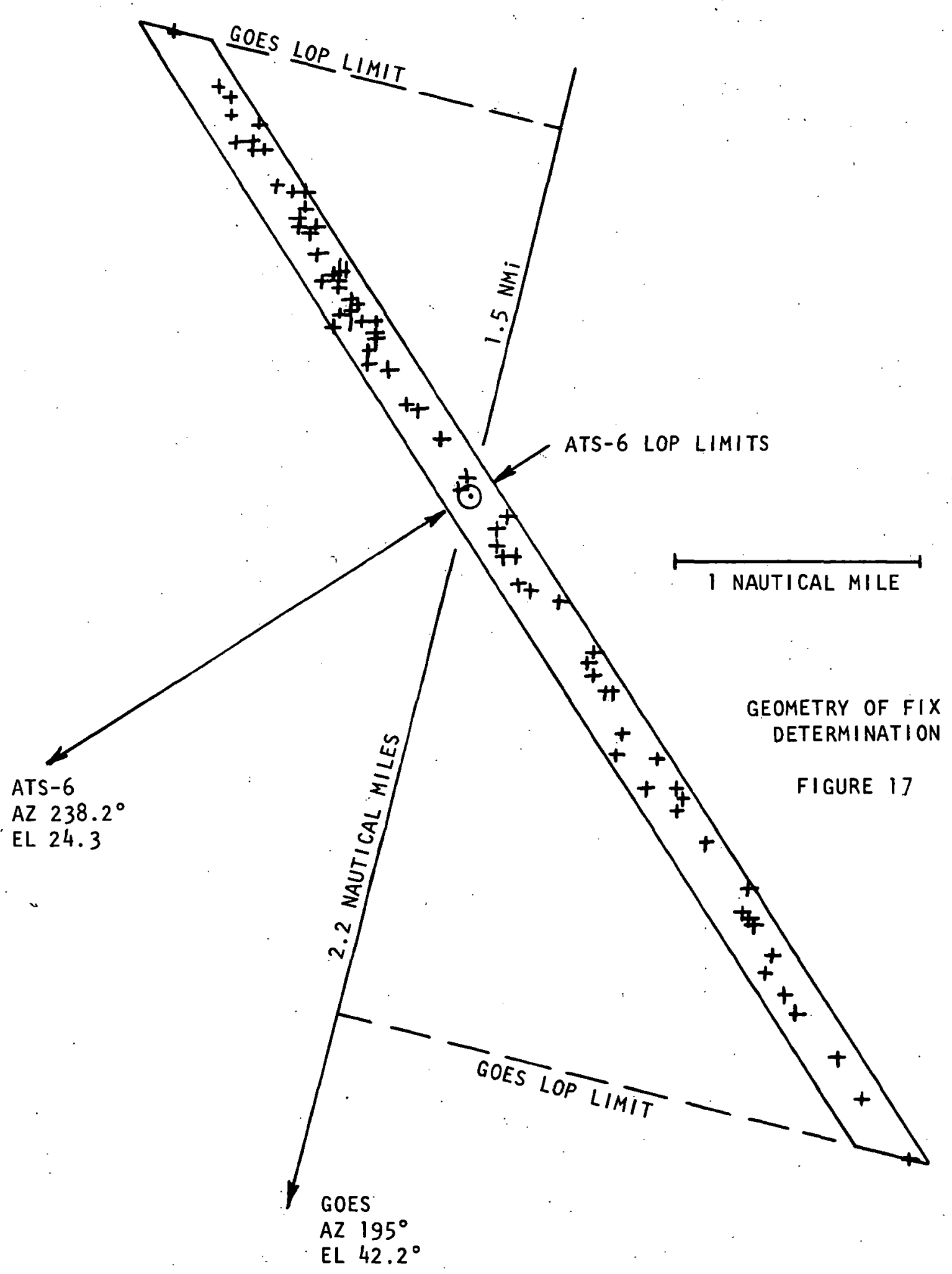

49 


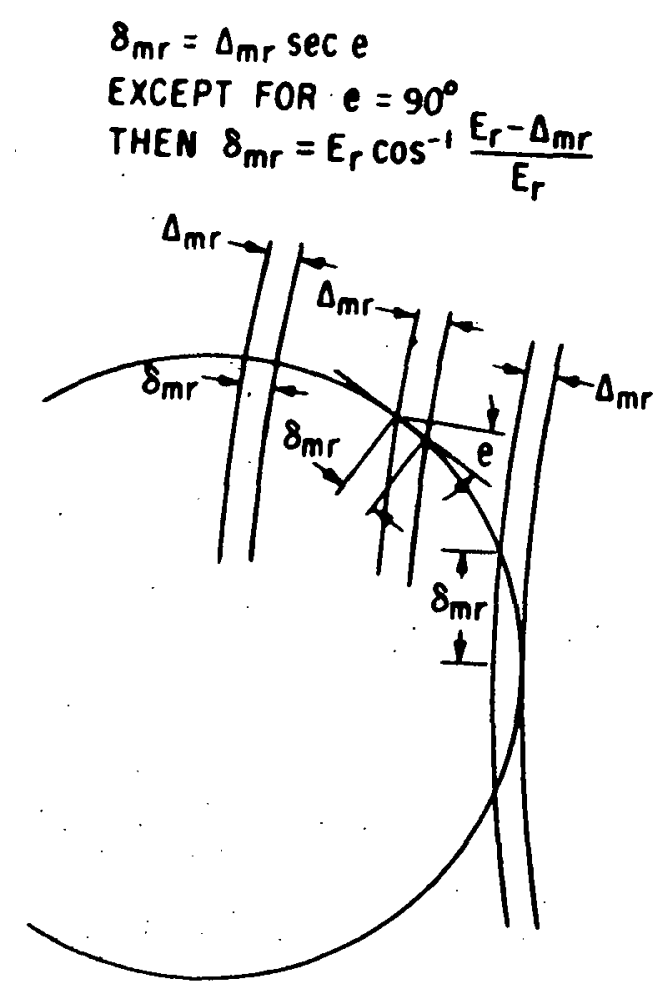

\author{
FIGURE 18 \\ RANGE MEASUREMENT \\ ERROR EFFECT ON \\ LINE-OF-POSITION
}

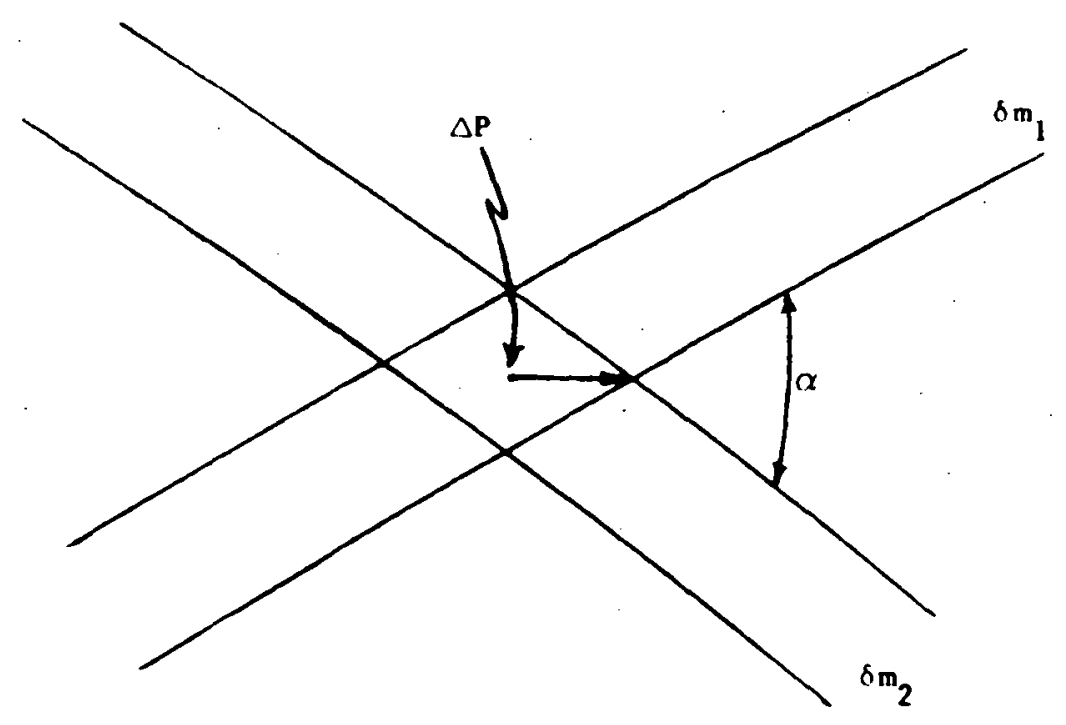

FIGURE 19

LOP CROSSING ANGLE

EFFECT ON POSITION

FIX 


$$
\delta_{m r}=E_{r} \cos ^{-1} \frac{E_{r}-\Delta_{m r}}{E_{r}}
$$

where: $\delta_{m r}=$ line-of-position uncertainty for range uncertainty

$$
\begin{aligned}
E_{r} & =\text { earth's radius } \\
\Delta_{m r} & =\text { range measurement uncertainty }
\end{aligned}
$$

There is further geometrical dilution in calculating a fix from two lines of position. The broadened lines of position intersect at an angle to produce a parallelogram of position, as shown in Figure 19.

One-half the longest diagonal of the parallelogram may be taken as the probable error of the fix.

$$
\Delta P=\frac{1}{2}\left[A^{2}+B^{2}+2 A B \cos \alpha\right]^{1 / 2}
$$

where: $\quad A=\delta_{m_{1}}$ secant $\alpha$

$$
B=\delta_{m_{2}} \operatorname{secant} \alpha
$$

and $\alpha$ is the angle of intersection of the lines-of-position, or the difference in azimuth angles to the two satellites from the vehicle location.

\subsubsection{Precision and Accuracy of ATS- 6 Lines-of-Position}

The precision and accuracy of the ATS-6 lines-of-position were estimated from the plots of fixes in Figures 20 through 29 . They include fixes made while the towboat was underway and while it was stopped. The fixes were plotted using the recalibrated values of equipment delays. As explained in Section 4.0, the recalibration used data taken on 26 July when the towboat was stopped in lock 19 at Keokuck, lowa. The 25 July data were selected for the plots of Figures 20 through 29 to verify that a calibration made using data taken on one day is valid on a different day and at a different location. A larger spread of time and location were not possible because of the deactivation of ATS -6 . 


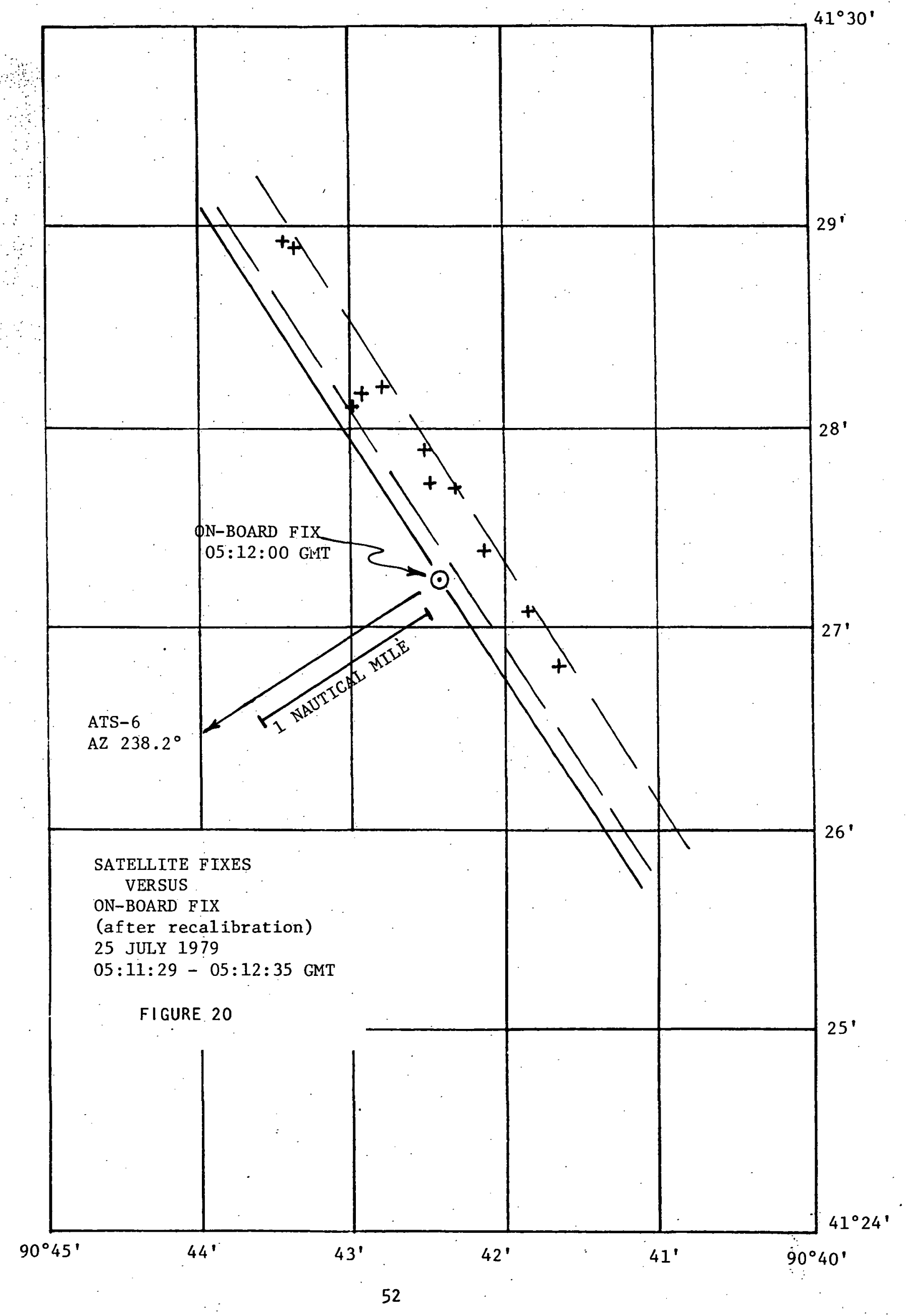




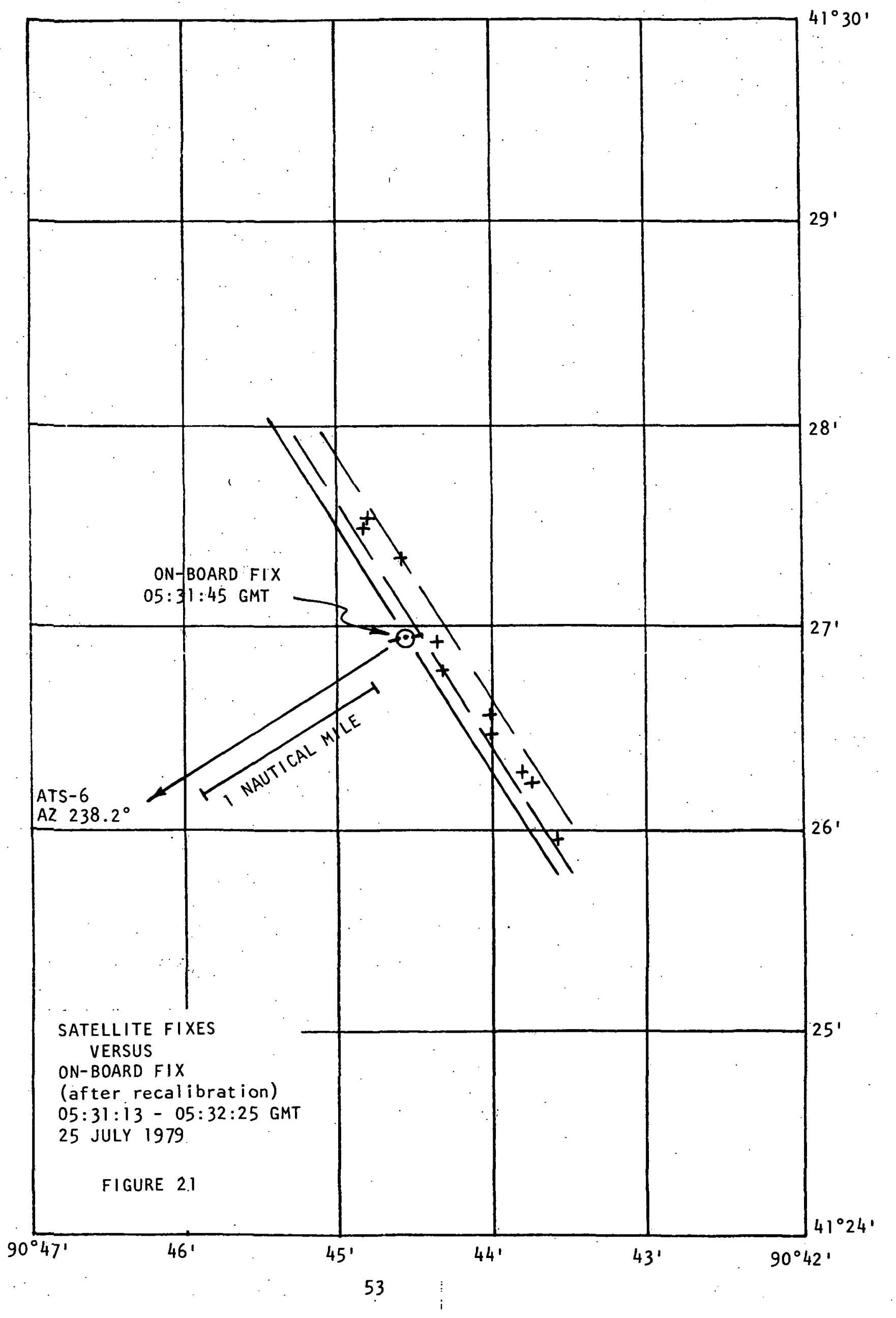




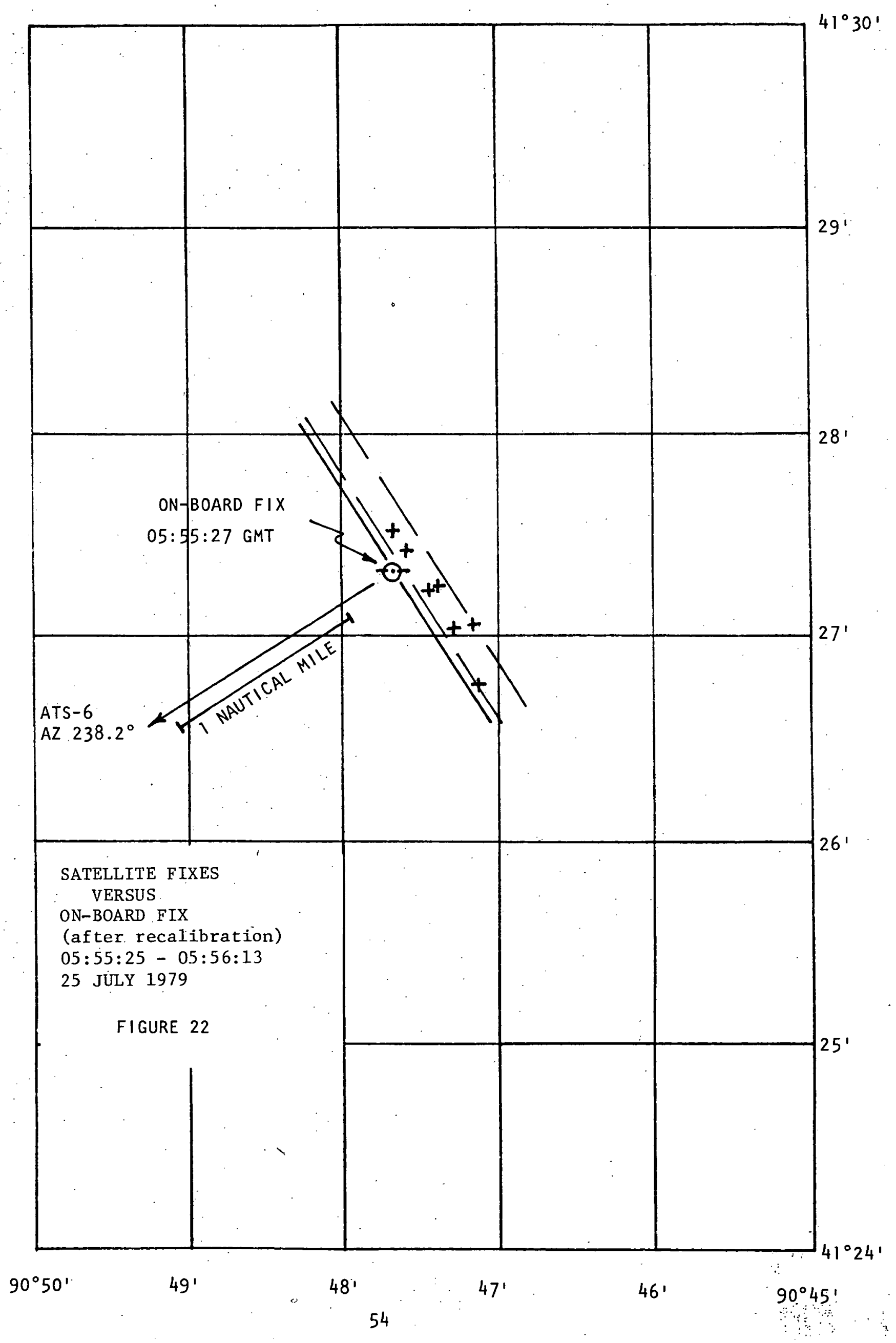




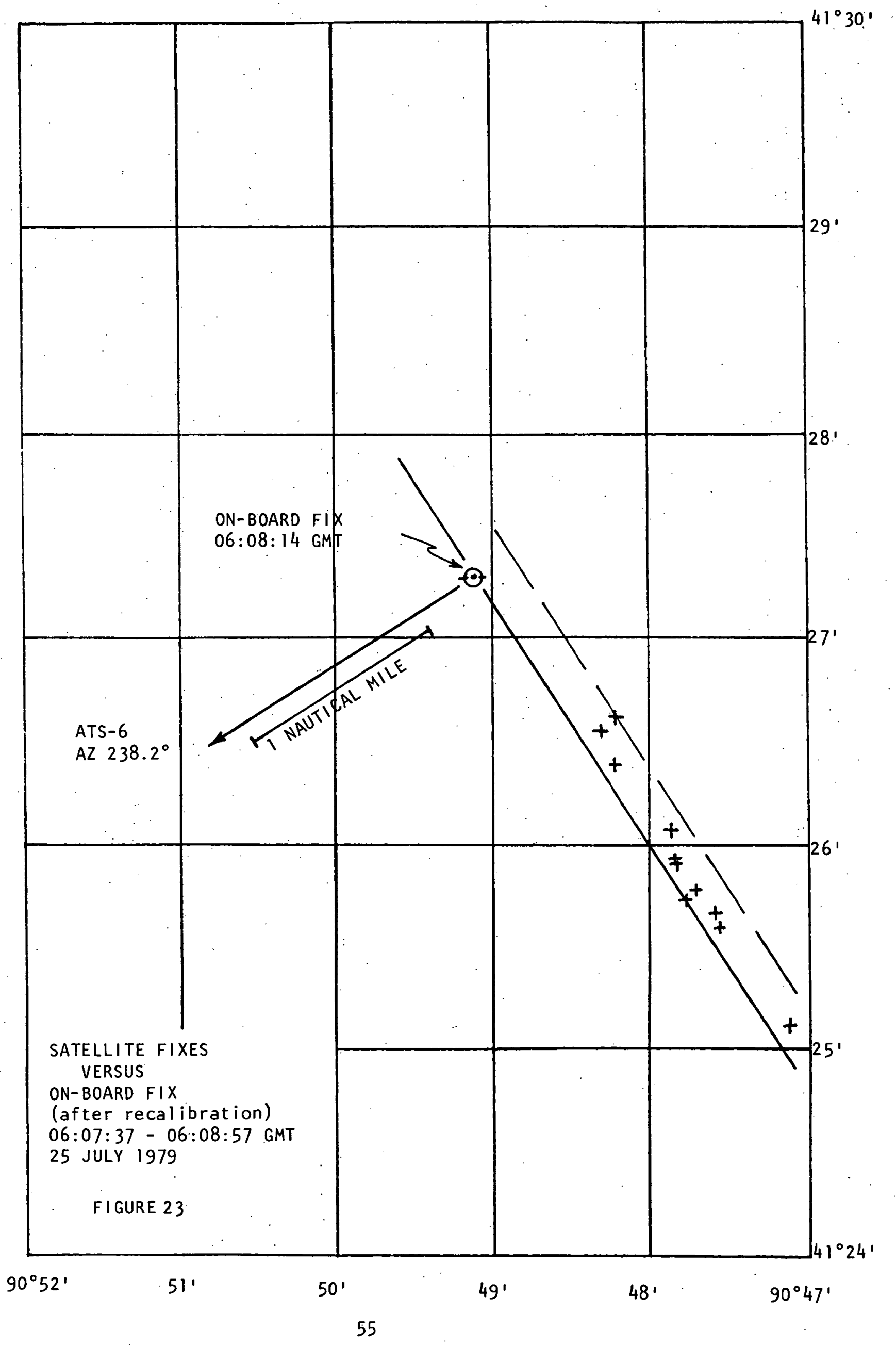




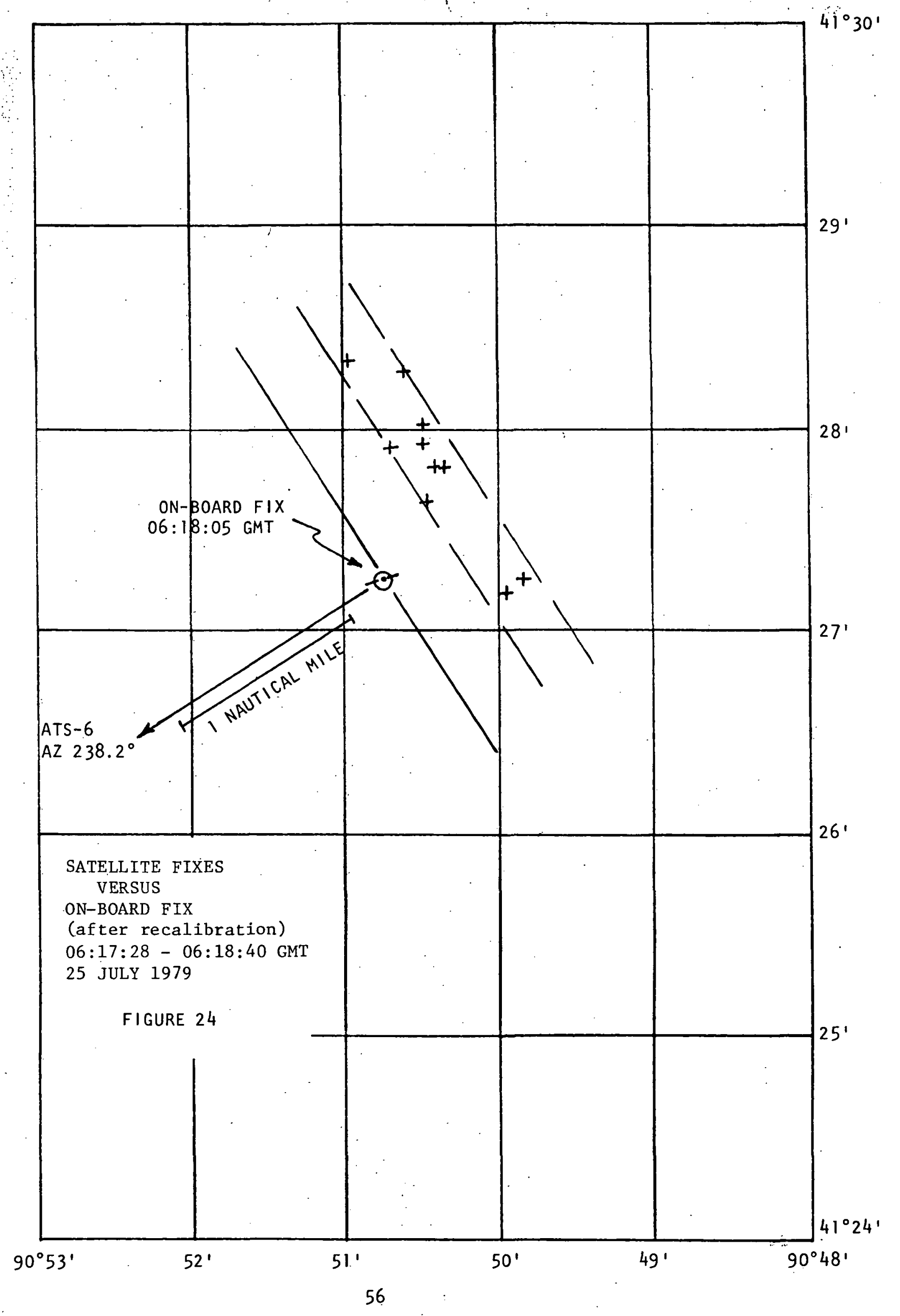




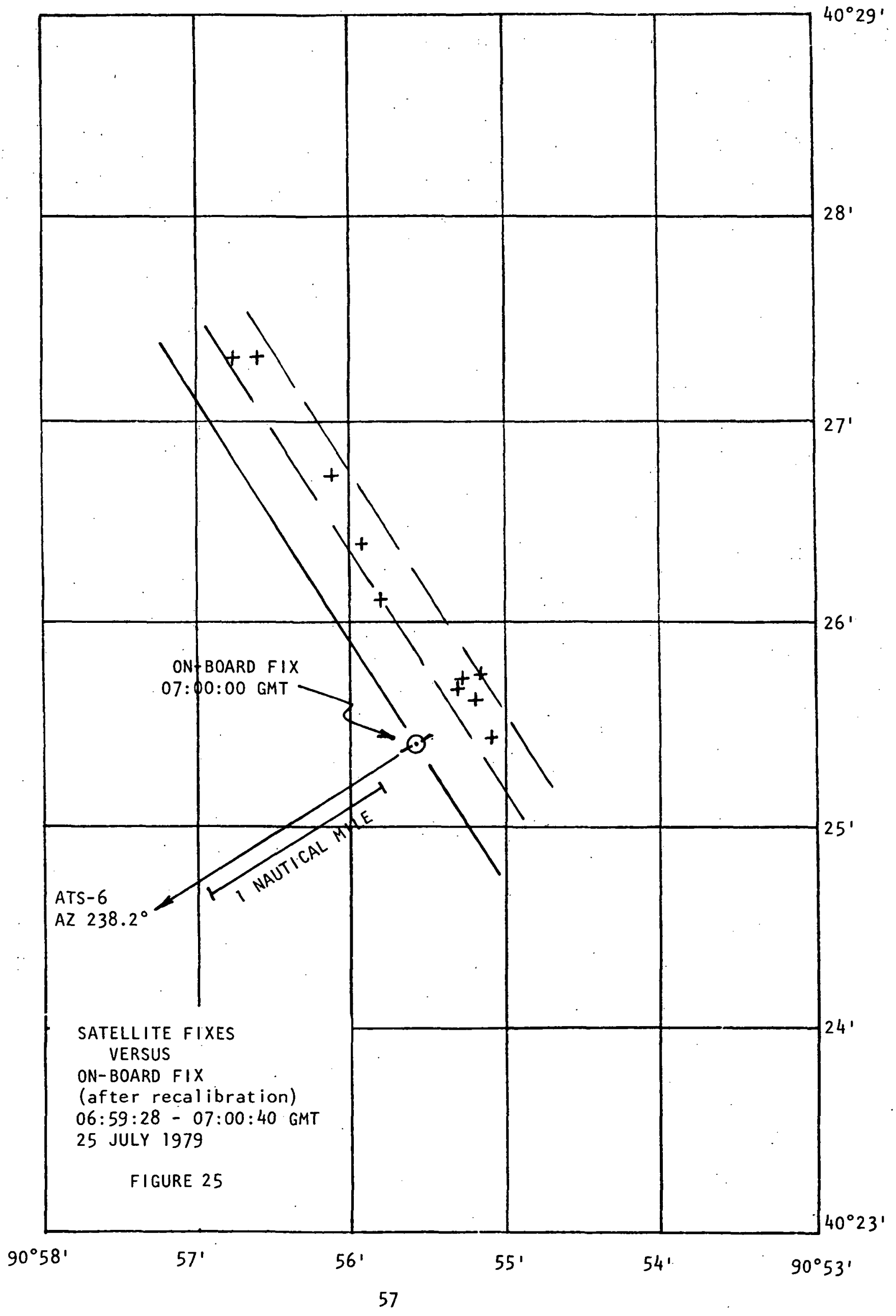




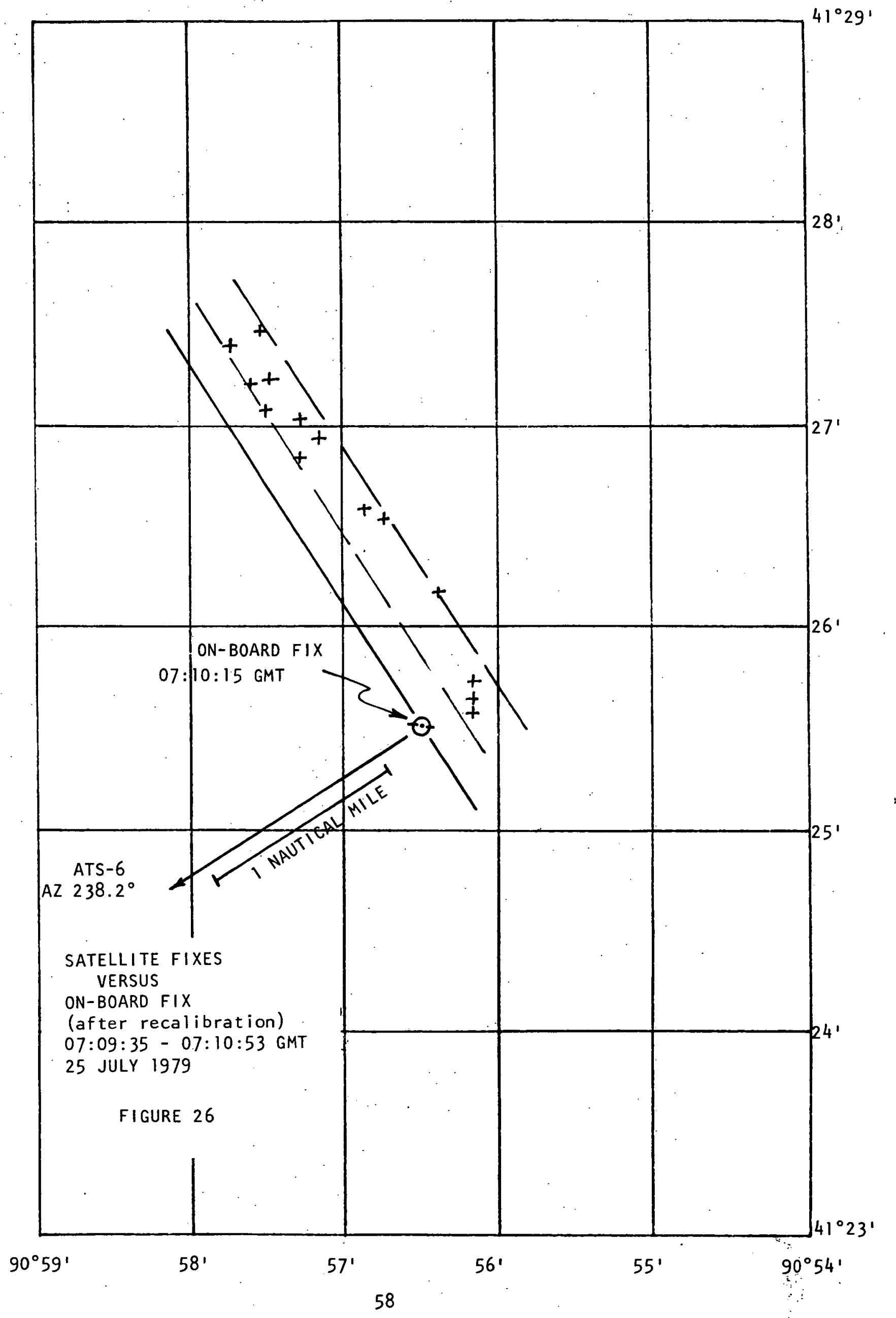




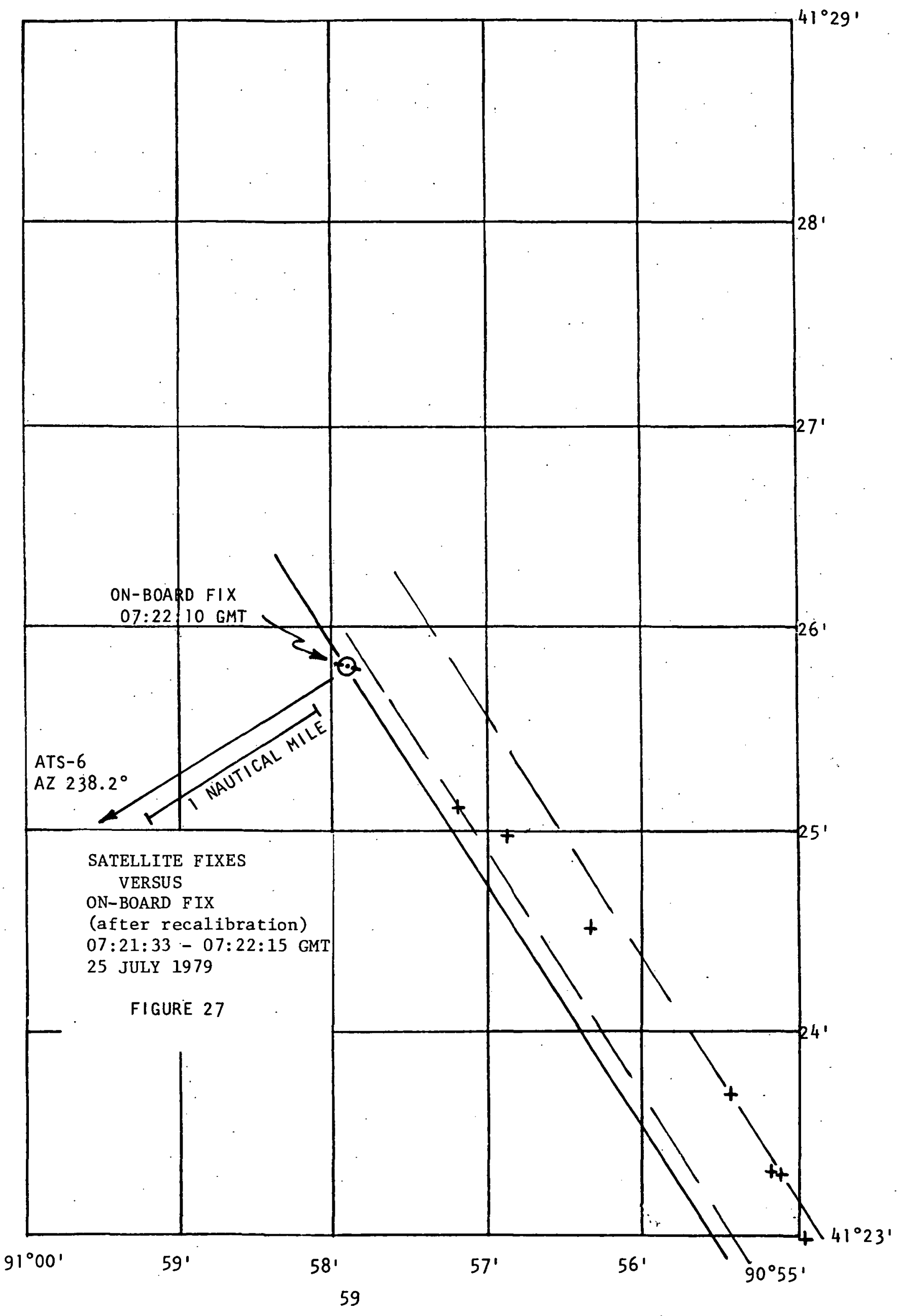




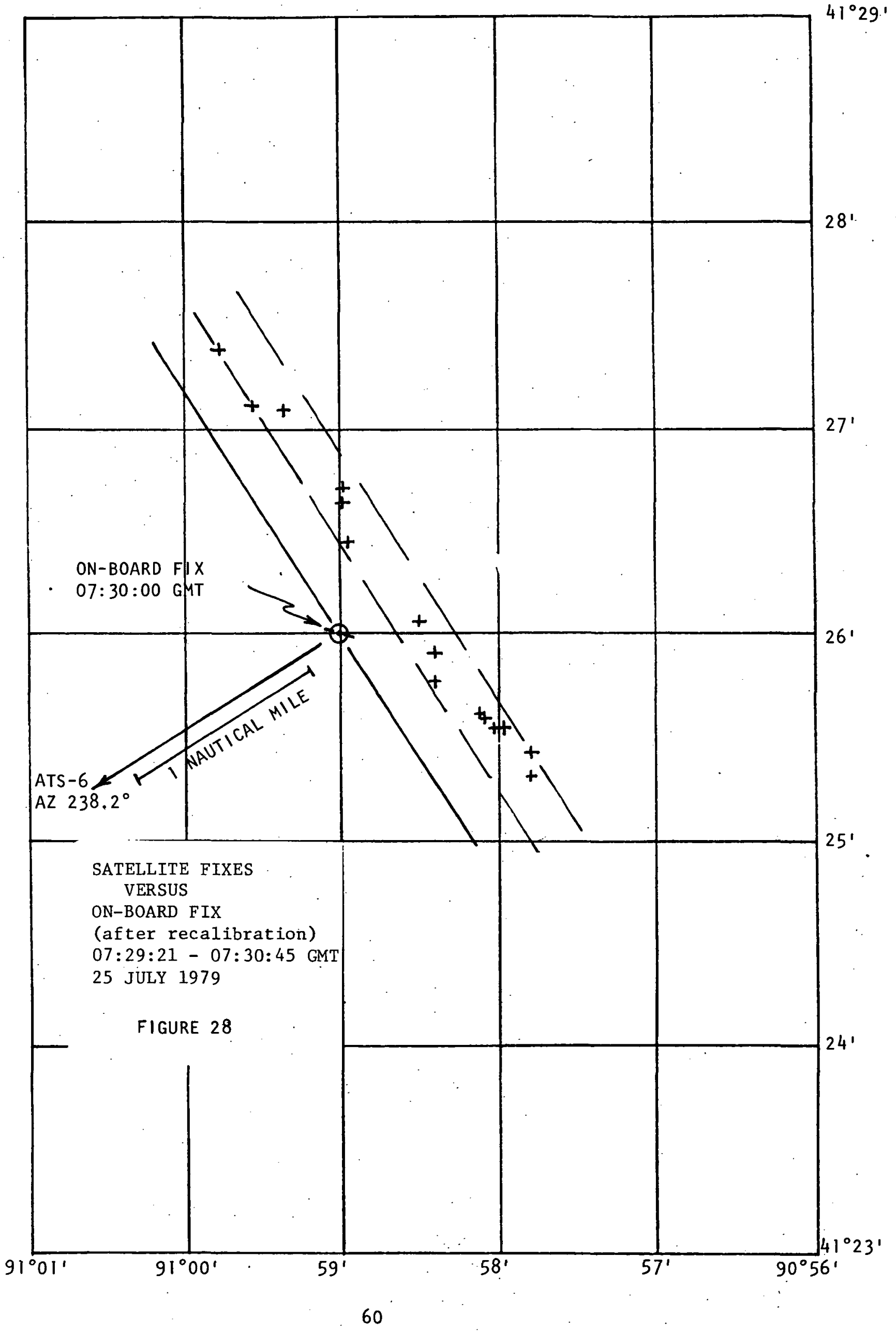




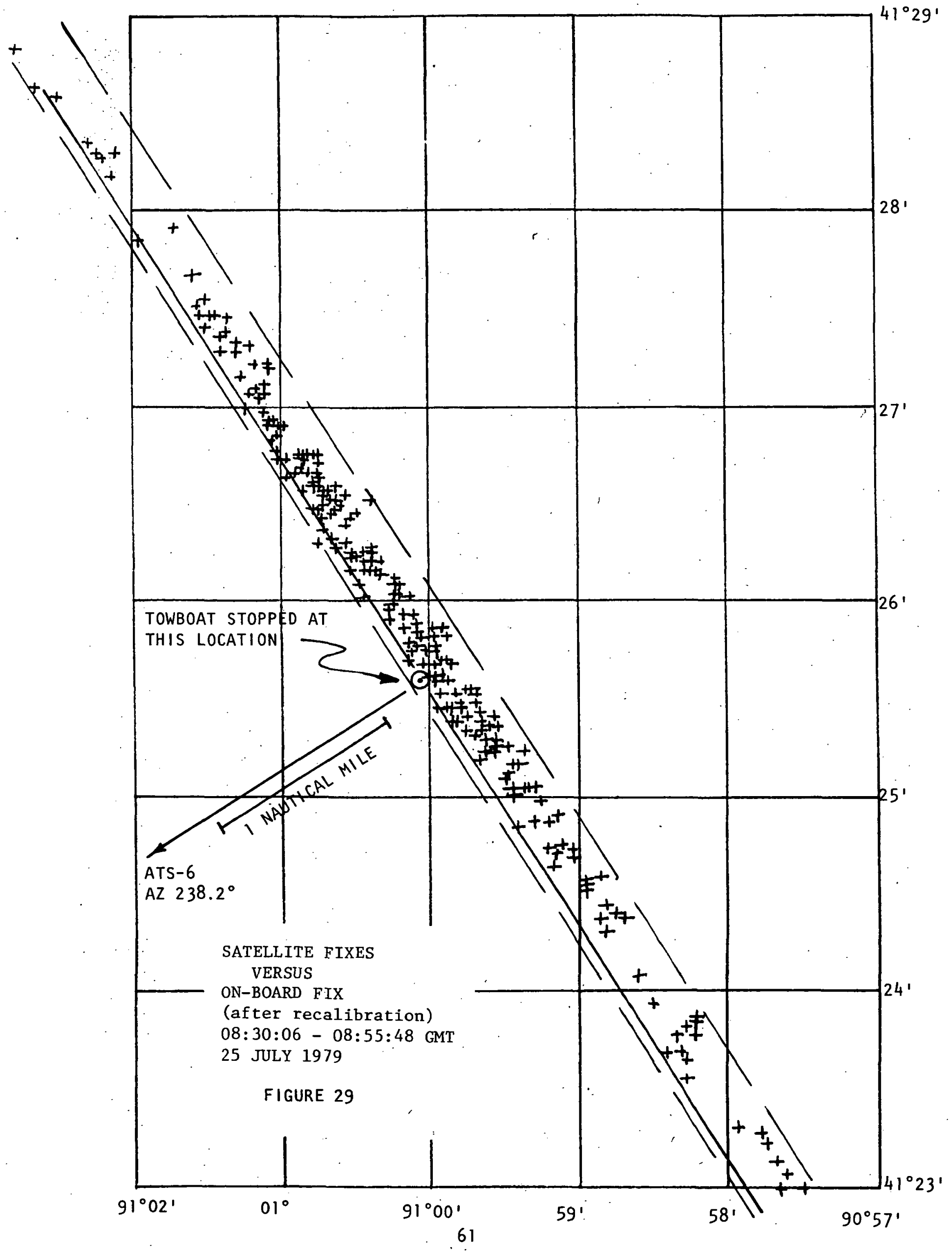


The punched tape data of 25 July were run through the PDP-11 computer with the recalibrated constants for equipment $t$ ime delays in the program. The output of the computer was applied to an $X-Y$ plotter. The on-board position of the towboat was plotted on each figure. A 1 ine in the azimuth direction to ATS- 6 was drawn, and a $l$ ine was drawn through the onboard fix perpendicular to the ATS -6 azimuth iine. The perpendicular is a reference 1 ine-of-position for ATS-6 that is as accurate as the on-board fix determined with reference to buoys and landmarks. The reference LOP is used for estimating accuracy of the satellite-determined LOPs.

Figures 20 through 28 are plotted from data taken while the towboat was underway. All of the fixes made during the indicated time interval are included in each plot. The short line through each on-board fix approximates the distance and direction of the towboat's motion during the time interval in which the fixes were made. The line indicates the spread in the ATS-6 line-of-position that is expected due to motion of the towboat.

Lines-of-position bounding the fixes are drawn as dashed lines parallel to the reference LOP. The separation of the dashed lines is the total spread of the ATS- 6 LOPs made during the interval, It includes the spread due to towboat motion.

A visual estimate was made of a mean ATS-6 LOP through each plot of fixes. The displacement of the mean from the reference LOP was scaled from the plots to provide an estimate of LOP accuracy. The distances from the mean to the dashed boundary LOPs was scaled to give an estimate of the spread of the LOPS and thus a conservative estimate of their precision. ATS-6 LOP displacement and spread for Figures 20 through 29 are listed in Table 2.

Figure 29 plots 176 position fixes made over a period of 25 minutes, 42 seconds, while the towboat was stopped, hence there is no spread due to towboat movement. Sixteen fixes made during the interval are not on the plot because their GOES line-of-position displaced them of $f$ the plot at the scale presented here. The omitted fixes lie along the ATS-6 line position like those that are in the plot. The larger number of fixes and elimination of towboat motion yield a result that has statistical significant for estimating accuracy and precision. The ATS -6 LOP is displaced 0.12 nautical miles, the spread is \pm 0.18 nautical mile. 


\section{TABLE 2}

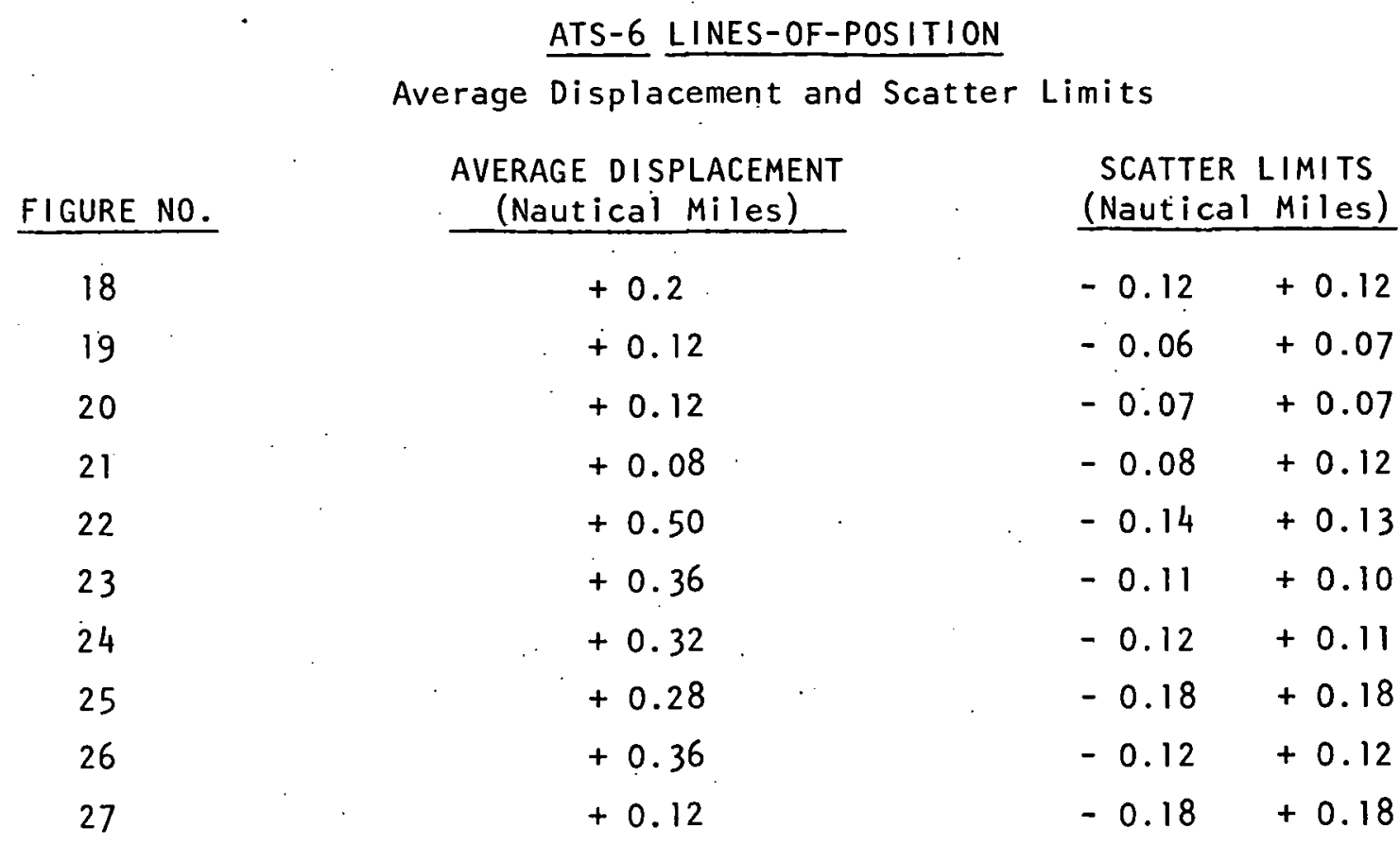

+ indicates displacement away from satellite

The results are a clear confirmation that the tone-code ranging technique can provide useful accuracy with signalling bandwidths and modulation characteristics that are the same as those used in conventional narrowband frequency modulation mobile radio communications.

\subsubsection{Precision and Accuracy of GOES Lines-of-Position}

The narrow bandwidth, $100 \mathrm{~Hz}$, of the GOES data stream 1 imited the precision achievable in the GOES lines-of-position. Accuracy was affected by a time varying difference in the characteristics of the GOES clocks. The exact cause of the difference was not identified. The receivers performed within the manufacturer's design specifications for their intended applications. It is possible that the more recent design by the same manufacturer (which was not available for this experiment) or a receiver specially designed for the ranging application would provide better precision and accuracy.

The large spread of the GOES LOPs relative to the ATS- 6 LOPS is evident in all of the plots. The time varying characteristic is evident in Figures 15 and 16 , and also in Figures 20 through 29 as the displacements of the clusters of fixes along the ATS -6 LOP. The values of the displacements and the limits of their scatter are presented in Table 3. 
TABLE 3

GOES LINES-OF-POSITION

Average Displacement and Scatter Limits

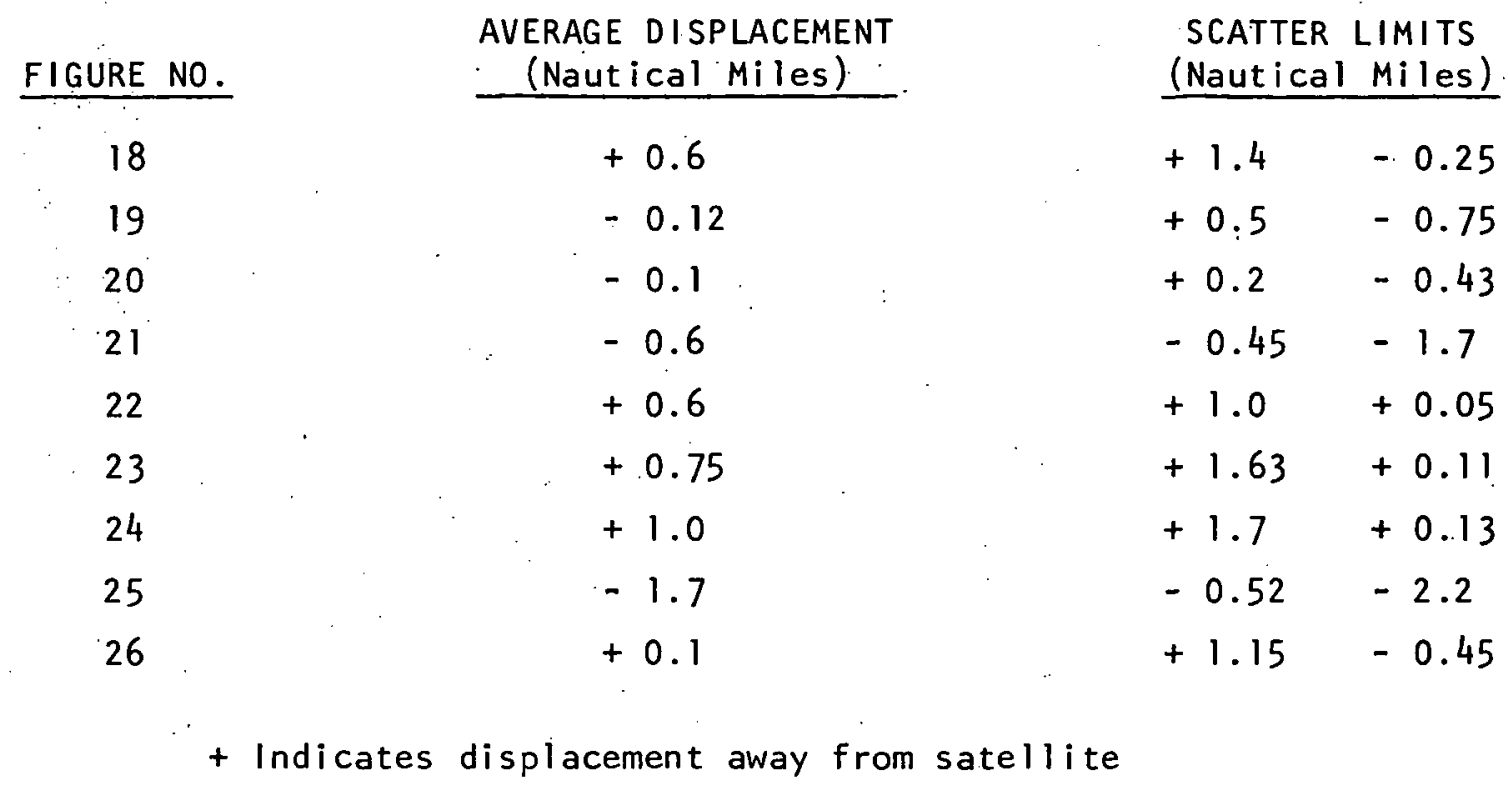

The characteristics of the three GOES receivers was compared by measuring the offsets in their time ticks as a function of time while the experiment was in progress.

Figure 30 is a sample of the measurements. The gradual slopes of the data were caused by the changing ranges to ATS-6 and GOES. It is taken into account in the computation of the position fixes and does not produce an error. The time variability with respect to a smooth 1 ine through the data is the cause of the errors in the GOES lines-of-position.

When a number of measurements in sequence are displaced to one side of a smooth line through the data, those measurements result in lines-ofposition displaced in a corresponding direction from the true 1 ines-ofposition. Some clusters of fixes in Figures 15 and 16 and 20 through 29 are displaced because the fixes were made when the time ticks of one or more of the GOES receivers were offset in one direction. An offset of one microsecond produces an error of 300 meters in the range measurement from GOES to the receiver. A range error introduces an LOP error that is larger than the range error, as explained in Section 5.3.1. 


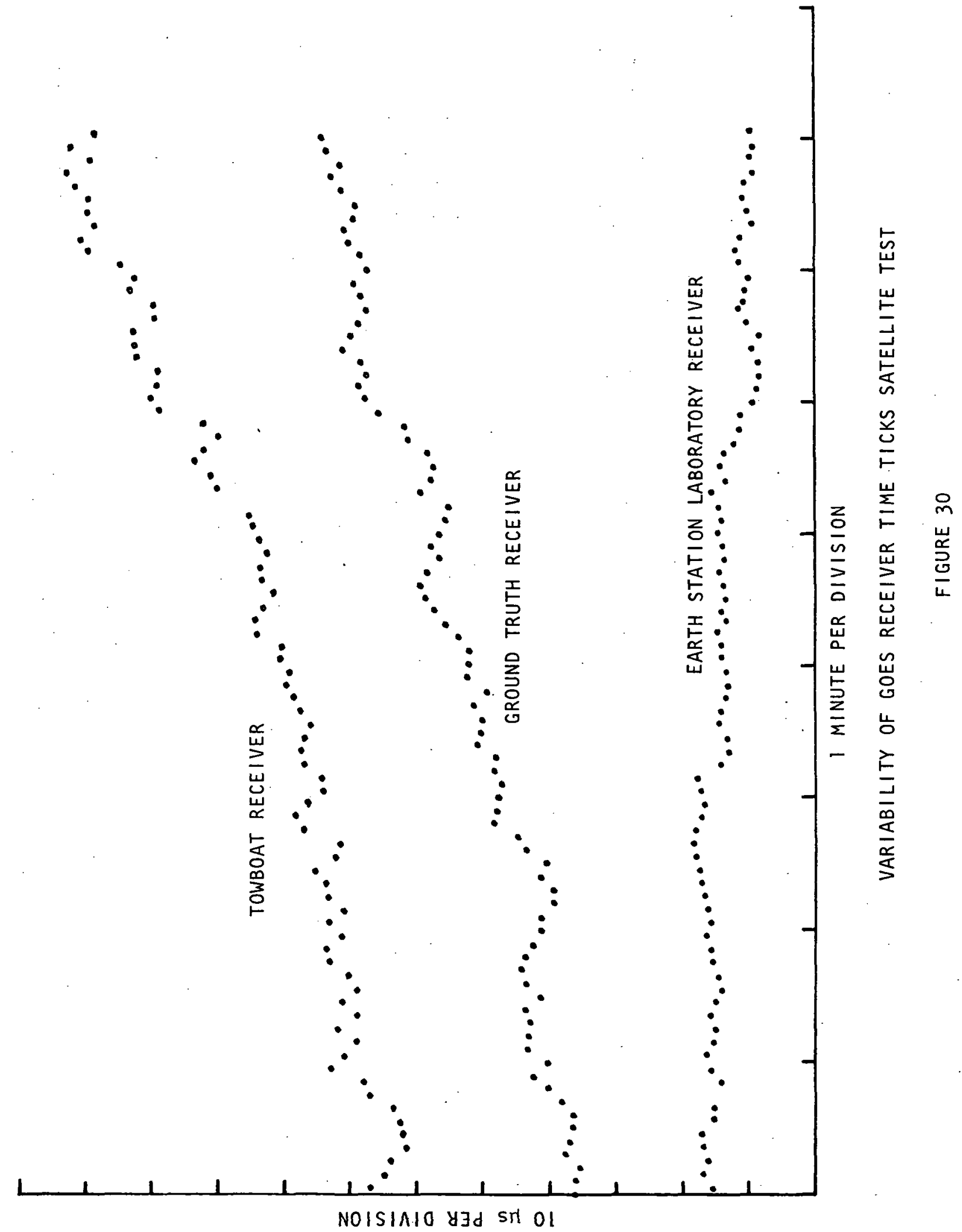


The characteristics of the three GOES receivers were also measured by the Earth Station Laboratory comparing the once-per-second time tick from each receiver with the time tick derived from a Manson Model 180 crystal oscillator that has a stability better than $10^{-9}$ per day. Figure 31 shows typical variations in differences when each receiver was connected to the antenna that was used in the satellite experiment. The gradual slope to the data reflects the changing range to GOES during the measurement.

The magnitude of the time variations is a function of signal-to-noise ratio, which in turn is affected by antenna gain. Table 4 summarizes measurements made as the antennas were exchanged between the receivers. Variability is apparent as standard deviation of the individual measurements from a least squares fit to the data. The standard deviations were taken over a sufficient number of data points to include several cycles of variation from the least squares fit. It is apparent that the variability is greater when the signal-to-noise ratio is poorer due to lower gain.

The receivers can correct a time offset only at a rate of one microsecond per second. In effect, that applies a narrowband filter to the receiver's response to noise.

The causes of the time variability were not fully investigated. A time consuming effort to do so seemed unjustified relative to other tasks that needed to be performed within the scope of the experiment. A newer version of the receivers is believed to have a smaller variability, and any future experiments may employ different receivers and perhaps wider bandwidth signalling. The results of the ATS -6 ranging are proof that high precision and accuracy are possible within acceptable bandwidth limits and with available receiver technology.

\subsection{Communications Performance}

Voice communications were relayed through ATS- 6 between the Earth Station Laboratory, the towboat, and the Davenport office. The towboat and the office transmitted on $1655.05 \mathrm{MHz}$, which was relayed by the satellite and received at the Earth Station Laboratory on $1555.05 \mathrm{MHz}$. The Earth Station Laboratory transmitted on $1652.00 \mathrm{MHz}$. Its transmissions were relayed by the satellite on $1532.00 \mathrm{MHz}$ and received by both the office and towboat. When the office and towboat talked with each other, the Laboratory retransmitted their signals so that there was a double hop between them. 

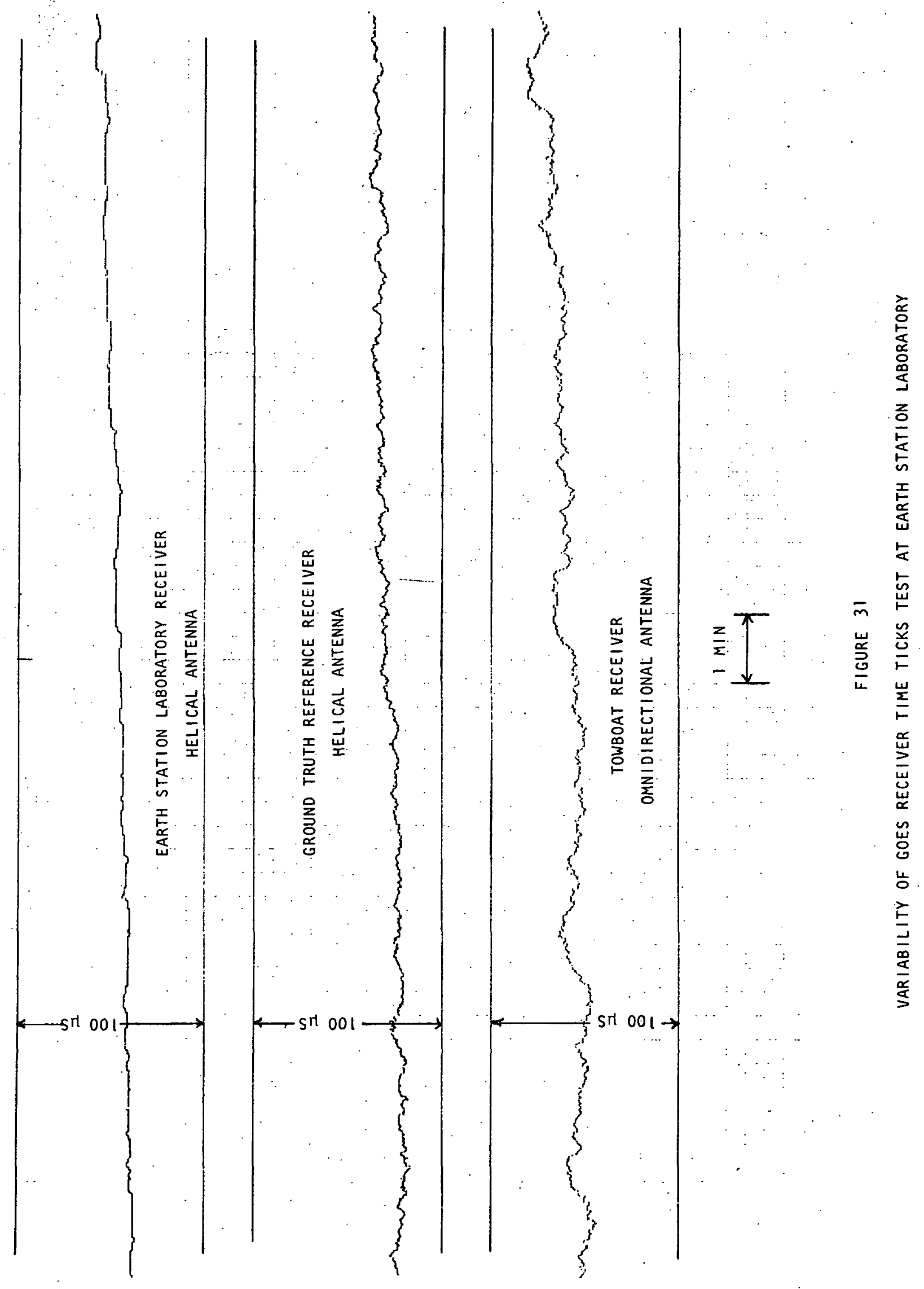
TABLE 4

TIME TICK OFFSETS OF GOES RECEIVERS

\begin{tabular}{l} 
EARTH STATION \\
LABORATORY RECEIVER \\
\hline
\end{tabular}

OMNI ANTENNA
A $\quad$ B S.D.

$\begin{array}{lll}-7.7 & 5.7 \quad 3.0\end{array}$

$-3.9$

$-7.0$

$-9.0$

$6.1 \quad 2.3$

$8.3 \quad 3.7$

$7.4 \quad 3.6$

HELICAL ANTENNA

$-5.8$

$-3.5$

$-3.3$

6.2

3.8

2.8

1.8

1.9

HELICAL ANTENNA

$-5.9$

$-4.3$

$-4.8$

\section{3}

3.2

5.8

1.9

1.7

2.8

HELICAL ANTENNA

$-5.1$

$-6.2$

$4.5 \quad 2.2$

$6.1 \quad 2.5$

$-5.6$

$-7.5$

5.6
8.1

9.4

9.3

7.7

\begin{tabular}{l} 
TOWBOAT \\
RECEIVER \\
\hline
\end{tabular}

HELICAL ANT.

A B S.D. A B S.D.

$-5.0$

6.5

6.0

4.9

5.0

$2.2-3$

$2.7-4.2$

$\begin{array}{ll}3.6 & 1.5\end{array}$

4.12 .0

$1.9-7.2$

4.12 .1

$\begin{array}{llll}2.0 & -4.4 & 4.2 & 1.7\end{array}$
NUMBER OF
MEASUREMENTS

HELICAL ANTENNA OMNI ANTENNA

5.5

5.9

5.7

$-8.6$

$-5.8$

$2.0-13.4$

$2.5-10.6$

2 .

$2 \cdot 3$

$9.6 \quad 5.0$

500

500

376

OMNI ANTENNA HELICAL ANT.

$-7.0$

$4.0-5.5 \cdot 4.92 .2$

374

$-10.3$

4.0

$-6.17 .2$

2.9

414

$\begin{array}{llll}3.9 & -6.4 & 7.1 & 2.5\end{array}$

500

HELICAL ANTENNA OMNI ANTENNA

.-6.2

$\begin{array}{rrrr}2.1 & -10.4 & 10.1 & 3.6 \\ 2.9 & -15.2 & 9.3 & 4.0\end{array}$

1448

1500

\footnotetext{
$A=$ Maximum Displacement from least squares fit, negative direction. $B=$ Maximum Displacement from least squares fit, positive direction. S.D. = Standard Deviation of measurements from least squares fit.
} 
Communications with the Laboratory were in the half-duplex mode because the Laboratory transmitted and received simultaneously. An operator at the Laboratory could hear the office or towboat while transmitting, but an operator on the towboat or office could not hear an incoming signal while transmitting but could interrupt the Laboratory operator.

The Laboratory sometimes provided an interconnection with the public switched telephone network. The half duplex mode was used with the interconnection so that a person on a telephone, talking via the satellite with the towboat or office, could be interrupted by someone on the towboat or at the office.

All of the communications during the 25 and 26 July tests were recorded on magnetic tape. The recordings were evaluated by a trained listener who judged the quality according to the following scale:

Q5 Loud and clear

Q4 Completely understood but with perceptible noise

Q3 Mostly understood with considerable noise

Q2 Poorly understood, mostly noise

Q1 Voice present in noise, but not understood

All of the communications from the Davenport Office were Q5.

Table 5 lists the quality of the voice communications recorded from the towboat where the quality was $Q 3$ or better $99.87 \%$ of the time.

Appendix B describes the communication needs of the inland waterways industry and the reactions of Port Captain Robert L. Gardner to the satellite communications experiment. 
TABLE 5

\section{VOICE COMMUNICATIONS QUALITY OF SIGNALS FROM TOWBOAT}

\begin{tabular}{|c|c|c|c|c|c|c|}
\hline \multirow{2}{*}{$\begin{array}{l}\text { VOICE } \\
\text { COMMUNICATION } \\
\text { TOTAL TIME } \\
\text { QUALITY } \\
\end{array}$} & \multicolumn{2}{|c|}{25 JULY 1979} & \multicolumn{2}{|c|}{26 JULY 1979} & \multicolumn{2}{|c|}{ TOTAL } \\
\hline & SECONDS & $\%$ & SECONDS & $\%$ & SECONDS & $\%$ \\
\hline Tota! & 1859 & - & 1901 & - & 3760 & - \\
\hline 05 & 1716 & 92.31 & 1868 & 98.26 & 3584 & 95.32 \\
\hline Q4 & 107 & 5.76 & 25 & 1.32 & 132 & 3.51 \\
\hline Q3 & 31 & 1.67 & 8 & 0.42 & 39. & 1.04 \\
\hline Q2 & 1 & 0.05 & 0 & 0 & 1 & 0.03 \\
\hline Q1 & 4 & 0.22 & 0 & 0 & 4 & 0.11 \\
\hline$Q 4-Q 5$ & 1823 & 98.06 & 1893 & 99.58 & 3716 & 98.83 \\
\hline $03-05$ & 1854 & 99.73 & 1901 & 100 & 3755 & 99.87 \\
\hline
\end{tabular}




\subsection{CONCLUSIONS}

1. Position surveillance is feasible using one active ranging satellite and the time-of-arrival of signals from an independent satellite.

2. Lines-of-position precise to better than 0.1 nautical mile, 10, were achieved at L-band using automatic tone-code ranging, $15 \mathrm{kHz}$ RF bandwidth, narrow band frequency modulation at 2.5 $\mathrm{kHz}$ baseband, 0.1 second integration time, 25 watts of mobile transmitter power with a non-directional antenna, ranging through the ATS- 6 satellite in the narrowband frequency translation mode where the satellite was at $25^{\circ}$ elevation.

3. Lines-of-position determined as described in conclusion 2 above had average displacements from on-board position fixes ranging from +0.12 to +0.5 nautical mile.

4. Lines-of-position precise to better than 1.6 nautical miles, $1 \sigma$, were achieved,by measuring the time-of-arrival of signals at $468 \mathrm{MHz}$, phase modulated at 100 bits per second with $\pm 60^{\circ}$ phase shift, a received signal-to-noise ratio of $20 \mathrm{~dB}$ in a $100 \mathrm{~Hz}$ bandwidth.

5. Lines-of-position determined as described in conclusion 4 above had average displacements from on-board position fixes ranging from -1.7 to +0.75 nautical miles.

6. Errors in the lines-of-position derived from the GOES satellite signals at $468 \mathrm{MHz}$ appear to have a systematic component that may be correctable by processing techniques different from those used in the experiment.

7. Range measurements for position location can be made with mobile equipment adapted for satellite communications if a tone-code ranging transponder is connected between the receiver and transmitter. Range measurements are automatic and do not require action by anyone aboard the vehicle. 
8. Satellite-aided mobile communications could provide needed, good quality. communications to the inland waterways industry. The communications can include the advanced features of modern mobile communications such as selective calling and interconnection with the public switched telephone network. Operation of the mobile equipment is simple. No training is necessary. Small, non-directional satellite antennas that do not require pointing are adequate. 


\subsection{RECOMMENDATIONS}

1. Position surveillance using one active ranging satellite and the time-of-arrival of signals from an independent satellite should be evaluated using operational satellites. Candidate satellites for oceanic maritime use are MARISAT and INMARSAT communication satellites, and GOES, METEOSAT, and Geostationary Meteorological Satellite for the time-of-arrival signals.

2. The position surveillance technique should be compared with other radio and satellite position fixing systems with respect to equipment cost, availability versus time, geographical coverage, and functional suitability for a variety of applications in the maritime, aeronautical, and land mobile services. Functional suitability refers to comparison of surveillance and on-board position fixing. 


\subsection{NEW TECHNOLOGY}

A patent disclosure document, number RD-12077, was filed by

James $R$. Lewis describing a method of measuring and correcting internal

time delay variations of narrowband receivers. The method is believe to be applicable to the GOES receivers used in the experiment to correct internal time variations that contributed to the GOES line-of-position errors. The method was not tested and no action has yet been taken toward filing a patent application. 


\subsection{REFERENCES}

1. Final Report "Application of Satellite Communication and Position Fixing Techniques to Land Mobile Systems" Contract DEA-76-20 for Drug Enforcement Administration and Immigration and Naturalization Service, 1976 General Electric Report SRD-77-001.

2. Taylor, Ralph E. "Vanguard/Place Experiment System Design and Test Plan"l IFT Journal, pp. 16-26, Jan.-Feb., 1974

3. Anderson, Roy E., "Communications and Position Fixing Experiments Using the ATS Satellites", Navigation, Vol: 20, No. 4, Winter 1973-74.

4. Final Report "ATS-5 Trilateration Support", NASA Contract NAS5-20034, 1976, General Electric Company Report SRD-76-004.

5. J. D. Krauss, "Antennas", Figure 7-22, 1950 McGraw Hill Book Company.

6. R. E. Anderson, R. L. Frey, J.. R. Lewis; "Final Report, Satellite-Aided Communications Limited Operational Test in the Trucking Industry," NASA Contract. NAS5-24365, 1980, General Electric Company.

7. R. E. Anderson, "Final Report on. Phase 3 ATS Ranging and Position Fixing Experiment", PP $11-1-13$, NASA Contract NAS5-11634, 1973, General Electric Company. 
APPENDIX $\underline{A}$

ANTENNA CHARACTERISTICS AND POWER BUDGETS

Tables Al through AlO show the details of the radio links used in this experiment. The first four tables describe the antenna systems used with the ATS-6 and the GOES spacecraft. The remaining tables show signal level calculations on links from the ATS- 6 and GOES spacecraft to each station in the experimental network.

ATS-6 L-band signals were received and transmitted at the Davenport office "Ground Truth" transponder by a 6-turn helix antenna described in Table Al. The helix was wound in the right hand circular sense to match the right hand circularly polarized signals emitted and received by the ATS- 6 spacecraft. The helix was wound of \#14 tinned copper wire around a 2-1/4 inch diameter plexiglass tube 10 inches long. At the operating frequency each turn has a circumference of approximately one wavelength and the complete structure is about 1.35 wavelengths long. According to Krauss [5] a helix of these dimensions will radiate a circularly polarized wave along its axis with an effective power gain of 20 , i.e., $13 \mathrm{~dB}$, and a $3 \mathrm{~dB}$ beamwidth of $46^{\circ}$.

Fifty feet of RG-214 feedline connected the ATS- 6 helix antenna to the transponder at the Davenport Office Ground Truth station. At the $L$-band operating frequency, the feed cable has $3 \mathrm{~dB}$ of loss degrading the $2.6 \mathrm{~dB}$ receiver noise figure to $5.6 \mathrm{~dB}$ referenced to the antenna terminals. The $5.6 \mathrm{~dB}$ receiver noise figure may be expressed as an equivalent noise temperature of 763 degrees kelvin. The antenna background temperature has been estimated rather than calculated in any rigorous way. At the L-band operating frequency, deep space has an equivalent noise temperature of only a few degrees kelvin, but the earth surrounding the antenna has an equivalent noise temperature near room temperature or $290^{\circ} \mathrm{K}$. As a result, the main beam of the helix pointed at ATS -6 will pick up very little noise. but various side lobes of the helix will pick up a substantial amount of noise from the surrounding earth. A conservative value of the effective antenna temperature was determined by estimating the temperature of objects surrounding the antenna averaged over all spherical angles from the antenna The total of the receiver temperature and the antenna temperature then comprises the total receive system equivalent noise temperature.

The towboat L-band antenna described in Table $A 2$ is identical to the antenna used on over-the-road trucks in a previous experiment. [6] The antenna is made of a series of half wave sections of coaxial cable whose inner and outer conductors are cross-connected at each joint. The outer and inner conductors are transposed each half wave to keep the currents on the outside of all segments in phase thus forming a collinear array with a radiation maximum perpendicular to the line of the elements. For this application, each element was cut slightly longer than a half wavelength to introduce a progressive phase delay along the length of the array. The progressive phase delay was chosen to raise the beam peak to the elevation angle above the horizon of the ATS- 6 spacecraft . 
The transposed coaxial antenna assembled for this experiment has a measured gain of $7.3 \mathrm{~dB}$ over an isotropic source and is linearly polarized in the vertical direction. Table A2 shows the elevation pattern of the antenna has a lower beam peak than at the transmit frequency. This difference stems from the smaller progressive phase delay at the lower receive frequency as compared to the progressive phase delay at the transmit frequency. The segment lengths actually used represent a compromise between receive and transmit performance. The horizontal pattern of the antenna does not vary more than $l \mathrm{~dB}$ from the nominal value.

On board the towboat, 50 feet of $7 / 8 "$ air dielectric cable connected the antenna to the transponder in the wheelhouse. This antenna cable has a loss of $0.9 \mathrm{~dB}$ degrading the $2.6 \mathrm{~dB}$ receiver noise figure to $3.5 \mathrm{~dB}$. The total receive system noise equivalent noise temperature is simply the sum of $3.5 \mathrm{~dB}$ noise figure expressed as a temperature and the antenna temperature taken as room temperature because of the broad antenna beam. The total receive system equivalent noise temperature of $649^{\circ} \mathrm{K}$ may be viewed as a conservative estimate of the receiver noise performance.

Tables $A 3$ and $A 4$ show details of the noise performance of the GOES clock receivers at the Davenport Office Ground Truth station and on the towboat. The preamplifier normally available from the receiver manufacturer having a noise figure of $3.5 \mathrm{~dB}$ was used at Davenport. Two quarter-wave coaxial cavity resonators were needed before the preamplifier to prevent overload from local two-way radio transmitters. Each cavity had $1 \mathrm{~dB}$ of insertion loss degrading the receiver noise figure to $5.5 \mathrm{~dB}$. This noise figure represented as an equivalent receiver temperature was summed with an estimate for the equivalent antenna noise temperature for a total equivalent system temperature of $1229^{\circ} \mathrm{K}$.

The GOES receiver aboard the towboat was preceded by a custom-made lownoise preamplifier having two stages and a measured noise figure of $1.6 \mathrm{~dB}$. To protect the preamplifier against overload, one quarter wave coaxial cavity resonator was placed before the first stage and another was inserted between the two preamplifier.stages. The second resonator does not significantly affect the overall receiver noise figure of $2.6 \mathrm{~dB}$ in this arrangement. The sum of the antenna temperature and equivalent receiver temperature totals $528^{\circ} \mathrm{K}$ for the towboat GOES receiver system.

Table A5 shows detailed signal level calculations along the path from earth to ATS-6. Two signals were simultaneously transmitted along this uplink path during this experiment. The "forward link" signal was transmitted from the Earth Station Laboratory to ATS-6 and relays to the Ground Truth station and the towboat. Either the Ground Truth station or the towboat would then reply through ATS -6 to the Earth Station Laboratory. The Laboratory repeated the weak signal received from the Ground Truth or the towboat to the other station in the network. The Laboratory continually transmitted a signal through ATS -6 to prevent broad band noise transmitted by the spacecraft under no signal conditions from desensitizing the spacecraft receiver. The term Ground Station as used in Table A5 denotes either the Earth Station Laboratory transmitting system or the Ground Truth station transmitting system. The first column contains figures for the uplink from the Earth Station Laboratory and the second column contains figures for the uplink from the Ground Truth Reference station. 
A six-foot dish was used with a duplexer for both transmit and receive at the Earth Station Laboratory. The gain of the dish was. calculated as $27.5 \mathrm{~dB}$ on the basis of an aperture efficienty of $55 \%$ but $3 \mathrm{~dB}$ were subtracted because the dish had a linearly polarized prime focus feed. The spacecraft antenna pointing loss was larger for the Ground Truth station than the Earth Station Laboratory because ATS -6 was pointed more directly at the Earth Station Laboratory. The Ground Truth station was located at approximately the $-3 \mathrm{~dB}$ contour of the spacecraft beam, while the Earth Station Laboratory was within the $-1 \mathrm{~dB}$ beam contour.

Table A5 shows that the signal from the Earth Station Laboratory passes through the spacecraft receiver at a level $15 \mathrm{~dB}$ higher than the Ground Truth station signal. When signals at substantially different levels pass through the spacecraft, with the larger signal strong enough to saturate the spacecraft receiver limiter, the weaker signals suffer $6 \mathrm{~dB}$ of degradation in the receiver. Much of the weaker signal power is distributed among intermodulation products formed in the limiter. The power sharing factor reflects this limiter degradation as well as the portion of the total spacecraft power allotted to each received signal (including noise) according to its strength.

Table A6 may be considered the downlink "half" of Table A5. Both tables show the details of the forward and return link calculations to the Ground Truth Reference station. The first column of Table A6 contains figures for the signal transmitted by the Earth Station Laboratory through ATS- 6 to the Ground Truth station. The second column contains figures for the return link signal transmitted by the Ground Truth station through ATS- 6 back to the Earth Station Laboratory. The "circuit losses" entry in Table A6 usually contains the sum of the losses of all components preceding the first receiving preamplifier, but for these downlink calculations these losses were included in the receiver noise figure and expressed as the effective noise temperature of the receive system. The calculation is explicitly shown for the Ground Truth Station in Table Al but is not shown for the Earth Station Laboratory, as various equipment configurations were used.

Tables A7 and A8 show the details of the forward and return link calculations along signal paths to the towboat transponder. These two tables are similar to Tables $A 5$ and $A 6$, respectively, but contain the parameters of the towboat transponder. It should be noted that the towboat antenna had an omnidirectional pattern in the horizontal plane and therefore had considerably less gain than the antenna used at the Ground Truth Reference station. The vertically polarized linear antenna was originally constructed for truck communication experiment [6]. Its design was selected for its physical characteristics. A circularly polarized conical quadrafiler helix would have been a better choice for the towboat. This compromise incurred a $3 \mathrm{~dB}$ cross polarization loss to the circularly polarized ATS-6.

Tables $A 7$ and $A 8$ also reflect the elevation pattern variations of the towboat antenna presented in Table A2. The ATS -6 spacecraft was elevated approximately $22^{\circ}$ above the horizon at the towboat location during the experiment. The transmit pattern of the antenna was only $0.6 \mathrm{~dB}$ from its maximum at this elevation angle, but the receive pattern suffered by nearly $6 \mathrm{~dB}$. This difference stems from the different transmit and receive 
frequencies used. Fortunately, the towboat transponder received a sufficiently strong signal to perform well.

This Appendix concludes with the presentation of the path calculations from the GOES spacecraft to the Ground Truth station and the towboat shown in Tables $A 9$ and $A 10$. The GOES receiver characteristics presented in Tables $A 3$ and $A 4$ have been included transcribed to these tables so the carrier to noise-power-density figure of merit could be calculated for the GOES signal received in each receiver. The towboat received a signal of $40.4 \mathrm{~dB}-\mathrm{Hz}$ with its omnidirectional antenna but the Ground Truth station could receive a $46.6 \mathrm{~dB}-\mathrm{Hz}$ signal with its larger, fixed, directional antenna.

The theoretical precision of the time ticks received from the GOES satellite may be calculated from, the signal to noise-power-density ratios given above. Milton and Helstrom [7] give the standard encoded deviation of a PSK time-of-arrival measurement as

$$
\dot{\sigma}=\frac{1}{2 \pi f_{m}} \frac{1}{\left(2 T P / N_{o}\right)^{1 / 2}}
$$

where: $\quad f_{m}=$ modulating tone (bit rate)

$$
\begin{aligned}
\frac{P}{N_{O}} & =\text { carrier to noise-power-density } \\
T & =\text { averaging time }
\end{aligned}
$$

This expression was developed for a phase shift of $180^{\circ}$ or the equivalent of DSB-SC modulation and represents the best that can be achieved under a given SNR. Milton [7] expects that practical PSK techniques would yield precision about 1.5 times worse than those of the optimum technique. If the towboat receiver averages the incoming time tick waveform for a period of one second, the best theoretical precision of a $100 \mathrm{~Hz}$ bit-rate waveform received at $40 \mathrm{~dB}-\mathrm{Hz}$ would be $11.25 \mu \mathrm{s}$ or $16.88 \mu \mathrm{s}$ using a practical PSK receiver. The $46.6 \mathrm{~dB}-\mathrm{Hz}$ signal received at the Ground Truth Reference station should result in a standard deviation of $7.90 \mu \mathrm{s}$ for a practical PSK receiver.

Considerable thought must be given to choice of the averaging interval, $T$, as it is applied to the GOES receivers used in this experiment. The GOES receivers employ a digital phase comparator that compares the local clock phase with the received data phase over a one second interval. At the end of each averaging interval, the local phase may remain the same, or may be advanced or retarded by $1 \mathrm{microsecond}$. The local phase cannot be adjusted more than 1 microsecond in each one second interval. This averaging technique permits the receiver to follow small phase fluctuation within a second but the time constant associated with large phase fluctuations varies directly with the magnitude of the phase change. The standard deviations predicted for the 1 -second averaging interval cannot be seen at the receiver output due to its 1 imited correction rate of $1 \mu s$ per second. The 1 -second averaging time figures can only serve as maximum limits for the fluctuation of the tick output from the GOES receiver. 

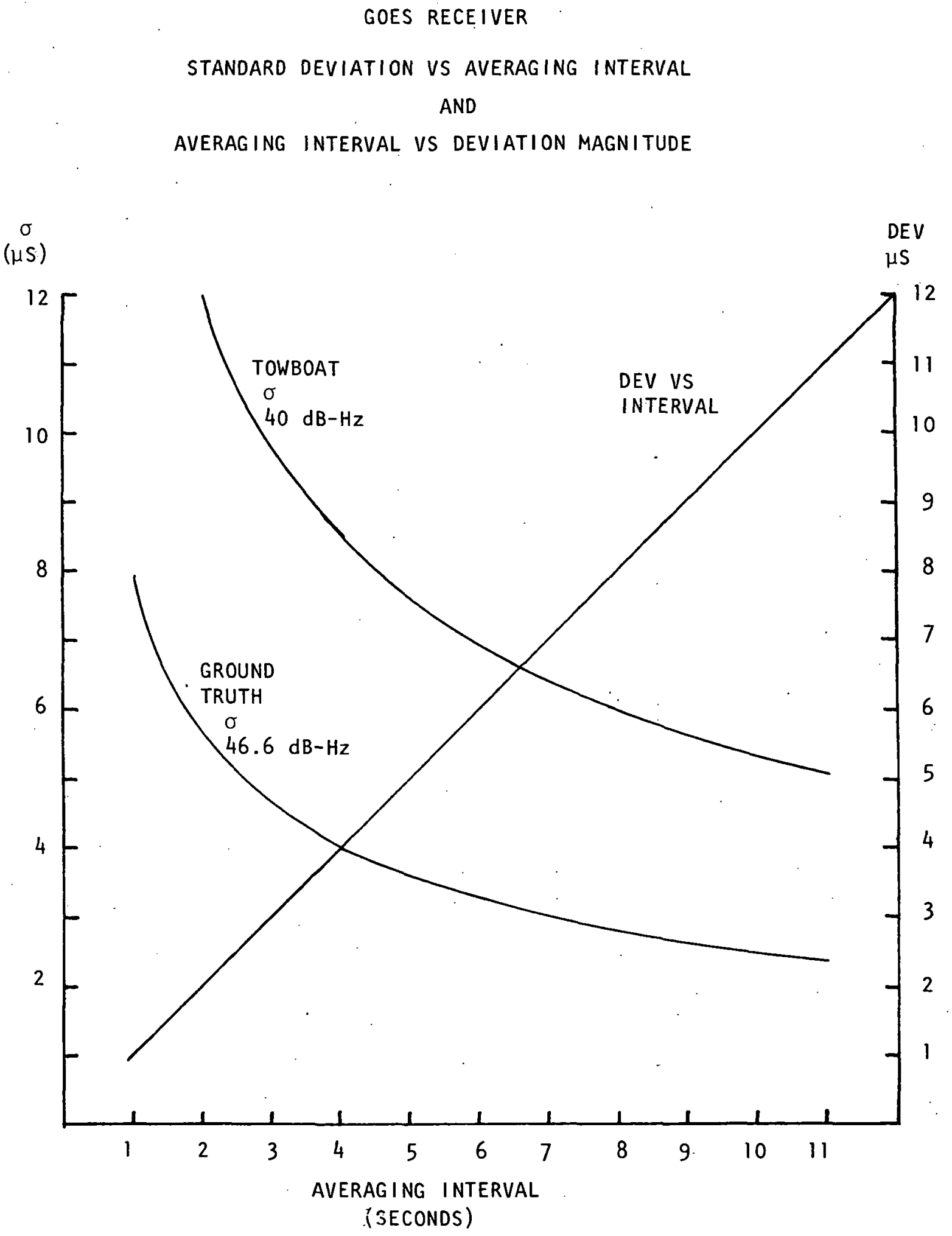

FIGURE AI 


\section{TABLE Al}

\section{DAVENPORT OFFICE "GROUND TRUTH"' L-BAND ANTENNA}

Antenna Type
Polarization
Gain
Beam Width
Feed Line Loss
Receiver Noise Figure
Total Receive System
Noise Figure
Estimated Antenna Background
Temperature
Total Receive System Equivalent
Noise Temperature

6 Turn Helix

Right Hand Circular

$13 \mathrm{dBi}$

$46^{\circ}$ at $-3 \mathrm{~dB}$

$3 \mathrm{~dB}(50 \mathrm{ft}$ of $\mathrm{RG}-214)$

$2.6 \mathrm{~dB}$

$5.6 \mathrm{~dB}$

$\left(763^{\circ} \mathrm{K}\right.$ equivalent temperature)

$200^{\circ} \mathrm{K}$

$963^{\circ} \mathrm{K}$ 


\section{TABLE A2}

\section{TOWBOAT L-BAND ANTENNA}

\begin{tabular}{|c|c|}
\hline Antenna Type & $\begin{array}{l}\text { "Wheeler" Transposed Coaxial } \\
\text { Segment Array }\end{array}$ \\
\hline Polarization & Linear - Vertical \\
\hline Gain & $7.3 \mathrm{dBi}$ (peak) \\
\hline Elevation Pattern $\left(0^{\circ}=\right.$ horizon $)$ & $\begin{array}{r}\text { At } 1550 \mathrm{MHz} \text { Receive } \\
\text { Beam peak }+11^{\circ} \\
-3 \mathrm{~dB} \text { points }+4^{\circ} \\
\text { and }+19^{\circ}\end{array}$ \\
\hline & $\begin{array}{l}\text { At } 1650 \mathrm{MHz} \text { Transmit } \\
\text { Beam peak }+18^{\circ} \\
-3 \mathrm{~dB} \text { points }+11^{\circ} \\
\text { and }+28^{\circ}\end{array}$ \\
\hline Horizontal Pattern & Omnidirectional $(< \pm 1 \mathrm{~dB})$ \\
\hline Feed Line Loss & $0.9 \mathrm{~dB}\left(50^{\prime}\right.$ of $\left.7 / 8 \mathrm{Heliax}\right)$ \\
\hline Receiver Noise Figure & $2.6 \mathrm{~dB}$ \\
\hline Total Receive System Noise Figure & $\begin{array}{l}3.5 \mathrm{~dB} \\
\left(359^{\circ} \text { equivalent temperature }\right)\end{array}$ \\
\hline $\begin{array}{l}\text { Estimated Antenna Background } \\
\text { Temperature }\end{array}$ & $290^{\circ} \mathrm{K}$ \\
\hline $\begin{array}{l}\text { Total Receive System Equivalent } \\
\text { Noise Temperature }\end{array}$ & $649^{\circ} \mathrm{K}$ \\
\hline
\end{tabular}




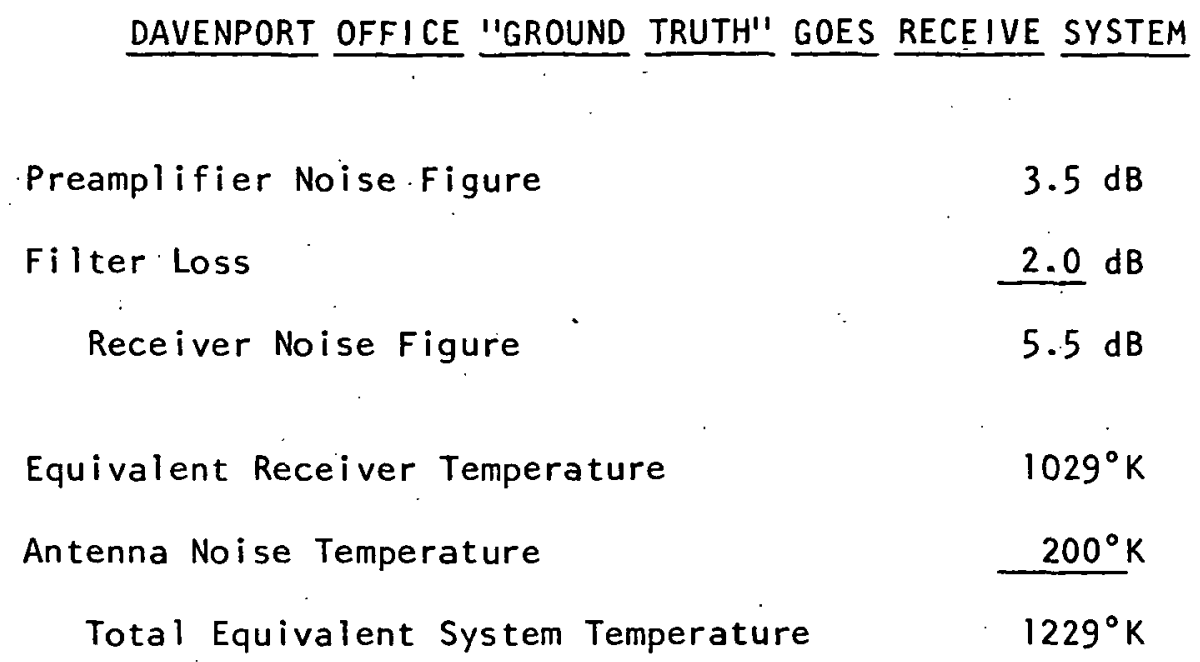

\section{TABLE A4}

TOWBOAT GOES RECEIVE SYSTEM

Preamplifier Noise Figure

Filter Loss

Receiver Noise Figure

Equivalent Receiver Temperature

Antenna Noise Temperature

Total Equivalent System Temperature
$1.6 \mathrm{~dB}$

$1.0 \mathrm{~dB}$

$2.6 \mathrm{~dB}$

$238^{\circ} \mathrm{K}$

$290^{\circ} \mathrm{K}$

$528^{\circ} \mathrm{K}$ 
TABLE A5

TWO-CARRIER ATS-6 POWER BUDGET

L-Band Pencil Beam

Earth Station Laboratory (ESL) and "Ground Truth" (GT)

Uplink at $1650 \mathrm{MHz}$

\begin{tabular}{|c|c|c|}
\hline \multirow[b]{2}{*}{ GROUND STAATION } & $\begin{array}{l}\text { FORWARD LINK } \\
\text { ESL - ATS-6 } \\
\end{array}$ & $\begin{array}{l}\text { RETURN LINK } \\
\text { GT - ATS- } 6 \\
\end{array}$ \\
\hline & & \\
\hline Transmitter Power (dBW) & 13.0 & 12.5 \\
\hline Antenna Gain (dBi) & 27.5 & 13.0 \\
\hline Pointing Loss $(\mathrm{dB})$ & -1.0 & -0.5 \\
\hline Polarization Loss (dB) & -3.0 & -0.5 \\
\hline Feedline Loss $(d B)$ & $-\quad 1.7$ & $-\quad 3.0$ \\
\hline Effective Isotropic Radiated Power (dBW) & 34.8 & 21.5 \\
\hline Space Loss at $1650 \mathrm{MHz}$ (dB) & -188.4 & -188.4 \\
\hline Spacecraft, G/T at Beam Peak $\mathrm{dB} /{ }^{\circ} \mathrm{K}$ & 8.1 & 8.1 \\
\hline Spacecraft Antenna Pointing Loss (dB) & $-\quad 1.0$ & -3.0 \\
\hline Spacecraft Received Signal dBW/ ${ }^{\circ} \mathrm{K}$ & -146.5 & -161.8 \\
\hline Boltzmann's Constant $\mathrm{dBW} /{ }^{\circ} \mathrm{K} / \mathrm{Hz}$ & -228.6 & $-228 \cdot 6$ \\
\hline $\begin{array}{l}\text { Received Signal to Noise Power } \\
\text { Density }(\mathrm{dB}-\mathrm{Hz})\end{array}$ & 82.1 & 66.8 \\
\hline $\begin{array}{l}\text { Satellite Noise Bandwidth, } 12 \mathrm{MHz} \\
\text { Relative to } 1 \mathrm{~Hz}(\mathrm{~dB})\end{array}$ & 70.8 & 70.8 \\
\hline$S / N$ in Spacecraft $\mid F(d B)$ & 11.3 & -4.0 \\
\hline $\mathrm{S} / \mathrm{N}$ in $15 \mathrm{kHz}$ Communications Bandwidth (dB) & 40.3 & 25.0 \\
\hline Limiter Degrading Factor $(A B)$ & 0.0 & -6.0 \\
\hline Power Sharing Factor $(\mathrm{dB})$ & $-0,4$ & -21.7 \\
\hline
\end{tabular}


TWO-CARRIER ATS-6 POWER BUDGET

L-Band Pencil Beam

Earth Station Laboratory (ESL) and "Ground Truth" (GT)

Downlink at $1550 \mathrm{MHz}$

$\begin{array}{ll}\text { FORWARD LINK } & \text { RETURN LINK } \\ \text { ATS }-6-\text { GT } & \text { ATS }-6-\text { ESL }\end{array}$

\section{SPACECRAFT TRANSMITTER}

Transmitter Power ( $d B W$ )

Antenna Gain, Peak (dBi)

Antenna Pointing Loss ( $d B$ )

Power Sharing Factor (dB)

Spacecraft EIRP (dBW)

Ground Antenna Gain ( $\mathrm{dBi}$ )

Ground Antenna Pointing Loss (dB)

Circuit Losses (dB)

Polarization Loss (dB)

Space Loss at $1550 \mathrm{MHz}(\mathrm{dB})$

Signal Power at Ground Receiver (dBW)

Total Receive System Noise Temperature $\left({ }^{\circ} \mathrm{K}\right)$

Boltzmann's Constant $\left(\mathrm{dBW} /{ }^{\circ} \mathrm{K} / \mathrm{Hz}\right)$

Receiver Noise Power Density (dBW/Hz)

$15 \mathrm{kHz}$ Receiver Bandwidth Referred to $1 \mathrm{~Hz}$ (dB)

Downlink $S / N$ in Communications BW (dB)

System $S / N$ in Communications (BW (dB)
15.3

$15 \cdot 3$

37.7

37.7

$-3.0$

1.0

$-\quad 0.4$

49.6

13.0

26.9

$-0.5$

$-0.1$

Included in System Temperature

$-0.5$

$-3.0$

$-187.8$

$-187.8$

$-126.20$

$-134.6$

963

600

$-228.6$

$-228.6$

$-198.8$

$-200.8$

41.8

41.8

30.8

24.4

30.3

21.7 
TABLE A7

TWO-CARRIER ATS-6 POWER BUDGET

Earth Station Laboratory and Towboat

Uplink at $1650 \mathrm{MHz}$

FORWARD L.INK

ESL - ATS -6
RETURN LINK

BOAT - ATS 6

\section{GROUND STATION}

Transmit Power (dBW)

Antenna Gain ( $d B i$ )

Pointing Loss ( $\mathrm{d} B$ )

Polarization Loss ( $\mathrm{dB}$ )

Feedline Loss (dB)

Effective Isotropic Radiated Power (dBW)

Space Loss at $1650 \mathrm{MHz}$ (dB)

Spacecraft G/T at Beam Peak $\left(\mathrm{dB} /{ }^{\circ} \mathrm{K}\right)$

Spacecraft Pointing Loss ( $d B$ )

Spacecraft Received Signal $\left(\mathrm{dBW} /{ }^{\circ} \mathrm{K}\right.$ )

Boltzmann's Constant $\left(\mathrm{dBW} /{ }^{\circ} \mathrm{K} / \mathrm{Hz}\right)$

Received Signal to Noise Power Density $(\mathrm{dB}-\mathrm{Hz})$

Satellite Noise Bandwidth, $12 \mathrm{MHz}$ Relative to $1 \mathrm{~Hz}(\mathrm{~dB})$

$S / N$ in Spacecraft IF (dB)

$\mathrm{S} / \mathrm{N}$ in $15 \mathrm{kHz}$ Communications Bandwidth ( $\mathrm{B}$ )

Limiter Degrading Factor (dB)

Power Sharing Factor (dB)
13.0

27.5

$-1.0$

$-3.0$

$-1.7$

34.8

$-188.4$

8.1

$-1.0$

$-146.5$

$-228.6$

82.1

70.8

11.3

40.3

0.0

$-0.3$
12.5

7.3

- 0.6

$-3.0$

$=0.9$

15.3

$-188.4$

8.1.

$=3.0$

$-168.0$

$-228.6$

60.6

70.8

$-10.2$

18.8

6.0

$-27.8$ 
TABLE A8

TWO-CARRIER ATS-6 POWER BUDGET

Earth Station Laboratory and Towboat

Downlink at $1550 \mathrm{MHz}$

\begin{tabular}{|c|c|c|}
\hline & $\begin{array}{l}\text { FORWARD LINK } \\
\text { ATS-6 - BOAT } \\
\end{array}$ & $\begin{array}{l}\text { RETURN LINK } \\
\text { ATS }-6 \text { - ESL }\end{array}$ \\
\hline \multicolumn{3}{|l|}{ SPACECRAFT TRANSMITTER } \\
\hline Transmitter Power (dBW) & 15.3 & 15.3 \\
\hline Antenna Gain, Peak (dBi) & 37.7 & 37.7 \\
\hline Antenna Pointing Loss ( $\mathrm{dB}$ ) & $-\quad 3.0$ & -1.0 \\
\hline Power Sharing Factor (dB) & $-\quad 0.3$ & -27.8 \\
\hline Spacecraft EIRP (dBW) & 49.7 & 24.2 \\
\hline Ground Antenna Gain (dBi) & 7.3 & 26.9 \\
\hline Ground Antenna Pointing Loss ( $d B$ ) & -6.0 & -1.0 \\
\hline Circuit Losses $(\mathrm{dB})$ & Included in & System Temperature \\
\hline Polarization Loss $(\mathrm{dB})$ & -3.0 & $\because 3.0$ \\
\hline Space Loss at $1550 \mathrm{MHz}(\mathrm{dB})$ & -187.8 & -187.8 \\
\hline Signal Power at Ground Receiver ( $\mathrm{dBW}$ ) & -139.8 & -140.7 \\
\hline Total Receive System Noise Temperature $\left({ }^{\circ} \mathrm{K}\right)$ & 649 & 600 \\
\hline Boltzmann's Constant $\left(\mathrm{dBW} /{ }^{\circ} \mathrm{K} / \mathrm{Hz}\right)$ & -228.6 & -228.6 \\
\hline Receiver Noise Power Density $(\mathrm{dBW} / \mathrm{Hz})$ & $-200 \cdot 5$ & -200.8 \\
\hline $\begin{array}{l}15 \mathrm{kHz} \text { Receiver Bandwidth Referred to } \mathrm{l} \mathrm{Hz} \\
\text { (dB) }\end{array}$ & 41.8 & 41.8 \\
\hline Downlink $S / N$ in Communications $B W(d B)$ & 18.9 & 18.3 \\
\hline System $S / N$ in Communications BW (dB) & 18.9 & 15.5 \\
\hline
\end{tabular}




\section{TABLE A9}

GOES DOWNLINK POWER BUDGET

To Davenport Office "Ground Truth" Transponders

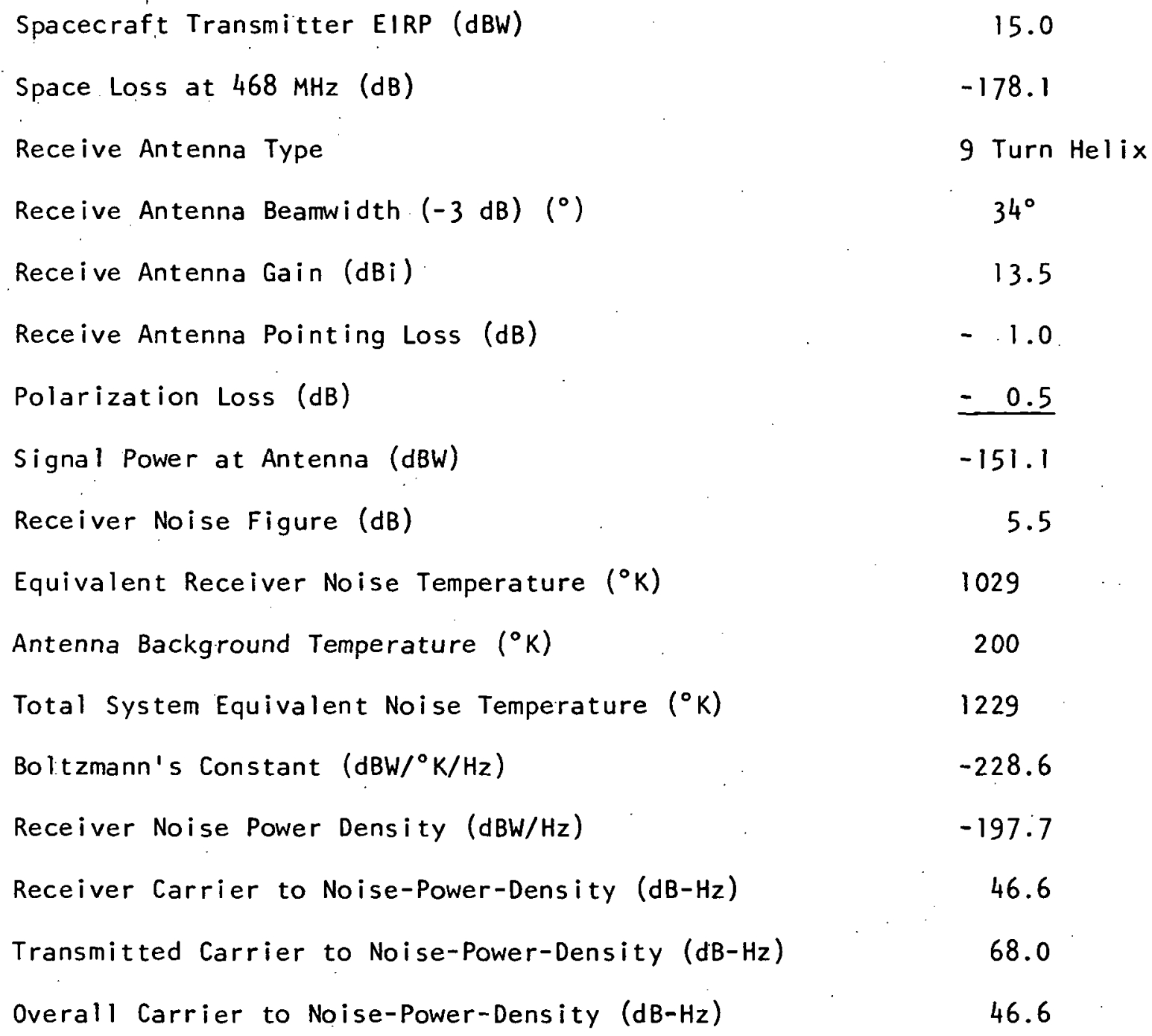




\section{TABLE A10}

GOES DOWNLINK POWER BUDGET

To Towboat

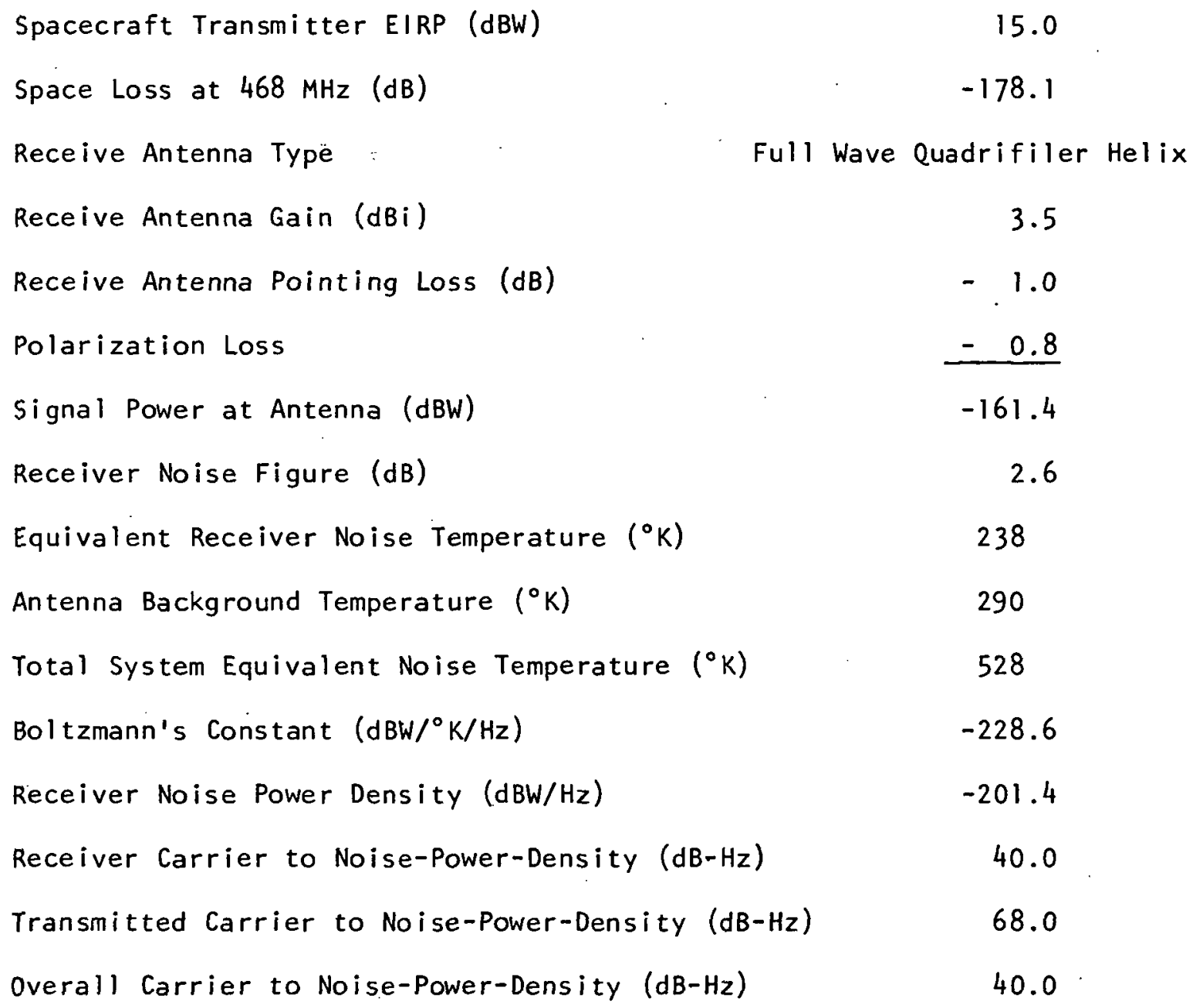


The following is extracted from a letter from Robert L. Gardner, Port Captain, Marine Division of Alter Company. Captain Gardner describes. communications on the inland waterways and how they could be improved by the use of satellites that have an interconnection with the public switched telephone network.

Presently our communications systems is comparable to a Chinese fire drill. We use virtually every means available, including contacting shore based positions such as locks and bridges and actually hailing the vessel or talking direct by low range radio to get and transmit information to our vessels. The work horse, however, of our office-to-vessel communications is supplied principally by VHF marine radio. The long distance aspect of that communications is accomplished via public correspondence radio/telephone stations located up and down the river from New Orleans to Dubuque, lowa. That system is less than sat isfactory, since it is so chopped up in ownership and there is no continuity in the procedure that is used in placing marine radio/telephone calls.

Communications between our office personnel, both in Hartford, Illinois and Davenport, are principally accomplished by contacting the local Bell Telephone operator and asking for the marine operator. Upon receipt of this operator, sometimes after a lengthy delay, we will give her the name of the vessel and its approximate location and request that a marine call be made to the city nearest that location. In most cases we have to instruct the operator what radio station to use, since they are unfamiliar with the entire network. This operator then would contact an operator for routing and once that is obtained, place a call to the marine operator, shall we say for example in Vicksburg, Mississippi. That operator, who incidentally is in Jackson, Mississippi, will then contact a local operator in Vicksburg, Mississippi. She will then in turn contact the private enterprise operated public correspondence station in Vicksburg to see if the channel is available. If so, the ticket is passed on to that operator and with some luck you can soon be speaking to your vessel via a complete duplex channel. The signalling. is done all by voice and should the vessel be on another radio frequency, he simply will miss the call. There are other factors that would cause him to miss that particular call also.

If, after receiving the attention of the private enterprise radio/telephone station in Vicksburg, they inform the Vicksburg operator it is busy, you simply must hang up and retry your call again, having to follow the lengthy procedures described above. The reliability of getting your vessel on the first call is about $50 \%$. In some areas that reliability factor is reduced to as little as $15 \%$.

When vessels are within a 40 -mile radius of our Davenport office, we can speak to them via a 50 watt VHF transmitter that is locally operated. This is without a doubt the best communications we have with our vessels. The drawback, obviously, is that our boats do not stay within the 40-mile 
radius of the Davenport office, but instead venture 1500 miles to New Orleans, Louisiana. We have another locally operated station located in Burlington, lowa, that is remotely controlled from Davenport. This, too, is ideal communications, but has the same restrictions of our Davenport station inasmuch that the vessel must be in a $40-\mathrm{mi}$ le radius of Burlington, lowa. With the combination of those two radio stations we are able to communicate over a river area of almost 200 miles. This is, fortunately for us, the busiest stretch of river for our corporation. Therefore, that aspect of our communications is good and solid. There is one drawback, however, we are not able to communicate via that station at night or from some remote location. In other words, our presence at the office is required for communication through that net.

We also utilize single sideband marine radio/telephone for obtaining information on a scheduled basis through a public correspondence operator. Daily our vessels are contacted by single sideband radio from Alton, Illinois, where the vessel gives the operator his faily traffic, which later is teletyped to our Davenport office. That small bit of communication is extremely expensive, inasmuch that single sideband equipment is very difficult to maintain and the equipment is used so infrequently.

Single sideband radio limited coast was used by this company in earlier years of operation, but was scrapped in 1971 when the frequencies became so congested it was impossible to communicate. The Federal Communications Commission has consistently urged the maritime community to disband from its use of single sideband marine frequencies.

To recap our basic communications net, it consists of limited coast VHF radio, public correspondence VHF radio, and single sideband public correspondence radio.

It is extremely difficult to keep tabs on our cost of communication, due to the many different stations that are operated up and down the Mississippi River system. Bell Telephone operates several and many others are operated by private enterprise, who all have different billing arrangements. We have calculated to the best of our ability the cost of communicating with the six vessels being operated by Alter Company. It appears that cost runs approximately $\$ 90$ per day for all six vessels, or $\$ 15$ per day per vesse 1. Naturally, some vessels cost more than others, since they nange farther away from the home office. Therefore, 1 think it is important to look at the overall cost of communicating with vessels when operating a barge line of our size. These costs do not include the expense of maintaining the equipment and/or any purchases for communications equipment, but simply represent the land line and radio link charges. As you can readily see, our communications cost per year for this very small barge line would be over $\$ 32,000$ for a less than sat isfactory system.

It is difficult to measure the costs of poor communications with our vessels. Since these tow boats are handling thousands of tons of cargo and represent such a large investment in capital, lost time calculates into big money. Lost revenue on one of our larger boats and the barges has been calculated as high as $\$ 800$ per hour. Many times poor communications costs our vessels time and, in effect, cost the shipper additional money for our services. Instantaneous, solid, clear communications between office and vessel is a must for this type of "remote controlled" business. 
The ability to track one of our vessels precisely is of no great importance to us at this time. However, general positioning is. It may be that in the future precise location would be important after we become more involved in data programs involving our operation. There is one thing that is for sure when you are talking about receiving any kind of information from a towboat, and that is it is highly desirable to obtain that information without any interference of the pilot or captain's duties. As you no doubt have learned from this experiment, we carry no "radio operator". It then becomes the duty of the pilot on watch to handle all types of communications to and from his vessel.

In evaluating the voice communications between our office, the M/V Renee G., and in one case my residence by telephone, we all have to vote, fantastic. The communications was clear, ungarbled, and virtually static free. This type of communications is comparable to our present VHF simplex limited coast communications.

Several advantages I noticed with the satellite communications were that the vessel is in the command position to control the duplex frequency. This makes communications with people who do not understand how to talk on the radio much easier. Since our personnel on board are there for 30 days at a time and away from their families, it is important that they have some method of communicating with their wives, children, parents, etc. This is where a duplex operation is extremely important, as these people are not trained in the use of radio/telephone. Even tho we were not operating in. the full duplex mode, the duplex capabilities were still advantageous because there was no delay in exchanging use of the frequency when the transmission. was reversed.

Good, solid communications has been needed in the barge and towing industry for years. We've tried every known way of improving communications in this industry and, quite frankly, have fallen flat on our face: Government cooperation to this point has not been outstanding and the regulatory process and bureaucratic entanglement has slowed, if not killed, every type of progress toward a solution. This is an industry that is moving two-thirds of all the domestic marine traffic in the United States, generating over 277 billion ton miles. The commodities that are being carried are basic to the needs of this country; specifically, petroleum and petroleum products, coal, and grains. Furthermore, we are moving over 60 per cent of all of the exported grain that leaves this United States annually, which. helps offset the cost of this country's" reliance on imported oils. With those kinds of credentials, it is deplorable that the industry does not have better office-to-vesisel communications to increase efficiency. 


\section{APPENDIX C \\ REAL-TIME COMPUTER SOFTWARE}

The computer software employed for the real-time determination of towboat position or line-of-position consists of two major components, an Assembler language data management program and a collection of several Fortran language numerical algorithms.

The entire software package would consume approximately $80 \mathrm{~K}$ words of core storage; the observatory PDP-11/20 computer contains a $24 \mathrm{~K}$ word memory. As a result of the limited core available, the software was written on a core resident, resident-as-needed basis. The data management Assembler language section remains core resident from program initiation until program termination. The Fortran numerical algorithms are selected, loaded into core from the high speed disc, and initiated by the data management software as required for a particular sample of input data. Upon completion of its specialized functions, the Fortran subroutine remains core resident until again required or until it is overwritten by another fortran subroutine as required by the next piece of input data. In all cases, the Fortran numerical algorithms finish their assigned tasks before the data management subroutine receives the next line of data; data are received at a maximum rate of one 48-character data line (results from one ranging interrogation) every three or four seconds. Input data buffers of the data management program can accommodate up to one minute of ranging data should the . printer be unable to cope with the amount and speed of output data.

In addition to loading and initiating the appropriate numerical algorithms, the data management program controls all computer $1 / 0$ devices. Computer inputs include the ranging times from the time interval counters, the time of day from the digital clock, the month, day, year, and experiment file number from the data scanner, the digital data stream on the remote transponder response from the correlator, and data from the GOES satellite receiver, which includes the location of the GOES satellite. Computer outputs include typically the input data to the high speed paper tape punch, input data and real-time numerical results to the 30-character per second printer and TV output display, and an $X-Y$ plotter. I/O functions may be switched in real time, depending on the need for additional or reduced input or output material. Figure $\mathrm{Cl}$ shows typical printed output containing ranging data, real-time towboat position and line-of-position determinations, and GOES satellite location data.

Core resident within the data management program is the system COMMON storage. All input and output data to and from the numerical algorithms pass via COMMON; all data saved from one ranging interrogation to the next reside in COMMON. None of the numerical subroutines have arguments, thus greatly increasing operating speed.

The data management program performs initial checks on input data quality. All input data characters are scanned to verify compliance with specified input formats. Lines of input data with unacceptable characters 


\section{TABLE CI}

MATHEMATICAL ALGORITHMS OF REAL-TIME COMPUTER SOFTWARE

\begin{tabular}{|c|c|c|}
\hline $\begin{array}{l}\text { CALLED } \\
\text { SUBROUTINE } \\
\end{array}$ & $\begin{array}{l}\text { REQUIRED } \\
\text { SUBROUT INES } \\
\end{array}$ & CONDITION \\
\hline STNASA & RTZERO & At start of program. \\
\hline STMADT & -- & On all manual data. \\
\hline STGOES & -- & $\begin{array}{l}\text { On new data received from the } \\
\text { GOES satellight }\end{array}$ \\
\hline STGTRF & -- & $\begin{array}{l}\text { For user code \#7 (Ground } \\
\text { Truth Reference). }\end{array}$ \\
\hline STPLOP & -- & For user code \#9 (Towboat). \\
\hline STVPOS & $\begin{array}{l}\text { SPHPF } \\
\text { POL } \\
\text { DATM } \\
\text { POSFIX } \\
\text { POLY } \\
\text { CVPOS } \\
\text { CONV }\end{array}$ & For position fix. \\
\hline STVLOP & $\begin{array}{l}\text { SPHLAT } \\
\text { DATM } \\
\text { LATCOM } \\
\text { POLY } \\
\text { CVLOP } \\
\text { CONV }\end{array}$ & For line-of-position. \\
\hline C7 & ALTTOR & Keyboard Command Interrogator \\
\hline
\end{tabular}


pass directly to the paper tape punch and to the printer and are thence ignored. Acceptable data are screened for type and loaded into COMMON; the appropriate numerical algorithm is selected, loaded into core and initiated; output data from the numerical algorithm pass through COMMON to the appropriate output device. Table $\mathrm{Cl}$ lists the individual numerical algorithms; the non-system subroutines required, and the condition under which the data management program selects them to process data.

Figure $\mathrm{Cl}$ is an example of the computer printout, displaying three types of output.

A. The live data from the GOES Receiver.

$\begin{array}{ll}207 & \text { Day of year or } 26 \text { July } 1979 \\ 04 & \text { Hour } \\ 09 & \text { Minute } \\ 00 & \text { Second } \\ -102.9670 & \text { GOES satellite longitude } \\ +\quad 0.0741 & \text { GOES satellite latitude } \\ +069.5 & \text { Microseconds difference in nominal altitude }\end{array}$

B. Raw ranging data.time interval.

0269752.4 Microseconds Time interval lab to ATS-6 to Lab

07 Transponder 10 number

04 Hours

$09 \quad$ Minutes

01 Seconds

0962925.6 Microseconds time interval Lab to ATS -6 to transponder to ATS-6 to Lab

000592.15 Microseconds time interval of Lab received GOES time tick and local oscillator time tick

339.6 Microseconds data sent back from transponder representing its internal time delay.

(space) Data send back from transponder, space if all is OK, "-"l or "-" if GOES receiver is out of sync, out of phase, or power is off

698918.1 Microseconds. Data sent back from transponder, the time from the last GOES tick and correlation of the responder of the interrogation via ATS-6. 
C. Any output from a Fortran data analys is subroutine.

C.l P Position fix, may be on $L$ for line-of-position.

4: Hours GMT of measurement

9: Minutes

4 Seconds

40/ Degrees latitude

35/ Minutes

35 Seconds

$91 /$ Degrees longitude

06/ Minutes

20 Seconds

2 ATS 6 position data source

$I=$ trilateration

$2=$ NASA predict

3 = Nominal longitude, 0 degree latitude

2 GOES position data source

$1=$ trilateration

$2=$ NASA predict

3 = Nominal longitude, 0 degree latitude

1 Ground truth indicator

1 - Used Ground Truth

$2=$ Did not use Ground Truth

C.2 MEAN $P$ mean position $f i x$ (MEAN $L$ line-of-position)

40/ Degrees latitude

37/ Minutes

37 Seconds

91/ Degrees longitude

$07 /$ Minutes

50 Seconds

9 Number of $f$ ixes used for the mean 
FIGURE C 1

COMPUTER PRINTOUT SHEET

\footnotetext{
02697508 07940855 99629247 00059220 3396 6989168 02697519 09049858 09624069 00959222 3219 E996027 F $4: 5: 58 \quad 40,35,45 \quad 91,06,24221$ 